\title{
The Effects of Student Behavior Alteration Techniques on Student Motives to Communicate, Student Talk, and Student Learning
}

Christopher J. Claus

West Virginia University

Follow this and additional works at: https://researchrepository.wvu.edu/etd

\section{Recommended Citation}

Claus, Christopher J., "The Effects of Student Behavior Alteration Techniques on Student Motives to Communicate, Student Talk, and Student Learning" (2013). Graduate Theses, Dissertations, and Problem Reports. 4956.

https://researchrepository.wvu.edu/etd/4956

This Dissertation is protected by copyright and/or related rights. It has been brought to you by the The Research Repository @ WVU with permission from the rights-holder(s). You are free to use this Dissertation in any way that is permitted by the copyright and related rights legislation that applies to your use. For other uses you must obtain permission from the rights-holder(s) directly, unless additional rights are indicated by a Creative Commons license in the record and/ or on the work itself. This Dissertation has been accepted for inclusion in WVU Graduate Theses, Dissertations, and Problem Reports collection by an authorized administrator of The Research Repository @ WVU.

For more information, please contact researchrepository@mail.wvu.edu. 
The Effects of Student Behavior Alteration Techniques on Student Motives to Communicate, Student Talk, and Student Learning

Christopher J. Claus

Dissertation submitted to the Eberly College of Arts and Sciences at West Virginia University in partial fulfillment of the requirements for the degree of

\author{
Doctor of Philosophy \\ in \\ Communication Studies
}

Scott A. Myers, Ph.D., Chair

Matthew M. Martin, Ph.D.

Melanie Booth-Butterfield, Ph.D.

Megan R. Dillow, Ph.D.

Danette Ifert-Johnson, Ph.D.

Department of Communication Studies

Morgantown, West Virginia

2013

Keywords: student behavior alteration techniques, student motives to communicate, student talk, student learning

Copyright 2013 Christopher J. Claus 


\section{ABSTRACT \\ The Effects of Student Behavior Alteration Techniques on Student Motives to Communicate, Student Talk, and Student Learning}

\section{Christopher J. Claus}

This dissertation addressed the effects of students' perceived effectiveness of and likelihood to use student behavior alteration techniques (BATs) on students' motives to communicate with. their instructors, student talk (i.e., willingness to talk, out-of-class communication), and student learning (i.e., cognitive learning, affective learning, state motivation, and student communication satisfaction). Results revealed that student perceived effectiveness of, and likelihood to use, student BATs did not influence, student talk or student learning, but indicated some significant relationships with the students' motives to communicate with their instructors. Specifically, the relational, functional, participatory, and sycophancy motives were generally related to the perceived likelihood to use some prosocial BATs. The relational, functional, and participatory. motives were not significantly related to the perceived effectiveness of, or likelihood to use, any of the antisocial BATs; however, the sycophancy motive was related positively to the perceived likelihood to use one antisocial BAT. The excuse-making motive was generally related to the perceived effectiveness of, and likelihood to use, antisocial BATs, but was not related negatively, as hypothesized, to the perceived effectiveness of, and likelihood to use, prosocial BATs. Collectively, the results of this dissertation revealed three prominent issues in regard to the examination of student prosocial and antisocial BATs. First, the situational demands of the classroom (e.g., instructor communicative behaviors, outcomes of the classroom assignment), more than students' motives to communicate or willingness to engage in student talk, may affect their students' perceived effectiveness of, and likelihood to use, student BATs. Second, students' perceived effectiveness of, and the likelihood to use prosocial and antisocial student BATs are not related to gains in their learning. Third, it appears that students use BATs infrequently. Overall, the lack of significant relationships may be due to the fact that students' perceived effectiveness of, and likelihood to use the BATs, are not closely associated with other student communicative behaviors, but perhaps related directly to the students' own personality traits or the immediate situational factors of the classroom and instructor. 


\section{TABLE OF CONTENTS}

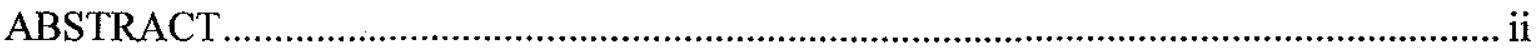

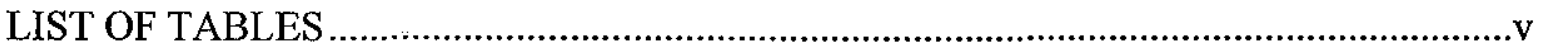

ACKNOWLEDGEMENTS ......................................................................................

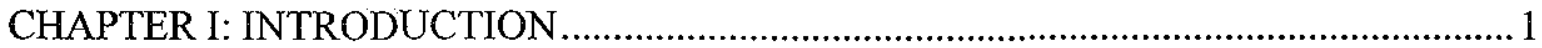

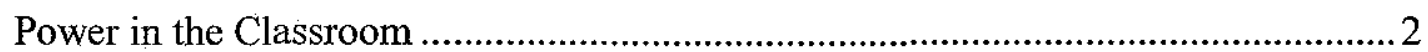

Power in the Classroom Series I-VII .......................................................... 3

Student Behavior Alteration Techniques .................................................................. 8

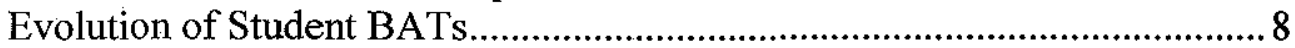

Student BATs Typology ...........................................................................

Student Motives to Communicate with their Instructor..............................................11

Student Talk .................................................................................................16

Willingness to Talk (WTT) ........................................................................17

Out-of-Class Communication (OCC) ………..............................................18

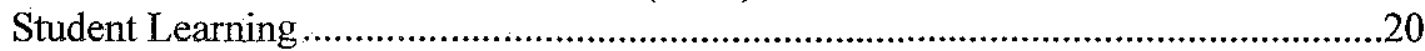

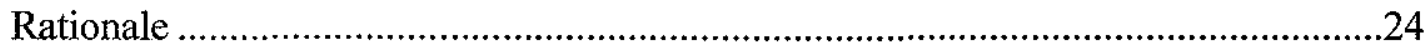

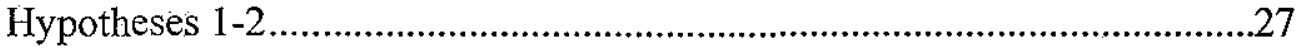

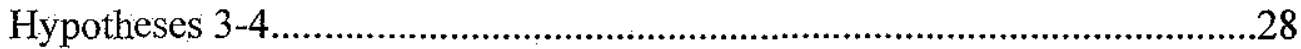

Research Questions 1 ............................................................................30

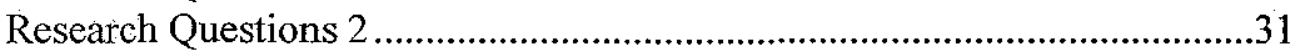

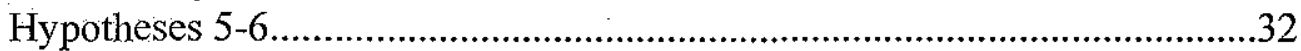

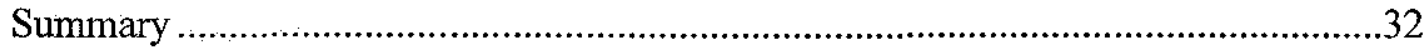

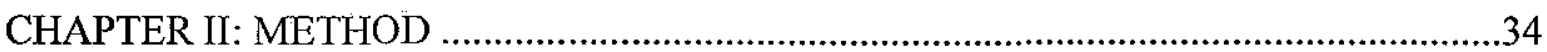

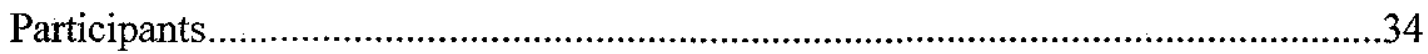

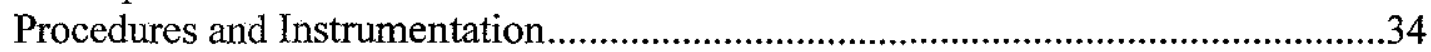

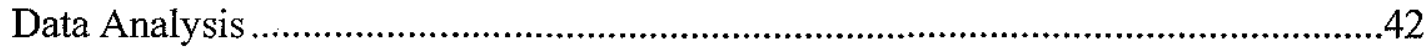

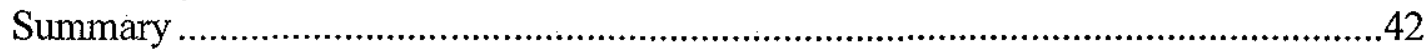

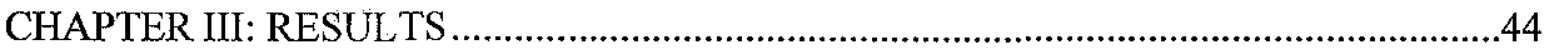

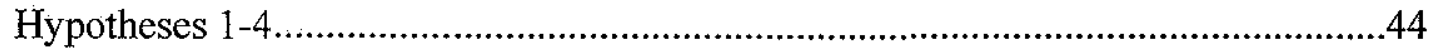

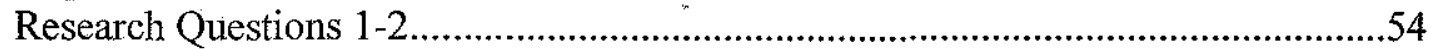

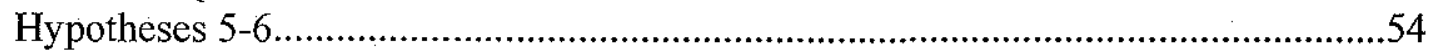

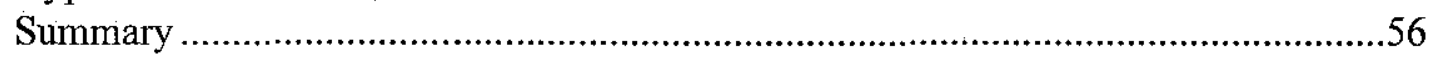

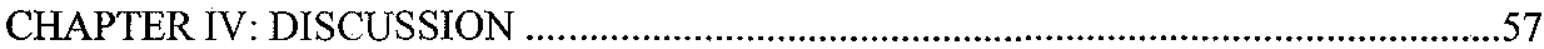

Limitations and Directions for Future Research......................................................66

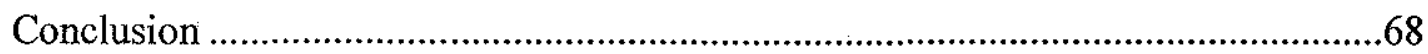

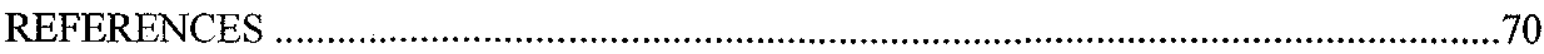

APPENDICES _... - 


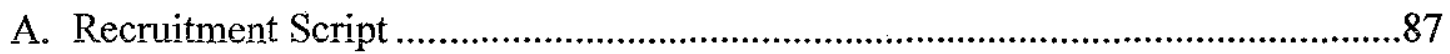

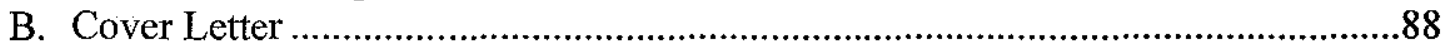

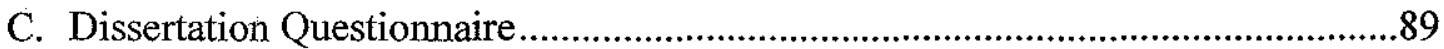

D. Students Behavioral Alteration Techniques and Messages Typology ..................100

E. Student Communication Motives Scale.............................................................104

F. Student Willingness to Talk in Class Scale ………..........................................105

G. Out-of-Class Communication Scale ……….....................................................106

H. Revised Cognitive Learning Indicators Scale ......................................................107

I. Instructional Affect Assessment Instrument....................................................108

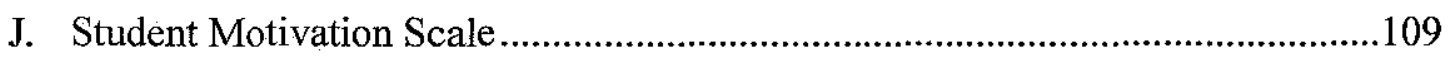

K. Student Communication Satisfaction Scale ……...............................................110 


\section{LIST OF TABLES}

Table 1. Instructor Behavior Alteration Techniques....................................................5

Table 2. Student Behavior Alteration Techniques.......................................................... 12

Table 3. Rotated Factor Loadings for Perceived Effectiveness of, Student BATs............. 37

Table 4. Rotated Factor Loadings for Perceived Likelihood to Use Student BATs...........39

Table 5. Means and Standard Deviations for Prosocial and Antisocial BATs ..................45

Table 6. Correlations among Effectiveness of and Likelihood of Using Student Prosocial

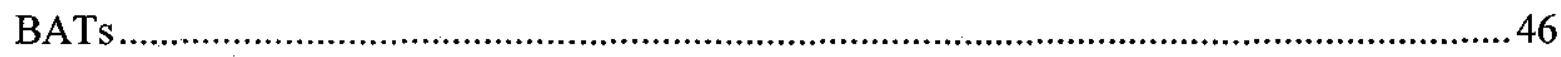

Table 7. Correlations among Effectiveness of and Likelihood of Using Student Antisocial

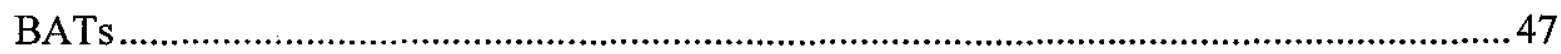

Table 8. Correlations among Effectiveness of Student Prosocial BATs, Student Motives to

Communicate, WTT, OCC, and Student Learning .........................................................48

Table 9. Correlations among Effectiveness of Antisocial BATs, Student Motives to

Communicate, WTT, OCC, and Student Learning ...................................................... 51

Table 10. Correlations among Likelihood of Using Prosocial BATs, Student Motives to

Communicate, WTT, OCC, and Student Learning .......................................................5 52

Table 11. Correlations among Likelihood of Using Antisocial BATs, Student Motives to

Communicate, WTT, OCC, and Student Learning ................................................... 53 


\section{ACKNOWLEDGEMENTS}

My gratitude goes to my advisor Dr. Myers for his hours of patience and guidance over the past four years. You have always been there for me when I have needed you the most. At times, when it appeared I had lost focus you were always there to put me back on track. Your expectation for quality work has made me a better scholar. Your years of teaching experience and insight has made me a more effective instructor. You have been a source of influence in both my academic and professional career and I thank you for being my advisor, professor, and friend. I would also like to thank my committee members, Dr. Martin, Dr. Booth-Butterfield, Dr. Dillow, and Dr. Ifert-Johnson. I am grateful for the advice provided by Dr. Martin and for helping me understand the true value of being collegial. You are an excellent and supportive department chair. Dr. Booth-Butterfield, thank you for your humor and positivity. Your depth of knowledge, enthusiasm, and continued encouragement has helped me put this program (and what I hope to gain from it) into perspective. Dr. Dillow, thank you for sharing your knowledge and experience; you took a sincere interest in me and helped me stay committed. Thank you for your tutelage, advice, guidance, and for always pushing me to become a better writer. I want to thank Dr. Ifert-Johnson, you helped me discover the line of research I am most passionate about within instructional communication. I am grateful for the time you spent helping me understand the compliance gaining literature during Summer Scholar and I appreciate your willingness to serve as my outside committee member.

In addition to my advisor and committee members, I want to thank my parents, James and Barbara. Mom and Dad, thank you for the countless phones calls and care packages throughout this $\mathrm{Ph} . \mathrm{D}$. program. Your love, encouragement, humor, and support have inspired and motivated me - I could not have completed this program without the both of you. 
I would like to thank my friends from California, especially Sean, The Lance, Kristin, and Martin - you have all been especially supportive throughout this program despite being 2,642 miles away. I would also like to thank Gabrielle Merandi and her family for all of the love, positive energy, and delicious food over the years. Finally, I would like to thank my colleagues, Colleen, Jessalyn, Zac Johnson, Zac Goldman, Shannon, Syd, Daniel, Sara, Kelly, Michael, Stephanie, and Lori who also supported me. 


\section{CHAPTER I}

\section{Introduction}

Power in the classroom has been examined over three decades (e.g., McCroskey \& Richmond, 1983; Richmond, 1990; Goodboy \& Bolkan, 2011). However, most of this area of research has focused on how instructors communicate power (McCroskey \& Richmond, 1983; Richmond \& McCroskey, 1984) through the use of compliance-gaining strategies, also known as behavioral alteration techniques (Kearney, Plax, Richmond, \& McCroskey, 1984; Kearney, Plax, Richmond, \& McCroskey, 1985) and the influence of these instructor communicative behaviors on students' self-reports of their student learning (e.g., Roach, 1994, Richmond, McCroskey, Kearney, \& Plax, 1987). Golish (1999) cautioned that placing emphasis on only the instructors' use of power assumes that students are passive participants in the compliance-gaining interaction. Therefore, in an attempt to give voice to the students as active participants, Golish (1999) and Golish and Olson (2000) developed a typology of student behavior alteration techniques. Similar to instructors, students were found to have the opportunity to enact power within the classroom and become a part of the transactional nature of the environment through the use of these unique (and student initiated) behavior alteration techniques (Golish, 1999).

To date, researchers have not examined the relationship between student behavior alteration techniques and other student initiated communicative behaviors (e.g., student motives to communicate, student talk) and student learning. However, the use of student behavior alteration techniques, much like the instructor behavior alteration techniques, may impact their own communicative behaviors and gains in student. Thus, the purposes of this dissertation are to examine the extent to which students' use of behavior alteration techniques is related to their motives to communicate with instructors, their willingness to talk in and outside 
of class, and their student learning.

To reach this end, this chapter has five parts. In the first part, the power in the classroom literature is reviewed with an emphasis on behavior alteration techniques. In the second part, the student motives to communicate with their instructors are identified and explained. In the third part, the relevant student talk literature is examined with emphasis on student willingness to communicate and out-of-class communication. In the fourth part, student learning is discussed with particular focus on cognitive learning, affective learning, state motivation, and student communication satisfaction. In the fifth part, the rationale for this dissertation is provided.

\section{Power in the Classroom}

Historically, the role of power between instructor and student has been grounded in the use of social influence in communication interactions (McCroskey \& Richmond, 1983; Richmond \& McCroskey, 1984). Social influence is considered to be an attempt by a source to persuade a target to perform an action that the target might not otherwise performed (Wheeless, Barraclough, \& Stewart, 1983). French and Raven (1968) identified five relational power bases that a source uses to persuade a target to perform an action. These power bases are coercive power, which is the source's ability to punish the target; expert power, which is the target's perception that the source has expertise in a specific content area; legitimate power, which is granted to the source by the target based on the source's assigned role; referent power, which affords the source power due to attraction and perceived similarity by the target about the source; and reward power, which is the source's ability to provide a reward to or to remove a punishment from the target (French \& Raven, 1968).

In terms of the study of power within the instructional communication context, the instructor (i.e., the source) employs power as a way to influence students (i.e., the target) to 
behave and to remain on task in order to ultimately increase their learning (Kearney, Plax, Richmond, \& McCroskey, 1984; McCroskey, Richmond, Plax, \& Kearney, 1985). To study how power operates in the classroom, McCroskey and his colleagues developed a line of research that originated with the study of instructor power; this study later morphed into the identification and study of the compliance-gaining strategies that instructors use with their students.

\section{Power in the Classroom Series I-VII}

There were seven studies within this seminal line of research known as the "Power in the Classroom" series. In "Power in the Classroom I," McCroskey and Richmond (1983) sought to uncover the perceptions of teacher's (K-12) use of these five power bases. They asked K-12 students about their perceptions of their teachers' use of power bases and teachers about their own use of power bases. The results indicated that both groups shared similar perceptions of how teachers use power in the classroom. Although both students and teachers generally shared a positive view of how power was used in the classroom, teachers viewed their power use as more positive. Furthermore, McCroskey and Richmond (1983) suggested that the effect of teachers' use of power in the classroom on student learning was potentially mediated by the students' perceptions of power use. Following this suggestion, in "Power in the Classroom II," Richmond and McCroskey (1984) found that both students' and instructors' perceived use of referent power was associated with cognitive learning gains. For affective learning, teachers perceived their use of legitimate power and coercive power was negatively associated with, and referent power was positively associated with, student affective learning. Students, however, reported that teacher use of coercive power and legitimate power was negatively associated with their affective learning whereas teachers' use of referent power and expert power was positively associated with their affective learning. Given both the student and teacher perspectives, Richmond and 
McCroskey suggested that coercive and legitimate power impede students' cognitive and affective learning, referent and expert power enhance students' cognitive and affective learning, and reward power is not related to either type of learning.

In "Power in the Classroom III," Kearney, Plax, Richmond, and McCroskey (1985) developed a typology of 18 behavior alteration techniques (i.e., BATs) with accompanying behavioral alteration messages (i.e., BAMs) teachers can employ to manage students in the classroom. BATs are conceptualized as the specific techniques instructors use to persuade students to stay on task or comply with various academic related requests (e.g., offer a reward to students for compliance/good behavior); BAMs are the actual verbal and nonverbal messages associated with each specific technique (see Table 1). Teachers (K-12) then were asked to complete self-reports indicating how often they used each of the 18 BATs. They reported that seven BATs (i.e., immediate reward, reward from teacher, personal responsibility, expert teacher, self-esteem, altruism, and responsibility to class) were perceived as effective and subsequently used frequently in their classrooms. These original 18 BATs were revisited in "Power in the Classroom IV" (Kearney et al. 1984) and validated by having teachers inductively generate a list of compliance-gaining techniques, with four additional BATs added to the original 18-item typology: deferred reward, punishment from others, peer modeling, and teacher responsiveness. In this study, each of the $22 \mathrm{BATs}$ then were classified as prosocial, antisocial, or neutral (Kearney, Plax, Sorensen, and Smith, 1988; see Table 1).

In "Power in the Classroom V," McCroskey et al. (1985) examined the effects of teacher training on teacher use of BATs and found that the teachers who are trained in using BATs did indeed use BATs more frequently than untrained teachers. (Untrained teachers were defined as those who had no communication training beyond what was offered at their undergraduate level.) 
Table 1

Instructor BATs

\section{BATs}

1. Immediate Reward*

2. Reward from Teacher

3. Reward from Others*

4. Self-Esteem*
Representative BAMs

You will enjoy it. It will make you happy. Because it's fun. You'll find it rewarding/interesting.

I will give you a reward if you do. I will give you a good grade. I will make it beneficial to you.

Others will respect you if you do. Others will be proud of you. Your friends will like you if you do.

You will feel good about yourself if you do. You are good at it. Because you are capable.

5. Punishment from Behavior^ You will be hurt if you don't. You'll feel bad if you don't.

6. Punishment from Teacher I will punish you if you don't. I'll give you an "F" if you don't.
7. Guilt^

8. Teacher/Student Relationship: Positive

9. Teacher/Student Relationship: Negative ${ }^{\wedge}$

10. Legitimate Higher Authority^

11. Legitimate Teacher Authority^

12. Personal (Student) Responsibility

13. Responsibility to Class*

14. Normative Rules*

15. $\mathrm{Debt}^{\wedge}$

16. Altruism*

17. Teacher Modeling*

18. Expert Teacher*

19. Deferred Reward*

If you don't, others will be hurt. Others will be punished.

I will like you better if you do. I will respect you.

I will dislike you if you don't. I will lose respect for you.

Do it, I'm just telling you what I was told. It is a rule.

Because I told you to. You don't have a choice. I'm in charge.

It is your obligation. It is your turn. Everyone had to do his/her share. It's your job.

Your group needs it done. The class depends on you.

Everyone else has to do it. The rest of the class is doing it. All of your friends are doing it.

You owe me. You promised to do it. I did it the last time.

If you do this, it will help others. Others will benefit if you do. It will make others happy if you do.

This is the way I always do it. People who are like me do it. Teachers you respect do it.

From my experience, it is a good idea. This has always worked for me. Trust me - I know what I am doing.

It will help you later on in life. It will help you with an upcoming assignment. It will prepare you for your job.

20. Punishment from Others^ No one will like you. Your friends will make fun of you.

21. Peer Modeling* Your friends do it. Classmates you respect do it.

22. Teacher Feedback* To see how well I have taught you. I need to know you understand.

Note. BATs 1-18 are the original typology (Kearney et al., 1985); BATs 19-22 were added by

Kearney et al. (1984). *Prosocial BATs, ^Antisocial BATs (Kearney, Plax, Sorensen et al., 1988). 
In "Power in the Classroom VI," Plax, Kearney, McCroskey, and Richmond (1986) attempted to clarify the role that perceived high school teacher and college instructor use of nonverbal immediacy behaviors (e.g., physical closeness, eye contact, and smiling) and BATs had on their self-reports of affective learning. Both high school students and college students reported that perceived teacher/instructor use of prosocial BATs was positively correlated with affective learning, whereas perceptions of teacher/instructor use of antisocial BATs was correlated negatively with their affective learning. Additionally, both high school students' and college students' perceptions of instructor nonverbal immediacy mediated the relationship between perceived teacher/instructor use of prosocial BATs and their affective learning.

Finally, in "Power in the Classroom VII," Richmond, McCroskey, Kearney, and Plax (1987) focused on isolating the instructor BATs that were associated with cognitive learning. It was found that (a) "good" instructors used prosocial BATs related to reward or responsibility (e.g., immediate reward from behavior and responsibility to the class) more than "bad" instructors, whereas "bad" instructors used more punishment-related antisocial BATs (e.g., punishment from teacher and guilt) than "good" instructors and (b) three BATs (i.e., punishment from others, guilt, and normative rules) were perceived as being used more by non-major instructors than by major instructors whereas major instructors employed the deferred reward BAT more frequently than non-major instructors. Across both sets of instructors, cognitive learning was positively associated with the use of prosocial BATs, and negatively associated with the use of antisocial BATs.

Following the "Power in the Classroom" series, researchers continued investigating the effects of teacher use of BATs in the K-12 classroom and began examining college instructors' 
use of BATs when faced with student misbehaviors and resistance. Plax, Kearney, and Tucker (1986) indicated that new teachers (K-12) only used two of the 22 BATs (i.e., self-esteem and teacher feedback) which appeared to be a result of limited teaching schemes that new teachers used in the classroom when faced with student misbehaviors. Additionally, Kearney and Plax (1987) reported that experienced teachers (K-12) use more prosocial BATs with passive student misbehaviors, but rely on the use of antisocial BATs to control active student misbehaviors. Moreover, Kearney et al. (1988) assessed new teachers' (K-12) and experienced teachers' BATs selection when faced with student misbehavior scenarios. Experienced teachers indicated using significantly more prosocial and antisocial BATs than new teachers. Both new and experienced teachers reported using antisocial BATs for active student misbehaviors and prosocial BATs for passive student misbehaviors.

Defined as constructive (e.g., questioning the instructor's reasoning for handing out what appears to be "busy-work") or deconstructive (e.g., student uses cellular phone during lecture) oppositional behavior, student resistance is used to refute an instructor's compliance gaining request within the classroom (Burroughs, Kearney, \& Plax, 1989). Kearney, Plax, and Burroughs (1991) classified student resistance behaviors as either teacher-owned resistance (i.e., student considers the instructor to be the cause of resistance) or student-owned resistance (i.e., student takes the blame/ownership for their resistance). Kearney, Plax, Smith, and Sorensen (1988) examined the effects of instructor immediacy and instructor use of BATs on student resistance within the classroom. Students reported that they are least likely to resist a teacher who was immediate and communicated prosocial BATs. Nonimmediate teachers were met with greater student resistance, such that students reported resisting nonimmediate teachers using prosocial BATs more so than nonimmediate teachers who used antisocial BATs. They suggested 
that students perceived a nonimmediate teacher using a prosocial BAT as being sarcastic or insincere. Burroughs et al. (1989) examined the influence of teacher immediacy and BATs use on student resistance behaviors and found that students generated more resistance strategies when instructors were nonimmediate and used more prosocial BATs rather than antisocial BATs.

\section{Student Behavior Alteration Techniques}

Much of the instructional compliance-gaining research has focused on instructors' use of power, students' perceptions of instructors' use of power, and instructor attempts to control student behavior (Kearney et al. 1984, 1985; McCroskey et al. 1985). Consequently, a great deal of attention has emphasized one-sided self-reports on perceptions of compliance-gaining strategies focusing primarily on the instructor. But because compliance-gaining is "an interdependent process, in which both the source and the target are active participants in the interaction, and both may be pursuing competing agendas" (Lee, Levine, \& Cambra, 1997, p. 30 ), instructional communication scholars have argued that research on compliance-gaining needs an interdependent approach to take into account the role of the student (Burroughs et al. 1989; Golish, 1999). Golish (1999) noted that, "if compliance-gaining is truly a dynamic, relational process, then students must also be examined and viewed as sources or agents of persuasion" (p. 13). This section will explore the evolution of the student behavior alteration techniques (BATs) construct and define the student BATs typology by providing a summary of the research conducted to date.

\section{Evolution of Student BATs}

Many of the studies on power in the classroom assume that the instructor is the initiator of compliance-gaining in instructor-student interactions. However, as Richmond et al. (1984) demonstrated in the organizational communication context, workplace individuals use BATs as 
well. Although they found that subordinates infrequently used BATs with their supervisors, their study provided insight to the ways that subordinates (i.e., those with less power) attempt to seek compliance from supervisors (i.e., those with more power). Referencing this study, Golish (1999) posited that a similar power differential structure exists within the college classroom (i.e., students are subordinates, instructors are superiors), which leads instructors and students to use different types of BATs in their interactions. Because people in less powerful positions (e.g., students) have more to risk when facing someone with more power (e.g., instructors), students may use BATs that are indirect and face-saving so as to prevent their position in the classroom from being negatively affected (Richmond \& Roach, 1992). Although the original BATs typology was developed as a set of strategies used by instructors to control student misbehaviors and to promote affective and cognitive learning, students are less likely (and rarely in a position) to use the same with their instructors. Student attempts at compliance-gaining likely are selfdirected (e.g., requesting a grade change) rather than instructor-directed or learning-focused. Based on this reasoning, Golish (1999) inductively derived a typology of 19 student compliancegaining strategies.

\section{Student BATs Typology}

In her attempt to develop a typology of student BATs, Golish (1999) provided 236 undergraduate students with a set of four hypothetical scenarios and asked them to construct their own compliance-gaining messages in reaction to these scenarios. (She defined compliancegaining as any verbal or nonverbal strategy a student would use to get an instructor to comply with his or her request.) Scenario 1 referenced a student not being able to make a deadline and asking for an extension (without penalty); scenario 2 referenced students agreeing with other students that an exam date should be pushed back; scenario 3 referenced a student perceiving 
that a grade received was unfair; and scenario 4 referenced that due to students feeling overwhelmed, the instructor should cancel the last exam. Students also were asked to report on the "believability" of each scenario. While the first, second, and third scenarios were deemed believable, the fourth scenario was not (students perceived this request as too extreme and extremely unlikely) and it was omitted from further analysis. Using a five stage analysis process modeled after the Burroughs et al. (1989) study on student resistance strategies, the responses to the scenarios were coded and 19 student BATs emerged from the data. Of these 19 BATs, seven were identified as prosocial, eight were identified as antisocial, and four were identified as neutral (Golish, 1999; Golish \& Olson, 2000; See Table 2).

Golish and Olson (2000) then conducted the first study in which this newly developed student BAT typology was examined in the classroom. They examined students' perceptions of their instructors' use of the five power bases and nonverbal immediacy behaviors and whether these behaviors had an effect on student BAT use. While student BAT use was not dependent on perceived instructor use of the legitimate power base, the expert power base, or nonverbal immediacy behaviors, students did indicate they would use specific BATs when their instructors used the reward, coercive, and referent power bases. Reward power was positively related to the use of guilt, flattery, evidence of preparation/logic, performance, and utilitarian justice; coercive power was positively related to the use of public persuasion, punishing the teacher, reference to higher authority, and verbal force/demand; and referent power was positively related to the use of evidence of preparation/logic. Moreover, consistent with Golish's (1999) findings, students indicated they would most likely use prosocial BATs, but would resort to using antisocial BATs if their use of prosocial BATs failed to work or they intended to retaliate against an instructor.

Several years later, Kennedy-Lightsey and Myers (2009) examined how students' 
perceptions of the appropriateness and effectiveness of using the 19 BATs in concert with their own aggressive communication traits (i.e., argumentativeness and verbal aggressiveness) influenced their likelihood to use BATs with their instructors. They found that students' verbal aggressiveness, but not argumentativeness, was a significant predictor of their likelihood to use antisocial BATs. Claus, Chory, and Malachowski (2012) then examined how students' perceptions of effectiveness of using the antisocial BATs together with their perceptions of instructors' aggressive communication and classroom justice. They found students' perceived instructor verbal aggressiveness, but not argumentativeness, was positively related to student perceptions of BATs effectiveness, use of antisocial BATs, and related negatively to perceived classroom justice. In the most recent study of student BATs, Claus, Booth-Butterfield, and Chory (2012) found that students are more likely to use antisocial BATs when instructors are not considered to be task attractive, are low in humor orientation, are not relationally close, and are considered to be both indolent and incompetent.

\section{Student Motives to Communicate with their Instructor}

Interpersonal communication motives are considered to be generally stable, personality characteristics that explain why individuals communicate and how their interpersonal communication needs are fulfilled (Graham, Barbato, \& Perse, 1993). These motives (i.e., affection, pleasure, inclusion, relaxation, escape, and control) influence to whom individuals communicate, the way in which they communicate, and the topics of conversation addressed (Graham et al., 1993; Rubin \& Martin, 1998). Based on this body of research, Martin, Myers, and Mottet (1999) argued that students may possess similar motives for communicating with their instructors. They identified five communication motives used by students with their instructors: relational, functional, participatory, excuse-making and sycophancy. When students 
Table 2

Student BATs

\section{BATs}

Representative BAMs

1. Honesty-Sincerity*

2. Blame $^{\wedge}$

3. Complaining $\wedge$

4. Pleading $\dagger$

5. Guilt

6. Flattery*

7. Play on the Teachers' Ability to Relate $\uparrow$

8. Group Persuasion*

9. Public Persuasion^

10. Private Persuasion*

11. Evidence of Preparation /Logic*

12. Performance*

13. Stress/Overload $\dagger$

14. Utilitarian Justice*

15. Emotional Displays ${ }^{\wedge}$

16. General Excuses ${ }^{\wedge}$

17. Punishing the Teacher ${ }^{\wedge}$

18. Reference to Higher Authority $^{\wedge}$

19. Verbal Force/Demand ${ }^{\wedge}$
To be totally honest, I was sick and didn't have enough time to study. I wish I had an excuse, but I just didn't get it finished.

We weren't prepared for this exam. You didn't explain this assignment well enough. You graded the assignment too hard.

The questions were too ambiguous. I have too much to do in other classes.

Please can you think about changing my grade? I really need this grade to graduate. I'll try to make it up in some other way.

If we take the test now, we will not do as good as if we waited. My paper will be better quality if I can have one more day.

This assignment has been very helpful, but it might be improved by... You have taught this material to us well, but there are a couple of things you could do differently.

Remember back when you were a student? You were in our shoes once, you should be able to relate to us.

We, the class, were talking before class and came to the conclusion that we need more time to study for this exam. Most of us aren't ready to take on this project.

You purposefully ask your professor about the class or an assignment in front of another student, thinking that it would be more difficult for him/her to say "no."

You first run by your request with your professor through e-mail, telephone, or office visit to discuss the matter privately.

Looking at my essay again, I think I clearly lay out my argument by using evidence from the text and lecture. I followed the criteria you gave us for how to receive a good grade.

I have really worked hard all semester. This final grade does not represent how well I have been doing in the class.

I have other classes besides this one. I have a lot of tests right now. I am bombarded with homework. I am stressed out.

If you delay the exam, it will benefit the whole class. You will also benefit by not having to grade our papers this weekend.

Attempting to look really sad, look like you are about to cry, or look the professor in the face so that he/she can see your emotion.

Using any excuse available that sounds reasonable.

Giving the professor a bad course evaluation.

If you don't change my grade, I will talk to the dean or the chair of the department.

I demand that you give me a better grade. I deserve a grade better than the one you gave me. You need to change this grade. 
communicate with instructors for relational reasons, they do so because they are interested in getting to know their instructors as people. This motive may be prompted by students' perceptions that their instructors share similar background and interests with them, which could lead to a potential friendship. When students communicate with instructors for functional reasons, they do so to learn more about the course. Students may ask questions or use information-seeking strategies to learn about course requirements, materials, and assignments (Myers, Mottet, \& Martin, 2000; Myers, Martin, \& Mottet, 2002a). Students communicating for this reason appear to take a more a more active role in the classroom (Martin et al., 1999).

When students communicate with instructors for participatory reasons, they do so to demonstrate their interest in being actively involved in the course. Students may respond to instructor questions, provide examples, and engage in class discussions. Students communicating for this reason tend to believe that academic success involves active participation. When students communicate with instructors for excuse-making reasons, they do so to provide a reason for their poor academic performance. Students may offer excuses for why their work is late or incomplete or why they are absent from class. When students communicate with instructors for sycophantic reasons, they do so to make a favorable impression on instructors. Students may appear interested in the course content or flatter their instructors as a way to increase their chances of being viewed positively by their instructors.

These student motives have been associated with several instructor communicative traits and behaviors. For instance, instructors who are confirming (Goodboy \& Myers, 2008), are high in humor orientation (Dunleavy, 2006), exhibit affective and instrumental functional communication skills (Myers \& Bryant, 2005), are nonverbally and verbally immediate (Gendrin \& Rucker, 2007), and self-disclose (Cayanus, Martin, \& Goodboy, 2009) in the classroom have 
students who report communicating due to the relational, functional, sycophancy, and participatory motives. Conversely, instructors who are verbally aggressive (Myers, Edwards, Wahl, \& Martin, 2007) or who misbehave (Goodboy, Myers, and Bolkan, 2010) have students who are generally not motivated to communicate for any of the five motives.

When students perceive their instructors using referent, reward, and expert power they are more likely to communicate for the relational, functional, participatory, excuse-making, and sycophancy motives (Goodboy \& Bolkan, 2011). When students perceive their instructors as using coercive power, but not expert power, they are more likely to communicate for the excusemaking and sycophancy motives and less likely to communicate for the functional motive (Goodboy \& Bolkan). When instructors employ power as a way to influence students to behave appropriately or remain on task, they may do so by using BATs. Students who perceive their instructors as using prosocial BATs are more likely to communicate for the relational motive, but when they perceive their instructors as using antisocial BATs, they are more likely to communicate for the excuse-making and sycophancy motives (Martin, Heisel, \& Valencic, 2000).

Other instructor variables such as socio-communicative style, communicator style, and use of verbal relational strategies are related to the motives students use to communicate with their instructors. In terms of socio-communicative style, Myers, Martin, and Mottet (2002b) found that students who communicated for the relational and sycophancy motives did so when they perceived both themselves and their instructors as being both high in assertiveness and high in responsiveness. Students who communicated for the participatory motive did so when they perceived themselves as high in assertiveness, but perceived their instructors as high in responsiveness, communicated for the excuse-making motive when they perceived themselves as 
being high in assertiveness, and communicated for the functional motive when they perceived themselves as high in assertiveness and high in responsiveness. In terms of communicator style, Myers, Mottet, and Martin (2000) found that students use of the relational motive was predicted by instructors' use of the impression leaving, contentious, and friendly attributes; use of the sycophancy motive was predicted by instructors' use of the contentious and friendly attributes; use of the participatory motive was predicted by instructors' use of the animated, friendly, and contentious attributes; use of the excuse-making motive was predicted by instructors' use of the attentive and contentious attributes; and use of the sycophancy motive was predicted by instructors' use of the friendly attribute. In regard to perceived instructor use of verbal relational strategies, Mottet, Martin, and Myers (2004) found that perceived instructor use of these strategies was related positively to students' use of all five motives.

Interpersonal attractiveness also appears to influence students' motives to communicate with their instructors. Weiss and Houser (2007) found that perceived instructor attractiveness (social, physical, task) was related positively with students' use of the relational and participatory motives and perceived instructor task attractiveness was related negatively to their use of the participatory, excuse making, and sycophantic motives. In a similar vein, Myers and Huebner (2011) found that perceived instructor social and physical attractiveness were related positively to students' use of the relational and sycophancy motives; social, physical, and task attractiveness were related positively to their use of the participatory motive; and social attractiveness was related positively to their use of the excuse-making motive. They also examined the relationship between students' motives to communicate and their perceived homophily (i.e., attitude and background) with instructors and their perceptions of their instructor's credibility (i.e., competence, character, and caring). Their results revealed that 
perceived instructor attitude and background homophily were related positively to their use of the relational and sycophancy motives; instructor attitude homophily was related positively to their use of the participatory and excuse-making motives; instructor character and caring were related positively to their use of the functional motive.

At the same time, the ways in which students communicate, perceive their own communicative traits and behaviors, and how they perceive their instructors influence their use of the five motives to communicate with instructors. Students' traits influence their motives to communicate with their instructors. For instance, students' self-reported communication apprehension is negatively related to their use of the relational, functional, and participatory motives (Jordan \& Powers, 2007; Martin, Valencic, \& Heisel, 2002). Students who are high in Machiavellianism communicate for functional, excuse-making, and sycophancy reasons (Martin, Myers, \& Mottet, 2006). Students' self-reports of argumentativeness and verbal aggressiveness were related negatively to their use of the sycophancy and functional motives (Edwards and Myers, 2010), although Mansson, Myers, and Martin (2011) found that students' argumentativeness was related positively to their use of the participatory, relational, and sycophancy motives and students' verbal aggressiveness was related positively to their use of the excuse-making and sycophancy motives.

\section{Student Talk}

Although many college instructors desire and expect student participation in the classroom, what constitutes participation varies between instructors. Student participation has been defined narrowly as unsolicited responses from students (Burchfield \& Sappington, 1999) and broadly defined as an active engagement that emerges across five categories: preparation, contribution to discussion, group skills, communication skills, and attendance (Dancer \& 
Kamvounias, 2005). Participation can include students' questions, comments, and concerns; can range from simply attending class and taking notes to giving oral presentations and engaging in class discussions (Fassinger, 1995, Fritschner, 2000); and can last in duration from a few seconds (e.g., answering "yes" or "no") to an extended period of time (e.g., presentations; Cohen, 1991). When students participate, they report gains in communication skills (Dancer \& Kamvounias, 2005), gains in self-perceived character (Kuh \& Umbach, 2004), become better critical thinkers (Garside, 1996), and earn higher grades (Handelsman, Briggs, Sullivan, \& Towler, 2005). In the classroom, two communicative variables--willingness to talk (WTT) and out-of-class communication (OCC)--act as a way to measure overall student talk.

\section{Willingness To Talk (WTT)}

In the classroom, WTT centers on an individual's preference to avoid or approach communication within the classroom. Based on the willingness to communicate (WTC) construct, which is conceptualized as the likelihood of a person voluntarily engaging in communication activities with friends, acquaintances or strangers (McCroskey, 1992), researchers have found that students who are higher in WTC participate more in the classroom (Chan \& McCroskey, 1987). Generally, students' WTC is related negatively to their communication apprehension and introversion, but related positively to their self-perceived communication competence (Barraclough, Christophel, \& McCroskey, 1988; Donovan \& MacIntyre, 2004; McCroskey et al., 1990). Culture also has been found to influence students' WTC. Mansson and Myers (2009) reported that American students are more willing to communicate in class than Swedish students; however, Swedish students' WTC was related positively to their OCC with instructors and in-class participation (Mansson \& Myers, 2011). 
To develop a similar construct with focus on the instructional context only, Christensen, Curley, Marquez, and Menzel (1995) developed the Willingness to Talk scale in which students were asked how willing they were to talk in class given several content specific conditions. They reported that student WTT was influenced by their interest and involvement in the subject matter as well as the discussion topics of the course subject. Subsequent researchers have found that student WTT is related positively to perceived instructor immediacy (Carrell \& Menzel, 1998; Menzel \& Carrell, 1999) and perceived instructor character and caring (Myers, 2004) and related negatively to instructor misbehaviors (Sidelinger, Bolen, Frisby, \& McMullen, 2011). WTT also has been found to be related positively to student self-reports of cognitive learning (Menzel \& Carrell, 1999), student state motivation (Carrell \& Menzel, 1998), and students' personal proactivity and academic locus of control (Sidelinger, 2010), but is related negatively to student state and trait anxiety (Carrell \& Menzel, 1998). In a more recent study, Myers (2010) used the Perry Scheme to explain students' in-class participation (i.e., asking questions, WTT, and interaction involvement). He found that multiplist students ask more questions than dualist students, and contextual relativist students are more involved in classroom interaction than multiplist students, but dualist, multiplist, and contextual relativist students did not differ in their WTT.

\section{Out-of-Class Communication (OCC)}

Primarily initiated by students (Bippus, Kearney, Plax, \& Brooks, 2003), OCC is conceptualized as structured and unstructured student-instructor communication that occurs outside of the normal requirements of the course (Terenzini, Pascarella, \& Blimling, 1996). Structured OCC includes student e-mails, telephone calls, or face-to-face office visits that pertain to course related problems, such as grade disputes, questions about academic standing, and 
requests for letters of recommendation (Cotton \& Wilson, 2006, Martin \& Myers, 2006). Unstructured OCC includes casual conversations before or after class (this does not include informal greetings; Nadler \& Nadler, 2001) and informal meetings, both of which can occur on or off campus (Jaasma \& Koper, 1999). While OCC occurs via face-to-face and mediated channels, mediated communication (specifically e-mail) accounts for one third of students OCC with instructors, with most college students reporting communicating with their instructor solely through e-mail (Bippus et al. 2003; Jones, 2002) and many instructors reporting that e-mail is the most used channel for student-instructor communication (Sheer \& Fung, 2007). Regardless of the channel, students engage in OCC as a way to inquire about course-related information, engage in self-disclosure or small talk, share intellectual ideas, seek advice, and ask instructors for favors (Jaasma \& Koper, 2001).

For many students, engaging in OCC generally is infrequent. Fusani (1994) reported that $23 \%$ of students in his sample had not engaged in either structured or unstructured OCC with their instructor, and 50\% of students had two or fewer interactions. Jaasma and Koper (1999) found that $50 \%$ of students in their sample reported visiting their instructor during office hours and $68 \%$ of students engaged in OCC with their instructor either before class, after class, or somewhere on campus. Aylor and Oppliger (2003) found that $72 \%$ of students in their sample engaged in one structured OCC interaction, whereas $76 \%$ of students reported at least one unstructured OCC interaction. Moreover, the time spent with instructors during $\mathrm{OCC}$ is not lengthy. For example, Jaasma and Koper reported a modal length of 6-10 minutes for structured OCC and a modal length of 1-5 minutes for unstructured OCC. Similarly, Bippus et al. (2003) found that over a semester, the median number of student-initiated OCC encounters was two with a median length of five minutes per OCC interaction. When students engage in OCC, their 
satisfaction (Aylor \& Opplinger, 2003), affective and cognitive learning (Frymier, 2005; Knapp \& Martin, 2002), and state motivation (Jassma \& Koper, 1999) increases.

\section{Student Learning}

Student learning is comprised of cognitive learning, affective learning, and behavioral learning (Bloom, 1956). Within instructional communication research, cognitive and affective learning have been the main focus of scholarship, due to the importance placed on the recall and synthesis of information (i.e., cognitive learning) as well as the emotional responses and feelings students experience about an instructor and a subject matter (i.e., affective). (Behavioral learning, or psychomotor learning, which refers to students' ability to perform physical action and skills as a result of instruction, has received much less attention from instructional communication researchers.) As a result, instructional communication researchers have focused on expanding the knowledge claims about instructor behaviors that contribute to greater student cognitive learning and affective learning. Additionally, student state motivation and student communication satisfaction have been proven to be useful variables in gaining a greater perspective on student learning outcomes (Brophy, 1987; Goodboy, Martin, \& Bolkan, 2009). Taken together, these four learning outcomes act as a way to measure overall student academic success.

Cognitive learning reveals the way in which students convert information into meaningful knowledge. Bloom, Hastings, and Madaus (1971) defined cognitive learning as ranging from student retention of simple information (i.e., lower level of cognitive learning) to student ability to synthesize complex material (i.e., higher level of cognitive learning). Earlier, Bloom (1956) conceptualized cognitive learning as having six distinct hierarchical levels: knowledge (i.e., the knowledge of specific information and the ways and means of dealing with 
specific information), comprehension (i.e., the ability to translate and reword information), application (i.e., the ability to use information in situations), analysis (i.e., the ability to break concepts into or process information in parts), synthesis (i.e., the ability to integrate concepts taken from multiple sources), and evaluation of knowledge (i.e., the ability to assess the worth and utility of concepts by using identifiable criteria). Anderson and Krathwohl (2001) revised Bloom's original taxonomy of cognitive learning to include a two-dimensional framework: Knowledge and Cognitive Processes. The former, which was derived from the subcategories of Bloom's Knowledge category, is comprised of factual knowledge (i.e., discrete and detailed information), conceptual knowledge (i.e., classifications, theories, principles, and models), procedural knowledge (i.e., processes on how to do something), and metacognitive knowledge (i.e., awareness of knowledge). The latter, which was derived from Bloom's original six categories, are remembering (i.e., the ability to recognize and recall information from memory), understanding (i.e., the ability to determine meaning from instructional messages), applying (i.e., the ability to use a procedure in a given situation), analyzing (i.e., the ability to break material into parts and detect relationships between those parts and to an overall structure), evaluating (i.e., the ability to make judgments based on criteria and standards), and creating (i.e., the ability to put together elements to form a novel, coherent whole or produce an original product). The lower three levels of cognitive learning are remembering, understanding, and applying; the highest three levels are analyzing, evaluating, and creating.

Affective learning is defined as "changes in interest, attitudes, and values, and the development of appreciation and adequate adjustment" (Bloom, 1956, p. 7). Krathwohl, Bloom, and Masia (1964) referred to affective learning as a combination of student feelings, emotions, and level of acceptance toward a specific subject matter. Their taxonomy of affective learning 
includes five levels: receiving (i.e., being aware of or sensitive to the existence of certain ideas, material, or phenomena and exhibiting tolerance toward them), responding (i.e., actively responding to ideas, materials, or phenomena), valuing (i.e., placing value on certain ideas, materials, or phenomena), organization (i.e., developing the ability to discuss, formulate, and examine the value attributed to certain ideas, materials, or phenomena), and complex value (i.e., being able to act consistently in accordance with internalized values). Affective learning ranges from lower levels wherein students are willing to minimally receive and respond to classroom information to higher levels wherein students take ownership of their learning by becoming more self-motivated and subsequently modify their attitudes, beliefs, and values in such a way that they perceive their world differently (Andersen, 1979; Krathwohl et al., 1964).

In the Communication Studies discipline, Andersen (1979) proposed that affective learning consisted of both lower-order and higher-order affect. Lower-order affect consisted of student attitudes toward the instructor, course content, and overall course; higher-order affect consisted of student intent to engage in the behaviors recommended in the course and probability to enroll in an additional course of the same subject. McCroskey (1994) argued that affect for the instructor and students' probability of enrolling in another course with the same instructor do not adequately represent affective learning as originally conceptualized by Bloom and Krathwohl et al. He proposed that affective learning consists of six dimensions: affect toward the instructor, affect toward the content of the course, affect toward the behaviors of the course, attitude toward the instructor and likelihood of taking another course with that instructor, attitude toward the content in the course and likelihood of taking another course in that content area, and attitude toward the behaviors recommended in the course and likelihood of engaging in the behaviors recommended. 
Motivation is a construct used to explain the initiation, direction, intensity, persistence, and quality of behavior, particularly goal-directed behavior (Maehr \& Meyer, 1997). Motivation is a process as opposed to a single activity, and includes directive and stimulating activities to try and make motivating behaviors persistent (Ames, 1986). In other words, Ames contended that a simple act alone could not increase motivational behaviors consistently; rather, the process of repeatedly engaging in activities that increase motivation would ultimately lead to persistence of these motivating behaviors. In the instructional context, "the concept of student motivation is used to explain the degree to which students invest attention and effort in various pursuits, which may or may not be the ones desired by their teachers" (Brophy, 2004, p. 4). Brophy (1987) conceptualized student motivation as either trait (i.e., general disposition) or state (i.e., situationspecific). Trait motivation occurs when students demonstrate a consistent desire over time and across situations to value learning by approaching the process of learning with effort and to acquire knowledge and skill regardless of the subject matter. State motivation exists when students purposefully engage in activities within a specific subject, course, or instructor by actively learning concepts and or skills. In the absence of trait motivation, students may exhibit state motivation if the instructor either has piqued their interest or made them realize the importance of the content or skill (Deci, Vallerand, Pelletier, \& Ryan, 1991). Students who are motivated will not always be overtly excited about learning, but they will find the content and process both meaningful and worthwhile while trying to take away the intended benefits from each classroom message and activity (Brophy, 2004).

Student communication satisfaction is an affective response and is achieved when conversational expectations and communicative goals are fulfilled (Hecht, 1978). Generally, the more intimate the relationship and topic of conversation, the greater the communication 
satisfaction (Hecht \& Sereno, 1985; Hecht, Sereno, \& Spitzberg, 1984). In the college classroom, student communication satisfaction refers to contextual satisfaction resulting from the fulfillment of student concerns and classroom expectations through communication with an instructor (Goodboy, Martin et al., 2009).

\section{Rationale}

Taking the perspective that communication between instructors and students is transactional in nature, this dissertation sought to determine if student initiated compliancegaining strategies (i.e. student BATs) used with their instructors was related positively to other student initiated communicative behaviors such as student motives to communicate (e.g., Martin et al., 2000), WTT (e.g., Menzel \& Carrell, 1999), and OCC (e.g., Jaasma \& Koper, 2001) and to their self-reported gains in student learning. Although researchers have explored the relationship between students' BATs use in response to perceived instructor behaviors (Claus, BoothButterfield et al., 2012; Goodboy, Bolkan, Beebe, \& Shultz, 2010; Goodboy, Bolkan, Myers, \& Zhao, 2011), much less is known about the influence of student initiated communication with instructors and student use of BATs. The reasons why students perceive specific BATs as more effective and why they are more likely to use particular BATs also may be explained by their communication with their instructor (i.e., motives to communicate with instructors, WTT, and $\mathrm{OCC}$.

Because students in the classroom communicate often for self-directed reasons (e.g., requesting a grade change; a paper extension; Golish, 1999) rather than learning-focused reasons, students are likely to engage in communicative behaviors with their instructors that are designed to increase the likelihood of instructor compliance. Not surprisingly, students favor the use of prosocial BATs over the use of antisocial BATs (Golish, 1999), and use antisocial BATs either 
when the use of a prosocial BAT fails (Golish \& Olson, 2000) or as a way to retaliate against a verbally aggressive instructor (Claus, Chory et al., 2012). Utilizing the rhetorical/relational theoretical framework Claus, Booth-Butterfield, et al. (2012) found that when instructors meet student expectations for interpersonal/relational needs, there are fewer instances of student antisocial BATs use. Additionally, when students perceived that academic goals were not being met (i.e., instructors enacting misbehaviors), students were not opposed to using these antisocial BATs as a way of displaying power/dominance in the classroom.

This dissertation will extend the existing student BATs literature by focusing on students' perceptions of the effectiveness of and their likelihood to use 15 student BATs (i.e., 7 prosocial, 8 antisocial) identified by Golish (1999; Golish \& Olson, 2000). This focus was selected because previous literature has shown that students' perceived effectiveness of the use of BATs is not always related to their self-reported likelihood to use BATs. For example, Claus, et al. (2011) found that perceived instructor verbal aggressiveness, but not perceived instructor argumentativeness, was related positively to students' reported likelihood to use several antisocial BATs. However, perceived instructor verbal aggressiveness was not related to students' perceptions of the effectiveness of using the same antisocial BATs (except for blame), suggesting that students' antisocial responses to instructor aggressiveness may be retaliative in nature. However, when Claus, Chory et al. (2012) re-examined the relationship between students' perceived effectiveness of and students' likelihood to use antisocial BATs, students reported that perceived instructor verbal aggressiveness was related positively to their perceived effectiveness of, and likelihood to use, antisocial BATs. This study will continue to examine the relationship between students perceived effectiveness of, and their perceived likelihood to use, prosocial and antisocial BATs with their instructors. 
As aforementioned in the literature review, only one study thus far has examined students' BATs use as a function of their own communication behaviors (i.e., Kennedy-Lightsey \& Myers, 2009), while other studies have examined students' BATs use in relation to their perceptions of their instructors' communicative behaviors (Claus, Booth-Butterfield et al., 2012; Claus, Chory et al. 2012; Goodboy et al., 2010; Goodboy et al., 2011). To gain a more complete picture of the student BATs construct, research is needed to explore how students' communication with their instructors (i.e., student motives to communicate, WTT, OCC) is related to why students perceive particular BATs as effective or why they are more likely to use particular BATs.

One way of assessing student initiated communication behavior is via the research on student motives for communicating with instructors. The student motives to communicate with their instructor literature explains why students approach their instructors and engage in communication interactions with their instructors (Martin et al., 1999). As a review of the motives to communicate literature indicates, the relational, functional, participatory, and sycophancy motives (or a combination of the four motives), but not the excuse-making motive, afford students the opportunity to become active participants in the classroom in which they can communicate their interest and involvement in the course with their instructors (Mottet et al., 2004; Myers et al., 2000; Myers et al., 2002a) and are dependent largely on student perceptions that are formed as a result of quality instructor--student interactions (Myers, 2006; Goodboy et al., 2009).

It is reasonable to assume that if students want to develop a relationship, show active involvement in the course, and would rather be perceived favorably than unfavorably by the instructor, then students would communicate for the relational, functional, participatory, and 
sycophancy motives. As such, when these students approach instructors with the goal of compliance-gaining, they would most likely turn to the prosocial BATs, as prosocial BATs elicit more positive relationships with their instructors (Claus, Booth-Butterfield et al., 2012; Golish, 1999; Golish \& Olson, 2000). Therefore, in the instructor-student relationship, it seems highly likely these students will be more likely to perceive prosocial BATs as effective and would be more likely to communicate those prosocial BATs to their instructors because prosocial BATs are those compliance-gaining messages that are rewarding and encouraging of the target. To investigate this idea, the following hypotheses are posited:

H1a: Students' self-reports of their use of the relational, functional, participatory, and sycophancy motives to communicate with their instructors will be related positively to their perceived effectiveness of prosocial BATs.

H1b: Students' self-reports of their use of the relational, functional, participatory, and sycophancy motives to communicate with their instructors will be related negatively to their perceived effectiveness of antisocial BATs.

H2a: Students' self-reports of their use of the relational, functional, participatory, and sycophancy motives to communicate with their instructors will be related positively to their perceived likelihood to use prosocial BATs.

$\mathrm{H} 2 \mathrm{~b}$ : Students' self-reports of their use of the relational, functional, participatory, and sycophancy motives to communicate with their instructors will be related negatively to their perceived likelihood to use antisocial BATs.

Martin et al. (2002) described the excuse-making motive as the way students rationalize their poor academic performance, explain why work was never submitted, or try to convince their instructors to provide them with a second chance to rectify the course expectation that they 
clearly failed to accomplish. Students who communicate for the excuse-making motive may do so due to their own communicative behaviors and communication traits rather than the situation or their perceptions of the instructors' in-class communicative behaviors (Jordan \& Powers, 2007; Martin et al., 2002; Martin et al., 2006). Students who communicate with their instructors for the excuse-making motive tend to be higher in deconstructive communication traits such as Machiavellianism (Martin et al., 2006) and verbal aggressiveness (Mansson, Myers, \& Martin, 2011). As such, it seems likely these students will be more likely to perceive antisocial BATs as effective and would be more likely to communicate those antisocial BATs to their instructor. To examine this notion, the following hypotheses are posited:

H3a: Students' self-reports of their use of the excuse-making motive to communicate with their instructors will be related positively to their perceived effectiveness of antisocial BATs.

H3b: Students' self-reports of their use of the excuse-making motive to communicate with their instructors will be related negatively to their perceived effectiveness of prosocial BATs.

H4a: Students' self-reports of their excuse-making motive to communicate with their instructors will be related positively to their perceived likelihood to use antisocial BATs.

H4b: Students' self-reports of their excuse-making motive to communicate with their instructors will be related negatively to their perceived likelihood to use prosocial BATs.

Another way to assess student initiated communication is through students' WTT and OCC. The student WTT literature explains why students approach or avoid communication 
within the classroom, and the student OCC literature explains why students are willing to engage in either structured or unstructured communication with their instructors outside of the classroom. As a review of the WTT and OCC literature indicates, whether communicating inclass or out-of-class, students' willingness to engage in communication with their instructors allows them to demonstrate participation and active involvement, increase their communication skills, and earn higher grades (Dancer \& Kamvounias, 2005; Fassinger, 1995; Fritschner, 2000; Handelsman et al., 2005; Menzel \& Carrell, 1999). These findings obtained in the literature suggest that although students who exhibit greater willingness to engage in student talk results in favorable outcomes for them, whether students perceive particular BATs as effective, or are more likely to use particular BATs, has not been explained in relation to their WTT and OCC.

In regard to in-class participation, previous research has reported that students participate for several rhetorical reasons, such as to seek information, gain clarification, contribute to the class discussion, or express anger about a topic (Christensen et al., 1995; Howard \& Henney, 1998). Conversely, students engage in OCC as a way to inquire about course-related information, engage in self-disclosure or small talk, share intellectual ideas, seek advice, or ask instructors for favors (Bippus et al., 2003; Jaasma \& Koper, 2001). Students perceive OCC to be more rewarding and worthwhile when they perceive their instructors to engage in career and course mentoring during OCC interactions, as well as demonstrating in-class behaviors that suggest they are socially accessible (Bippus et al., 2003). Because of these reasons for in-class and out-of-class communication, students may be motivated to use particular BATs in order to satisfy their course-related issues.

Generally, students who perceive their instructors as being open to communication and demonstrate caring and concern report greater willingness to engage in WTT and OCC (Myers, 
2004; Sidelinger et al., 2011; Theophilides \& Terenzini, 1981). Additionally, instructors' use of relational themes has been shown to increase students' receptiveness to engage in OCC. Nadler and Nadler (2000) reported that instructors who use the equality relational theme have students who participate in OCC about course specific issues; instructors who use the receptivity/trust and equality relational themes have students who participate in $\mathrm{OCC}$ about non-course specific academic-related issues; and instructors who use the receptivity/trust, equality, immediacy/affection, and similarity/depth relational themes have students who participate in more unstructured OCC. These same constructive instructor behaviors also may influence students to use prosocial BATs rather than antisocial BATs. Thus, it would be likely that those students who report a willingness to engage in WTT and OCC would use prosocial BATs when seeking compliance from their instructor. When faced with deconstructive instructor behaviors, students most often actively avoid engaging in student talk (Sidelinger et al., 2011); however, in certain circumstances, students may initiate communication in order to voice their concerns or resist the deconstructive instructor (Burroughs, 2007; Chory-Assad \& Paulsel, 2004; Edwards \& Myers, 2010). For example, some students report that antisocial BATs are effective and are more likely to use antisocial BATs (in-class or out-of-class) to retaliate against these deconstructive instructors (Claus, Chory et al., 2012). Because the impact of willingness to engage in student talk on students' perceived effectiveness of, and likelihood to use BATs is unclear, the following four research questions are posed:

RQ1a: To what extent are students' self-reports of their WTT and their OCC related to their perceived effectiveness of prosocial BATs?

RQ1b: To what extent are students' self-reports of their WTT and their OCC related to their perceived effectiveness of antisocial BATs? 
RQ2a: To what extent are students' self-reports of their WTT and their OCC related to their perceived likelihood to use prosocial BATs?

RQ2b: To what extent are students' self-reports of their WTT and their OCC related to their perceived likelihood to use antisocial BATs?

In addition to examining the potential relationship between students' communication with their instructors and student BATs, another purpose of this dissertation is to examine the relationship between students BATs use and student learning for two reasons. First, student learning has long been regarded as an important outcome in instructional communication research (Waldeck, Kearney, \& Plax, 2010). Not surprisingly, the instructional communication literature has produced consistent findings such that instructor prosocial BATs are associated positively with these affective learning, cognitive learning, and state motivation (Plax, Kearney, \& McCroskey et al., 1986; Richmond et al., 1987; Roach, 1994) and instructor antisocial BATs are associated negatively with these outcomes (Paulsel \& Chory-Assad, 2004; Plax \& Kearney, 1982; Plax, Kearney, \& Downs, 1986; Richmond, 1990). In regard to student communication satisfaction, while no current study has examined this construct in relationship with instructor BATs, Goodboy et al. (2011) examined the effects of perceived instructor power on student communication satisfaction. They found that instructors' use of antisocial power (i.e., coercive, legitimatè) was related negatively to students' communication satisfaction, whereas instructors' use of prosocial power (i.e., reward, expert, referent) was related positively to students' communication satisfaction. Based on these findings, it is likely that student BATs will yield similar results (i.e., prosocial student BATs will most likely be associated positively with learning and antisocial student BATs will most likely be associated negatively with learning). For instance, Goodboy et al. (2011) found that when students were satisfied with their 
communication with their instructor they indicated using BATs less frequently, however, when American students reported using BATs they did so using prosocial strategies (e.g., performance, honest-sincerity). Second, Kennedy-Lightsey and Myers (2009) advised that future researchers should examine student learning with student BATs. To do so and to contribute further to the study of the student BATs construct, the following hypotheses are posited:

H5a: Students' self-reports of their cognitive learning, affective learning, state motivation, and student communication satisfaction will be related positively to their perceived effectiveness of prosocial BATs.

H5b: Students' self-reports of their cognitive learning, affective learning, state motivation, and student communication satisfaction will be related negatively to their perceived effectiveness of antisocial BATs.

H6a: Students' self-reports of their cognitive learning, affective learning, state motivation, and student communication satisfaction will be related positively to their perceived likelihood to use prosocial BATs.

H6: Students' self-reports of their cognitive learning, affective learning, state motivation, and student communication satisfaction will be related negatively to their perceived likelihood to use antisocial BATs.

\section{Summary}

The purpose of this dissertation is threefold. The first purpose is to examine the relationship between students' motives to communicate (i.e., relational, functional, participatory, sycophancy, and excuse-making) with their instructors with students' perceived effectiveness of, and likelihood to use, student BATs. The second purpose is to examine the relationship between student talk (i.e., WTT, OCC) and students' perceived effectiveness of, and likelihood to use, 
student BATs. The third purpose is to examine the extent to which student learning (i.e., cognitive learning, affective learning, state motivation, and communication satisfaction) are related to students' perceived effectiveness of, and likelihood to use, student BATs. 


\section{CHAPTER II}

\section{Method}

\section{Participants}

Participants were 294 full-time undergraduate students enrolled in communication courses at two large Mid-Atlantic universities during the $11^{\text {th }}$ and $12^{\text {th }}$ week of the Fall 2012 semester. The participants included 105 men and 187 women ( 2 participants did not indicate their sex) whose ages ranged from $18-30$ years $(M=21.04, S D=2.08)$. They included 1 first year student, 35 sophomores, 106 juniors, 149 seniors, and 3 students who did not indicate their year in school. The majority of participants (82.3\%) were Caucasian. Other ethnicities were African American, $10.5 \%$; Asian, 1.7\%; Hispanic, $1.0 \%$; other, 3.1\%; and Native American, $.3 \%$. Students reported on 127 male and 167 female instructors from several academic disciplines (52.7\%, Communication Studies; 9.5\%, English; 8.5\%, Business; 8.2\%, Natural Science; 7.5\%, Psychology; 5.4\%, Mathematics; 4.8\%, Foreign Language; and 3.4\%, Performing Arts). One hundred and fifty students indicated being enrolled in a large lecture course with an average class size of $224.16(S D=91.27)$ students whereas 142 students indicated being enrolled in a small class with an average class size of $27.48(S D=23.24)$ students.

\section{Procedures and Instrumentation}

Utilizing a paper-and-pencil questionnaire, participants were recruited for data collection via a verbal recruitment script (see Appendix A). This recruitment script (a) introduced the researcher, (b) introduced the study, (c) identified the inclusion criteria, and (d) asked the participants to complete an anonymous questionnaire. They were then provided a cover letter (see Appendix B) attached to the questionnaire (see Appendix C). Participants were instructed to complete a series of instruments in reference to the instructor of the course they attended 
immediately prior to data collection (Plax et al., 1986). These instruments included the Student Behavioral Alteration Techniques and Messages Typology (Golish, 1999), the Student Communication Motives Scale (Martin et al., 1999), the Student Willingness to Talk in Class Scale (Christensen et al., 1995), the Out-of-Class Communication Scale (Knapp \& Martin, 2002), the Revised Cognitive Learning Indicators Scale (Frymier \& Houser, 1999), the Instructional Affect Assessment Instrument (McCroskey, 1994), the Student Motivation Scale (Christophel, 1990), and the Student Communication Satisfaction Scale (Goodboy, Martin, et al. 2009).

The Student Behavioral Alteration Techniques and Messages Typology (see Appendix D) is assessed by items based on the Student Behavioral Alteration Techniques and Messages Typology (Golish, 1999). Although the typology was not developed as an instrument, Golish and Olson (2000) had their participants rate their frequency of use of the BATs with their instructors. Kennedy-Lightsey and Myers (2009) used the same typology and asked students to report on their perceptions of the appropriateness of, and their likelihood to use, each BAT. Students' perceived effectiveness of, and likelihood of using, the 19 BATs are assessed using a 5-point Likert-type scale ranging from completely ineffective (0) to very effective (4) for perceived effectiveness of use and from not very likely (0) to very likely (4) for likelihood of use. A Cronbach alpha reliability coefficient of .91 has been reported for the 19 item instrument (Goodboy et al., 2010, 2011) and when examining only the antisocial BATs (i.e., 8 items), a previous Cronbach alpha reliability coefficient of .81 has been reported (Claus, BoothButterfield et al., 2012; Claus, Chory et al., 2012).

In this dissertation, a principal components factor analysis using orthogonal varimax rotation was conducted on the students' perceived effectiveness of, and likelihood to use, the 19 
BATs. Despite Golish and Olson's (2000) conceptual distinctions between the BATs, the underlying factor structure of the typology should be statistically supported, therefore, warranting the use of exploratory factor analysis (Comrey \& Lee, 1992; Levine, 2005; McCroskey \& Young, 1979) and because the factors were believed to be uncorrelated, an orthogonal varimax rotation was selected (Vogt, 1993). To determine the factor structure of the typology, several criteria were used. Items were retained if they achieved an eigenvalue of 1.0 or greater, had a primary factor loading of 0.60 or greater, no secondary loadings greater than 0.40 , and no item cross-loaded on another factor (McCroskey \& Young, 1979).

For the perceived effectiveness of the $19 \mathrm{BATs}$, a principal components factor analysis with varimax rotation was conducted in three rounds. In the first round, 10 BATs (i.e., honestysincerity, blame, complaining, pleading, guilt, play on the teachers' ability to relate, group persuasion, stress/overload, emotional displays, general excuses) failed to meet the $.60 / .40$ factor loading criteria, resulting in a three factor solution. The first factor consisted of 2 BATs (i.e., public persuasion, utilitarian justice; eigenvalue $=5.06$ ) that accounted for $17.20 \%$ of the variance, the second factor consisted of 3 BATs (i.e., punish the teacher, reference to authority, verbal force/demand; eigenvalue $=1.85$ ) that accounted for $13.19 \%$ of the variance, and the third factor consisted of 4 BATs (i.e., flattery, private persuasion, evidence of preparation/logic, performance; eigenvalue $=1.35$ ) that accounted for $13.14 \%$ of the variance. In the second round, a three factor solution emerged. The first factor consisted of 4 BATs (i.e., flattery, private persuasion, evidence of preparation/logic, and performance; eigenvalue $=2.71$ ) that accounted for $20.71 \%$ of the variance, the second factor consisted of 3 BATs (i.e., punish the teacher, reference to higher authority, verbal force/demand; eigenvalue $=1.68$ ) that accounted for $20.79 \%$ of the variance, and the third factor consisted of 2 BATs (i.e., public persuasion, utilitarian 
Table 3

Rotated Factor Loadings for Perceived Effectiveness of, Student BATs

\begin{tabular}{lll}
\hline BAT & Prosocial & Antisocial \\
\hline 1. Flattery & .61 & .07 \\
2. Private Persuasion & .68 & -.01 \\
3. Evidence of Preparation/Logic & .80 & .01 \\
4. Performance & .72 & .17 \\
5. Punishing the Teacher & .12 & .72 \\
6. Reference to Higher Authority & .12 & .82 \\
7. Verbal Force/Demand & -.06 & .81 \\
\hline
\end{tabular}

Note. Primary loadings are bolded. 
justice; eigenvalue $=.96$ ) that accounted for $16.04 \%$ of the variance. Because this third factor failed to meet the 1.0 or greater eigenvalue criteria, these two items were eliminated. In the third round, a two factor solution emerged (see Table 3). The first factor consisted of 4 BATs (i.e., flattery, private persuasion, evidence of preparation, and performance; eigenvalue $=2.31$ ) that accounted for $29.43 \%$ of the variance and achieved a Cronbach alpha reliability coefficient of .67 $(M=11.15, S D=2.84)$. The second factor consisted of 3 BATs (i.e., punish the teacher, reference to higher authority, verbal force/demand; eigenvalue $=1.64$ ) that accounted for $27.15 \%$ of the variance and achieved a Cronbach alpha reliability coefficient of .66 $(M=2.24, S D=$ 2.20).

For the perceived likelihood to use the 19 BATs, a principal components factor analysis using varimax rotation was conducted in two rounds. In the first round, 10 BATs (i.e., honestysincerity, blame, complaining, pleading, flattery, public persuasion, stress/overload, emotional displays, general excuses, punishing the teacher) failed to meet the $.60 / .40$ factor loading criteria, resulting in a three factor solution. The first factor consisted of 4 BATs (i.e., guilt, play on the teachers' ability to relate, group persuasion, utilitarian justice; eigenvalue $=5.76$ ) that accounted for $19.14 \%$ of the variance, the second factor consisted of 2 BATs (i.e., reference to authority, verbal force/demand; eigenvalue $=1.74$ ) that accounted for $15.81 \%$ of the variance, and the third factor consisted of 3 BATs (i.e., private persuasion, evidence of preparation/logic, performance; eigenvalue $=1.38)$ that accounted for $11.86 \%$ of the variance. In the second round, a three factor solution emerged (see Table 4). The first factor consisted of 4 BATs (i.e., guilt, play on the teachers' ability to relate, group persuasion, utilitarian justice; eigenvalue $=3.23$ ) that accounted for $26.56 \%$ of the variance and achieved a Cronbach alpha reliability coefficient of .76 ( $M=$ 5.13, $S D=3.49$ ). The second factor consisted of 3 BATs (i.e., private persuasion, evidence of 
Table 4

Rotated Factor Loadings for Perceived Likelihood to Use Student BATs

\begin{tabular}{lccc}
\hline BAT & Neutral & Prosocial & Antisocial \\
\hline 1. Guilt & .73 & .13 & .09 \\
2. Play on Teachers Ability to Relate & .73 & .03 & .23 \\
3. Group Persuasion & .71 & .24 & .08 \\
4. Utilitarian Justice & .79 & .06 & .07 \\
5. Private Persuasion & -.06 & .79 & .04 \\
6. Evidence of Preparation/Logic & .23 & .81 & .05 \\
7. Performance & .25 & .73 & .08 \\
8. Reference to Higher Authority & .19 & .14 & .84 \\
9. Verbal Force/Demand & .12 & .01 & .89 \\
\hline
\end{tabular}

Note. Primary loadings are bolded. 
preparation/logic, and performance; eigenvalue $=1.49$ ) that accounted for $21.44 \%$ of the variance and achieved a Cronbach alpha reliability coefficient of $.71(M=7.67, S D=2.69)$. The third factor consisted of 2 BATs (i.e., reference to higher authority, verbal force/demand; eigenvalue $=1.20)$ that accounted for $17.93 \%$ of the variance and achieved a Cronbach alpha reliability coefficient of $.71(M=.54, S D=1.14)$.

The Student Communication Motives Scale (see Appendix E) is 30 items and asks participants to report on their motives for communicating with their instructors. Six items represent each of the five motives: relational, functional, participatory, excuse-making, and sycophancy. Responses are solicited using a 5-point Likert scale ranging from not at all like me (1) to exactly like me (5). Previous Cronbach alpha reliability coefficients ranging from .79 to .94 have been reported for the five motives (Goodboy et al., 2010; Myers \& Claus, 2012; Myers \& Huebner, 2011). In this dissertation, a Cronbach's alpha reliability coefficient of .92 ( $M=$ 82.64, $S D=18.37$ ) was obtained.

The Student Willingness to Talk in Class Scale (see Appendix F) is 19 items and asks participants to report how often they would be willing to participate in class across a variety of circumstances. Responses are solicited using a 5-point Likert scale ranging from never ( 0 ) to very often (4). Previous Cronbach alpha reliability coefficients ranging from .83 to .93 have been reported for the scale (Myers, 2004; Sidelinger, 2010; Sidelinger \& Booth-Butterfield, 2010). In this dissertation, a Cronbach's alpha reliability coefficient of $.90(M=44.56, S D=$ 12.40) was obtained.

The Out-of-Class Communication Scale (see Appendix G) is nine items and asks participants to indicate the frequency with which they engage in OCC with their instructors. Responses are solicited using a 5-point Likert scale ranging from strongly disagree (1) to 
strongly agree (5). Previous Cronbach alpha reliability coefficients ranging from .81 to .86 have been reported for the scale (Knapp, 2010; Knapp \& Martin, 2002; Myers et al., 2005). In this dissertation, a Cronbach's alpha reliability coefficient of $.78(M=23.66, S D=6.62)$ was obtained.

The Revised Cognitive Learning Indicators Scale (see Appendix H) is seven items and asks participants to report on their behaviors or activities that are associated with learning course content. Responses are solicited using a 5-point Likert scale ranging from never (0) to very often (4). Previous Cronbach alpha reliability coefficients ranging from .84 to .91 have been reported for the scale (Houser \& Frymier, 2009; Hsu, 2012; Wei \& Wang, 2010). In this dissertation, a Cronbach's alpha reliability coefficient of $.82(M=18.23, S D=5.38)$ was obtained.

The Instructional Affect Assessment Instrument (see Appendix I) is 24 items and consists of six sets of four-item, 7-point bipolar scales in which participants were asked to circle the number toward either word which best represented their feeling toward the particular question. The first set measured students' attitude about the course content, the second set measured students' attitude about the behaviors recommended in the class, the third set measured students' attitude about the instructor in the class, the fourth set measured students' likelihood of actually attempting to engage in the behaviors recommended in the class, the fifth set measure students' likelihood of actually enrolling in another class with similar content, and the sixth set measured students' likelihood of taking another course with the same instructor. Previous Cronbach alpha reliability coefficients ranging from .90 to .94 have been reported for the subscales (Hsu, 2012; Mazer, Murphy, \& Simonds, 2007; Tibbles, Richmond, McCroskey, \& Weber, 2008). In this dissertation, a Cronbach's alpha reliability coefficient of $.97(M=126.40, S D=33.25)$ was obtained for the summed scale. 
The Student Motivation Scale (see Appendix J) is 12 items and asks participants to report on their levels of state motivation toward a specific instructor. Responses are solicited using a 7point bipolar adjective scale. Previous Cronbach alpha reliability coefficients ranging from .91 to .94 have been reported for the scale (Goodboy et al., 2009; Titsworth, Quinlan, \& Mazer, 2010; Wei \& Wang, 2010). In this dissertation, a Cronbach's alpha reliability coefficient of .90 $(M=51.01, S D=13.90)$ was obtained.

The Student Communication Satisfaction Scale (see Appendix K) is eight items and asks participants to report on their levels of satisfaction with their communication with an instructor. Responses are solicited using a 7-point Likert scale ranging from strongly disagree (1) to strongly agree (7). Previous Cronbach alpha reliability coefficients ranging from .86 to .97 have been reported for the scale (Goodboy et al., 2009, 2011; Goodboy \& Bolkan, 2009). In this dissertation, a Cronbach's alpha reliability coefficient of $.92(M=39.15, S D=10.70)$ was obtained.

\section{Data Analysis}

To address the hypotheses and research questions, a series of Pearson product-moment correlations were conducted (a) between students' perceived effectiveness of the 19 BATs and the five student motives to communicate, WTT, OCC, the three dimensions of affective learning, cognitive learning, state motivation, and student communication satisfaction and (b) between students' perceived likelihood to use student BATs and the same aforementioned set of variables. Due to the number of potential relationships being examined in the hypotheses and research questions, the significance level for all correlations was adjusted to $p<.001$.

\section{Summary}

The methodology was conducted in two steps. The first step determined the factor 
structure of the student BATs typology (Golish \& Olson, 2000), and the factor structure of each scale used in this dissertation. The second step examined the perceived effectiveness of, and the perceived likelihood to use, student BATs in relation to (a) student motives to communicate with their instructor, (b) student WTT and OCC, and (c) student affective learning, cognitive learning, student state motivation, and student communication satisfaction. 


\section{Chapter III}

\section{Results}

Because only seven of the 19 BATs for perceived effectiveness and nine of the 19 BATs for perceived likelihood to use emerged as factors in the factor analyses described in Chapter II, a decision was made to analyze the data by using each of the 15 BATs (i.e., 7 prosocial, 8 antisocial) singly based upon the conceptual distinctions outlined by Golish and Olson (2000). Due to the number of potential relationships being examined in the six hypotheses and the two research questions, the significance level for all correlations was adjusted to $p<.001$.

Before discussing the results obtained in this dissertation, two preliminary analyses were conducted. First, the mean score and standard deviation of each BAT (for both perceived effectiveness of and likelihood to use) were calculated (see Table 5). Second, because previous research has yielded mixed results between students' perceived effectiveness of and perceived likelihood to use, antisocial BATs (Claus, et al., 2011; Claus, Chory, et al., 2012), the relationship between perceived effectiveness of and perceived likelihood to use each, of the prosocial and antisocial student BATs was examined. It was found that a positive relationship was obtained between the perceived effectiveness of, and the likelihood to use, each of the 7 prosocial BATs (see Table 6) and the 8 antisocial BATs (see Table 7).

\section{Hypotheses 1-4}

The first four hypotheses examined the relationship between student motives to communicate with instructors and the perceived effectiveness of, and likelihood to use, student BATs. Hypothesis 1a predicted students' self-reports of their use of the relational, functional, participatory, and sycophancy motives to communicate with their instructors would be related positively to their perceived effectiveness of prosocial BATs. It was found (see Table 8) that the 
Table 5

Means and Standard Deviations for Prosocial and Antisocial BATs

Perceived Effectiveness Likelihood of Using

$\begin{array}{llll}M & S D & M & S D\end{array}$

Prosocial BATs

Private Persuasion

Evidence of

$3.18 \quad .89$

$2.99 \quad 1.05$

Logic/Preparation

Flattery

$2.95 \quad .93$

$2.57 \quad 1.12$

Group Persuasion

$2.60 \quad 1.12$

$\begin{array}{ll}1.77 & 1.22\end{array}$

Performance

$2.45 \quad 1.13$

$1.78 \quad 1.25$

Utilitarian Justice

$2.42 \quad 1.19$

$2.11 \quad 1.05$

Honesty-Sincerity

$1.73 \quad 1.13$

$1.24 \quad 1.78$

$1.53 \quad 1.06$

$1.13 \quad 1.16$

Antisocial BATs

General Excuses

Emotional Displays

$2.12 \quad 1.30$

$1.47 \quad 1.21$

$1.39 \quad 1.35$

Public Persuasion

$1.40 \quad 1.13$

$.87 \quad 1.16$

Blame

$1.35 \quad 1.04$

$.96 \quad 1.10$

Complaining

$1.16 \quad 1.01$

$.98 \quad 1.05$

Punishing the Teacher

$1.12 \quad 1.16$

$.89 \quad 1.01$

Reference to Authority

$.84 \quad .76$

$.70 \quad 1.08$

Verbal Force/Demand

$.28 \quad .61$

$.37 \quad .61$

$.17 \quad .51$ 
Table 6

Correlations among Effectiveness of and Likelihood of Using Student Prosocial BATs

$\begin{array}{lllllllllllll}1 & 2 & 3 & 4 & 5 & 6 & 7 & 8 & 9 & 10 & 11 & 12 & 13\end{array}$

\section{Effectiveness}

1. Honesty-Sincerity

2. Flattery

3. Group Persuasion

4. Private Persuasion

5. Evidence of Logic/Preparation

6. Performance

7. Utilitarian Justice

\section{Likelihood of Using}

8. Honesty-Sincerity

9. Flattery

10. Group Persuasion

11. Private Persuasion

12. Evidence of Logic/Preparation

13. Performance

14. Utilitarian Justice

$-\infty$

.00

$.04 \quad .36^{*} \quad--$

$-.09 .27 * .20 *$

$--$

$.08 \quad .31 * \quad .34 * \quad .41^{*} \quad--$

$.07 \quad .29 * \quad .37 * \quad .28 * \quad .51 * \quad--$

$\begin{array}{lllllll}.14 & .13 & .44 & .08 & .18^{*} & .17 & --\end{array}$

$\begin{array}{lllllllll}.58^{*} & .02 & .06 & .02 & .16 & .06 & .14 & --\end{array}$

$\begin{array}{lllllllll}. .01 & .56 * & .26 * & .15 & .29 * & .28 * & .20 * & .04 & --\end{array}$

$\begin{array}{llllllllll}.16 & .14 & .57 * & .04 & .20 * & .21 * & .37 * & .19 * & .41 & --\end{array}$

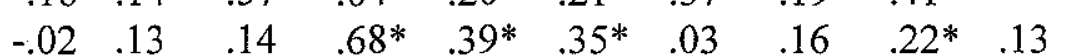

$0121 * 24 * 31 * 66 * 48 * \quad 15 \quad 17 \quad 42 * 30 \quad-78 *$

$\begin{array}{lllllllllllll}.12 & .25 * & .29 * & .21 * & .37 * & .69 * & .17 & .17 & .34 * & .34 * & .35 * & .55 * & \ldots\end{array}$

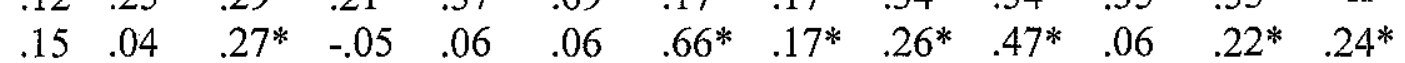

$\overline{\text { Note. }}{ }^{*} p<.001$ 
Table 7

Correlations among Effectiveness of and Likelihood of Using Antisocial BATs

$\begin{array}{llllllll}1 & 2 & 3 & 4 & 5 & 6 & 7 & 8\end{array}$

9

10

\begin{tabular}{|c|c|c|c|c|c|c|c|c|c|c|c|c|c|}
\hline $.34 *$ & -- & & & & & & & & & & & & \\
\hline $.20^{*}$ & $.34^{*}$ & -- & & & & & & & & & & & \\
\hline .04 & $.24^{*}$ & $.33 *$ & -- & & & & & & & & & & \\
\hline .12 & $.22^{*}$ & $.20^{*}$ & $.41^{*}$ & -- & & & & & & & & & \\
\hline $.22 *$ & $.35^{*}$ & $.30^{*}$ & .15 & $.19^{*}$ & -- & & & & & & & & \\
\hline $.22 *$ & $.31^{*}$ & $.22 *$ & $.25^{*}$ & $.26^{*}$ & $.43^{*}$ & -- & & & & & & & \\
\hline $.23^{*}$ & $.29^{*}$ & $.22^{*}$ & .13 & .17 & $.37 *$ & $.52^{*}$ & - & & & & & & \\
\hline $.63^{*}$ & $.29^{*}$ & $.19^{*}$ & .09 & .14 & $.23^{*}$ & $.28^{*}$ & $.25^{*}$ & - & & & & & \\
\hline $.28 *$ & $.64^{*}$ & $.26^{*}$ & $.22 *$ & $.21^{*}$ & $.26^{*}$ & $.28^{*}$ & $.27^{*}$ & $.46^{*}$ & -- & & & & \\
\hline .13 & $.24^{*}$ & $.61 *$ & .15 & .07 & $.29 *$ & $.25^{*}$ & $.22^{*}$ & $.26^{*}$ & $.36^{*}$ & -- & & & \\
\hline .01 & .09 & $.23^{*}$ & $.59 *$ & $.28^{*}$ & .14 & $.21 *$ & .16 & $.18^{*}$ & $.22 *$ & $.30 *$ & -- & & \\
\hline .07 & .09 & .13 & $.26^{*}$ & $.58^{*}$ & $.22 *$ & $.22^{*}$ & $.16^{*}$ & .16 & $.22^{*}$ & $.17^{*}$ & $.41^{*}$ & -- & \\
\hline .13 & $.23^{*}$ & $.19^{*}$ & .11 & .13 & $.64 *$ & $.34 *$ & $.31^{*}$ & $.29 *$ & $.31 *$ & $.35^{*}$ & $.22^{*}$ & $.19^{*}$ & -- \\
\hline $.25^{*}$ & $.27^{*}$ & $.24 *$ & .14 & $.23^{*}$ & $.38 *$ & $.63^{*}$ & $.46^{*}$ & $.34^{*}$ & $.35^{*}$ & $.37^{*}$ & $.20^{*}$ & $.29^{*}$ & $.45^{*}$ \\
\hline $.21 *$ & $.21^{*}$ & .13 & .11 & $.14^{*}$ & $.26^{*}$ & $.40^{*}$ & $.72 *$ & $.30^{*}$ & $.31^{*}$ & $.34^{*}$ & $.26^{*}$ & $.21^{*}$ & $.39 *$ \\
\hline
\end{tabular}

Note. ${ }^{*} p<.001$. 
Table 8

Correlations among Effectiveness of Student Prosocial BATs, Student Motives to Communicate, WTT, OCC, and Student Learning

\begin{tabular}{|c|c|c|c|c|c|c|c|c|c|c|c|c|c|c|c|c|c|}
\hline & 1 & 2. & 3 & 4 & 5 & 6 & 7 & 8 & 9 & 10 & 11 & 12 & 13 & 14 & 15 & 16 & 17 \\
\hline \multicolumn{18}{|l|}{ Effectiveness } \\
\hline 1. Honesty-Sincerity & -- & & & & & & & & & & & & & & & & \\
\hline 2. Flattery & .00 & -- & & & & & & & & & & & & & & & \\
\hline 3. Group Persuasion & .04 & $.36^{*}$ & -- & & & & & & & & & & & & & & \\
\hline 4. Private Persuasion & -.09 & $.27 *$ & $.20^{*}$ & -- & & & & & & & & & & & & & \\
\hline $\begin{array}{l}\text { 5. Evidence of } \\
\text { Logic/Preparation }\end{array}$ & .08 & $.31 *$ & $.34 *$ & $.41^{*}$ & -- & & & & & & & & & & & & \\
\hline 6. Performance & .07 & $.29 *$ & $.37^{*}$ & $.28^{*}$ & $.51 *$ & -- & & & & & & & & & & & \\
\hline 7. Utilitarian Justice & .14 & .13 & $.44 *$ & .08 & $.18 *$ & .17 & -- & & & & & & & & & & \\
\hline Student Motives & & & & & & & & & & & & & & & & & \\
\hline 8. Relational & -.01 & .12 & .11 & .06 & $.18^{*}$ & .13 & .09 & -- & & & & & & & & & \\
\hline 9. Functional & -.04 & .06 & .09 & .17 & .07 & .08 & .14 & $.24^{*}$ & -- & & & & & & & & \\
\hline 10. Participatory & -.01 & .12 & .14 & .14 & .10 & .08 & .13 & $.43^{*}$ & $.39^{*}$ & -- & & & & & & & \\
\hline 11. Sycophancy & .05 & .11 & $.21 *$ & .02 & .12 & $.19^{*}$ & $.25^{*}$ & $.35^{*}$ & $.19^{*}$ & $.54 *$ & -- & & & & & & \\
\hline 12. Excuse-Making & .07 & .11 & .12 & .08 & .11 & $.22 *$ & .16 & $.15^{*}$ & $.40^{*}$ & $.39 *$ & $.33 *$ & -- & & & & & \\
\hline 13. WTT & .02 & .12 & .11 & .07 & .03 & .06 & .06 & $.32 *$ & $.24^{*}$ & $.46^{*}$ & $.20^{*}$ & $.25^{*}$ & -- & & & & \\
\hline 14. OCC & .03 & .00 & -.03 & .06 & -.00 & .05 & .10 & $.50^{*}$ & $.29^{*}$ & $.35^{*}$ & $.22 *$ & .09 & $.35^{*}$ & -- & & & \\
\hline Student Learning & & & & & & & & & & & & & & & & & \\
\hline $\begin{array}{l}\text { 15. Affective } \\
\text { Learning }\end{array}$ & .01 & .10 & .09 & .06 & .03 & .03 & .02 & $.20^{*}$ & $.29 *$ & $.29^{*}$ & .11 & .05 & $.19^{*}$ & $.31 *$ & $m$ & & \\
\hline $\begin{array}{l}\text { 16. Cognitive } \\
\text { Learning }\end{array}$ & .14 & .09 & .13 & .12 & .16 & .16 & .15 & $.36^{*}$ & $.35^{*}$ & $.37^{*}$ & $.29^{*}$ & .14 & $.23^{*}$ & $.38 *$ & $.50 *$ & -- & \\
\hline 17. State Motivation & .04 & .08 & .07 & .01 & .06 & -.00 & .07 & .16 & $.27^{*}$ & $.31^{*}$ & .14 & .07 & $.28^{*}$ & $.30^{*}$ & $.67^{*}$ & $.45^{*}$ & -- \\
\hline $\begin{array}{l}\text { 18. Communication } \\
\text { Satisfaction }\end{array}$ & .05 & .14 & .10 & .05 & .05 & .09 & .05 & $.22^{*}$ & $.31^{*}$ & .30 & $.18^{*}$ & .05 & $.23 *$ & $.38^{*}$ & $.76^{*}$ & $.44^{*}$ & $.55^{*}$ \\
\hline
\end{tabular}

Note. ${ }^{*} p<.001$. 
relational motive was related positively to the perceived effectiveness of evidence of preparation/logic $(r=.18)$ and the sycophancy motive was related positively to the perceived effectiveness of group persuasion $(r=.21)$, performance $(r=.19)$, and utilitarian justice $(r=$ .25). Hypothesis 1a was largely unsupported.

Hypothesis $1 \mathrm{~b}$ predicted that students' self-reports of their use of the relational, functional, participatory, and sycophancy motives to communicate with their instructors would be related negatively to their perceived effectiveness of antisocial BATs. It was found (see Table 9) that the relational, functional, participatory, and sycophancy motives were not significantly related to perceived effectiveness of student antisocial BATs. Hypothesis $1 \mathrm{~b}$ was not supported.

Hypothesis 2a predicted that students' self-reports of their use of the relational, functional, participatory, and sycophancy motives to communicate with their instructors would be related positively to their perceived likelihood to use prosocial BATs. It was found (see Table 10) that the relational motive was related positively to the perceived likelihood to use flattery ( $r$ $=.18)$ and evidence of logic/preparation $(r=.19)$. The functional motive was related positively to the perceived likelihood to use private persuasion $(r=.18)$. The participatory motive was related positively to the perceived likelihood to use flattery $(r=.19)$ and group persuasion $(r=$ .21). The sycophancy motive was related positively to the perceived likelihood to use flattery ( $r$ $=.21)$, group persuasion $(r=.20)$ and utilitarian justice $(r=.21)$. Hypothesis $2 \mathrm{a}$ was partially supported.

Hypothesis $2 b$ predicted that students' self-reports of their use of the relational, functional, participatory, and sycophancy motives to communicate with their instructors would be related negatively to their perceived likelihood to use antisocial BATs. It was found (see 
Table 11) that the sycophancy motive was related positively to the perceived likelihood to use complaining $(r=.25)$ and emotional displays $(r=.18)$. Hypothesis $2 \mathrm{~b}$ was not supported.

Hypothesis 3a predicted that students' self-reports of their use of the excuse-making motive to communicate with their instructors would be related positively to their perceived effectiveness of antisocial BATs. It was found (see Table 9) that the excuse-making motive was related positively to the perceived effectiveness of complaining $(r=.20)$, general excuses $(r=$ $.18)$, and reference to higher authority $(r=.21)$. Hypothesis 3 a was partially supported.

Hypothesis $3 b$ predicted that students' self-reports of their use of the excuse-making motive to communicate with their instructors would be related negatively to their perceived effectiveness of prosocial BATs. It was found (see Table 8) that the excuse-making motive was related positively to the perceived effectiveness of performance $(r=.22)$. Hypothesis $3 \mathrm{~b}$ was not supported.

Hypothesis 4a predicted that students' self-reports of their use of the excuse-making motive to communicate with their instructors would be related positively to their perceived likelihood to use antisocial BATs. It was found (see Table 11) that the excuse-making motive was related positively to the perceived likelihood to use blame $(r=.24)$, complaining $(r=.25)$, public persuasion $(r=.24)$, emotional displays $(r=.19)$, and reference to higher authority $(r=$ .23). Hypothesis 4a was generally supported.

Hypothesis $4 b$ predicted that students' self-reports of their use of the excuse-making motive to communicate with their instructors would be related negatively to their perceived likelihood to use prosocial BATs. It was found (see Table 10) that the excuse-making motive was related positively to the perceived likelihood to use flattery $(r=.23)$, group persuasion $(r=$ $.21)$, evidence of logic/preparation $(r=.21)$, performance $(r=.31)$, and utilitarian justice $(r=$ 
Table 9

Correlations among Effectiveness of Antisocial BATs, Student Motives to Communicate, WTT, OCC, and Student Learning

\begin{tabular}{|c|c|c|c|c|c|c|c|c|c|c|c|c|c|c|c|c|c|c|}
\hline & 1 & 2 & 3 & 4 & 5 & 6 & 7 & 8 & 9 & 10 & 11 & 12 & 13 & 14 & 15 & 16 & 17 & 18 \\
\hline \multicolumn{19}{|l|}{ Effectiveness } \\
\hline 1. Blame & -- & & & & & & & & & & & & & & & & & \\
\hline 2. Complaining & $.34^{*}$ & -- & & & & & & & & & & & & & & & & \\
\hline 4. Emotional & .04 & $.24^{*}$ & $.33^{*}$ & -- & & & & & & & & & & & & & & \\
\hline \multicolumn{19}{|l|}{ Displays } \\
\hline 5. General Excuses & .12 & $.22 *$ & $.20^{*}$ & $.41^{*}$ & -- & & & & & & & & & & & & & \\
\hline $\begin{array}{l}\text { 7. Reference to } \\
\text { Higher Authority }\end{array}$ & $.22 *$ & $.31 *$ & $.22 *$ & $.25^{*}$ & $.26^{*}$ & $.43^{*}$ & -- & & & & & & & & & & & \\
\hline 8. Verbal & $.23^{*}$ & $.29^{*}$ & $.22 *$ & .13 & .17 & $.37^{*}$ & $.52 *$ & -- & & & & & & & & & & \\
\hline Force/Demand & & & & & & & & & & & & & & & & & & \\
\hline \multicolumn{19}{|l|}{ Student Motives } \\
\hline 9. Relational & .07 & .11 & .12 & .14 & .01 & -.03 & -.01 & .01 & -- & & & & & & & & & \\
\hline 14. WTT & -.05 & .01 & .04 & .02 & -.01 & -.04 & -.02 & .01 & $.32 *$ & $.24 *$ & $.46^{*}$ & $.20^{*}$ & $.25^{*}$ & -- & & & & \\
\hline $15 . \mathrm{OCC}$ & -.09 & -.02 & .07 & .11 & -.02 & -.04 & -.03 & .02 & $.50^{*}$ & $.29^{*}$ & $.35^{*}$ & $.22 *$ & .09 & $.35 *$ & -- & & & \\
\hline \multicolumn{19}{|l|}{ Student Learning } \\
\hline $\begin{array}{l}\text { 16. Affective } \\
\text { Learning }\end{array}$ & .01 & -.03 & -.03 & .07 & .02 & -.07 & -.06 & -.07 & $.20 *$ & $.29^{*}$ & $.29^{*}$ & .11 & .05 & $.19^{*}$ & $.31 *$ & -- & & \\
\hline $\begin{array}{l}\text { 17. Cognitive } \\
\text { Learning }\end{array}$ & .02 & .09 & $.17^{*}$ & .13 & .05 & .07 & .03 & .06 & $.36^{*}$ & $.35^{*}$ & $.37^{*}$ & $.29 *$ & .14 & $.23 *$ & $.38^{*}$ & $.50^{*}$ & -- & \\
\hline 18. State Motivation & .04 & -.01 & .06 & .06 & -.02 & -.04 & -.06 & -.09 & .16 & $.27^{*}$ & $.31^{*}$ & .14 & .07 & $.28 *$ & $.30 *$ & $.67^{*}$ & $.45^{*}$ & -- \\
\hline 19. Communication & .03 & -.05 & .00 & .07 & .01 & -.06 & -.05 & -.05 & $.22^{*}$ & $.31^{*}$ & .30 & $.18^{*}$ & .05 & $.23^{*}$ & $.38 *$ & $.76^{*}$ & $.44^{*}$ & $.55^{*}$ \\
\hline
\end{tabular}

\section{Satisfaction}

Note. ${ }^{*} p<.001$. 
Table 10

Correlations among Likelihood of Using Prosocial BATs, Student Motives to Communicate, WTT, OCC, and Student Learning

\begin{tabular}{|c|c|c|c|c|c|c|c|c|c|c|c|c|c|c|c|c|c|}
\hline & 1 & 2 & 3 & 4 & 5 & 6 & 7 & 8 & 9 & 10 & 11 & 12 & 13 & 14 & 15 & 16 & 17 \\
\hline \multicolumn{18}{|l|}{ Likelihood of Using } \\
\hline 1. Honesty-Sincerity & -- & & & & & & & & & & & & & & & & \\
\hline 2. Flattery & .04 & -- & & & & & & & & & & & & & & & \\
\hline 3. Group Persuasion & $.19^{*}$ & $.41^{*}$ & -- & & & & & & & & & & & & & & \\
\hline 4. Private Persuasion & .16 & $.22^{*}$ & .13 & -- & & & & & & & & & & & & & \\
\hline 5. Evidence of & .16 & $.42 *$ & $.30 *$ & $.48^{*}$ & -- & & & & & & & & & & & & \\
\hline \multicolumn{18}{|l|}{ Logic/Preparation } \\
\hline 6. Performance & .17 & $.34^{*}$ & $.34 *$ & $.35^{*}$ & $.55^{*}$ & -- & & & & & & & & & & & \\
\hline 7. Utilitarian Justice & $.17^{*}$ & $.26^{*}$ & $.47^{*}$ & .06 & $.22^{*}$ & $.24^{*}$ & -- & & & & & & & & & & \\
\hline \multicolumn{18}{|l|}{ Student Motives } \\
\hline 8. Relational & .02 & .18 & .12 & .11 & $.19^{*}$ & .07 & .14 & -- & & & & & & & & & \\
\hline 9. Functional & -.02 & .13 & .17 & $.18^{*}$ & .14 & .09 & .11 & $.24^{*}$ & -- & & & & & & & & \\
\hline 10. Participatory & .05 & $.19 *$ & $.21^{*}$ & .15 & .16 & .09 & .11 & $.43^{*}$ & $.39^{*}$ & -- & & & & & & & \\
\hline 11. Sycophancy & .08 & $.21 *$ & $.20^{*}$ & .03 & .10 & .17 & $.21^{*}$ & $.35^{*}$ & $.19^{*}$ & $.54^{*}$ & -- & & & & & & \\
\hline 12. Excuse-Making & .11 & $.23^{*}$ & $.21^{*}$ & .13 & $.21^{*}$ & $.31^{*}$ & $.23^{*}$ & $.15^{*}$ & $.40^{*}$ & $.39 *$ & $.31^{*}$ & -- & & & & & \\
\hline 13. WTT & .06 & $.23^{*}$ & .16 & .03 & .03 & .06 & .08 & $.32 *$ & $.24 *$ & $.46^{*}$ & $.20^{*}$ & $.25^{*}$ & -- & & & & \\
\hline 14. OCC & .03 & .15 & .11 & .11 & .03 & .07 & .12 & $.50^{*}$ & $.29 *$ & $.35^{*}$ & $.22^{*}$ & .09 & $.35^{*}$ & -- & & & \\
\hline \multicolumn{18}{|l|}{ Student Learning } \\
\hline $\begin{array}{l}\text { 15. Affective } \\
\text { Learning }\end{array}$ & .03 & .05 & .03 & -.01 & .02 & -.06 & -.01 & $.20^{*}$ & $.29^{*}$ & $.29 *$ & .11 & .05 & $.19^{*}$ & $.31^{*}$ & -- & & \\
\hline $\begin{array}{l}\text { 16. Cognitive } \\
\text { Learning }\end{array}$ & .14 & $.18^{*}$ & $.20^{*}$ & .12 & .13 & .12 & .08 & $.36^{*}$ & $.35^{*}$ & $.37^{*}$ & $.29 *$ & .14 & $.23 *$ & $.36^{*}$ & $.50^{*}$ & - & \\
\hline 17. State Motivation & .03 & .10 & .04 & .00 & -.01 & -.07 & .06 & .16 & $.27^{*}$ & $.31^{*}$ & .14 & .07 & $.28 *$ & $.30 *$ & $.67^{*}$ & $.45^{*}$ & -- \\
\hline $\begin{array}{l}\text { 18. Communication } \\
\text { Satisfaction }\end{array}$ & .08 & .15 & .10 & .05 & .01 & -.01 & .03 & $.22^{*}$ & $.31^{*}$ & $.30^{*}$ & $.18^{*}$ & .05 & $.23 *$ & $.38 *$ & $.76^{*}$ & $.44^{*}$ & $.55^{*}$ \\
\hline
\end{tabular}

Note. ${ }^{*} p<.001$ 
Table 11

Correlations among Likelihood of Using Antisocial BATs, Student Motives to Communicate, WTT, OCC, and Student Learning

\begin{tabular}{|c|c|c|c|c|c|c|c|c|c|c|c|c|c|c|c|c|c|c|}
\hline & 1 & 2 & 3 & 4 & 5 & 6 & 7 & 8 & 9 & 10 & 11 & 12 & 13 & 14 & 15 & 16 & 17 & 18 \\
\hline \multicolumn{19}{|l|}{$\begin{array}{l}\text { Likelihood of } \\
\text { Using }\end{array}$} \\
\hline 1. Blame & -- & & & & & & & & & & & & & & & & & \\
\hline 3. Public Persuasion & $.26^{*}$ & $.36^{*}$ & -- & & & & & & & & & & & & & & & \\
\hline $\begin{array}{l}\text { 4. Emotional } \\
\text { Displays }\end{array}$ & $.18^{*}$ & $.22 *$ & $.30^{*}$ & -- & & & & & & & & & & & & & & \\
\hline $\begin{array}{l}\text { 7. Reference to } \\
\text { Higher Authority }\end{array}$ & $.34^{*}$ & $.35^{*}$ & $.37^{*}$ & $.20^{*}$ & $.29 *$ & $.45^{*}$ & - & & & & & & & & & & & \\
\hline $\begin{array}{l}\text { 8. Verbal } \\
\text { Force/Demand }\end{array}$ & $.30^{*}$ & $.31 *$ & $.34^{*}$ & $.26^{*}$ & $.21^{*}$ & $.39^{*}$ & $.60^{*}$ & -- & & & & & & & & & & \\
\hline Student Motives & & & & & & & & & & & & & & & & & & \\
\hline 13. Excuse-Making & $.24^{*}$ & $.25^{*}$ & $.24^{*}$ & $.19^{*}$ & $.23^{*}$ & .14 & $.23 *$ & .17 & .15 & $.40^{*}$ & $.39 *$ & $.31 *$ & -- & & & & & \\
\hline 14. WTT & -.02 & .05 & -.01 & -.09 & -.06 & -.05 & .02 & .02 & $.32 *$ & $.24^{*}$ & $.46^{*}$ & $.20^{*}$ & $.25^{*}$ & -- & & & & \\
\hline $15 . \mathrm{OCC}$ & -.10 & .07 & .11 & -.01 & -.09 & -.01 & .07 & .12 & $.50^{*}$ & $.29^{*}$ & $.35^{*}$ & $.22 *$ & .09 & $.35^{*}$ & -- & & & \\
\hline Student Learning & & & & & & & & & & & & & & & & & & \\
\hline $\begin{array}{l}\text { 16. Affective } \\
\text { Learning }\end{array}$ & -.07 & -.13 & -.08 & -.07 & -.11 & -.08 & -.12 & -.12 & $.20^{*}$ & $.29 *$ & $.29 *$ & .11 & .05 & $.19^{*}$ & $.31^{*}$ & -- & & \\
\hline $\begin{array}{l}\text { 17. Cognitive } \\
\text { Learning }\end{array}$ & -.01 & .08 & .13 & .05 & -.01 & .07 & .06 & .09 & $.36^{*}$ & $.35^{*}$ & $.37^{*}$ & $.29^{*}$ & .14 & $.23^{*}$ & $.38^{*}$ & $.50^{*}$ & -- & \\
\hline 18. State Motivation & -.06 & -.05 & -.06 & -.09 & -.09 & -.09 & -.08 & -.09 & $.16^{*}$ & $.27 *$ & $.31 *$ & .14 & .07 & $.28^{*}$ & $.30^{*}$ & $.67^{*}$ & $.45^{*}$ & -- \\
\hline $\begin{array}{l}\text { 19. Communication } \\
\text { Satisfaction }\end{array}$ & -.02 & -.08 & -.02 & .01 & -.04 & -.06 & -.10 & -.06 & $.22 *$ & $.31 *$ & .30 & $.18^{*}$ & .05 & $.23^{*}$ & $.38^{*}$ & $.76^{*}$ & $.44^{*}$ & $.55 *$ \\
\hline
\end{tabular}

Note ${ }^{*} p<.001$. 
$.23)$. Hypothesis $4 \mathrm{~b}$ was not supported.

\section{Research Questions 1-2}

The two research questions examined the relationship between WTT, OCC, and the perceived effectiveness of, and likelihood to use, student BATs. Research question 1a inquired about the extent to which students' self-reports of their WTT and their OCC were related to their perceived effectiveness of prosocial BATs. It was found (see Table 8) that WTT and OCC were not significantly related to students' perceived effectiveness of prosocial BATs. Research question $1 \mathrm{~b}$ inquired about the extent to which students' self-reports of their WTT and their OCC were related to students' perceived effectiveness of antisocial BATs. It was found (see Table 9) that WTT and OCC were not significantly related to students' perceived effectiveness of antisocial BATs.

Research question 2a inquired about the extent to which students' self-reports of their WTT and their OCC were related to their perceived likelihood to use prosocial BATs. It was found (see Table 10) that WTT was related positively to the perceived likelihood to use flattery $(r=.23)$, but OCC was not related to students' perceived likelihood to use prosocial BATs. Research question $2 b$ inquired about the extent to which students' self-reports of their WTT and their OCC were related to their perceived likelihood to use antisocial BATs. It was found (see Table 11) that WTT and OCC were not significantly related to students' perceived likelihood to use antisocial BATs.

\section{Hypotheses 5-6}

The last two hypotheses examined the relationship among cognitive learning, affective learning, state motivation, and student communication satisfaction and the perceived effectiveness of, and likelihood to use student BATs. Hypothesis 5a predicted that students' self- 
reports of their cognitive learning, affective learning, state motivation, and student communication satisfaction would be related positively to their perceived effectiveness of prosocial BATs. It was found (see Table 8 ) that cognitive learning, affective learning, state motivation, and student communication satisfaction were not significantly related to students' perceived effectiveness of prosocial BATs. Hypothesis $5 \mathrm{a}$ was not supported.

Hypothesis $5 \mathrm{~b}$ predicted that students' self-reports of their cognitive learning, affective learning, state motivation, and student communication satisfaction would be related negatively to their perceived effectiveness of antisocial BATs. It was found (see Table 9) that cognitive learning was related positively to the perceived effectiveness of public persuasion $(r=.17)$. Affective learning, state motivation, and student communication satisfaction were not significantly related to perceived effectiveness of antisocial BATs. Hypothesis $5 \mathrm{~b}$ was not supported.

Hypothesis 6a predicted that students' self-reports of their cognitive learning, affective learning, state motivation, and student communication satisfaction would be related positively to their perceived likelihood to use prosocial BATs. It was found (see Table 10) that cognitive learning was positively related to the perceived likelihood to use flattery $(r=.18)$ and group persuasion $(r=.20)$. Affective learning, state motivation, and student communication satisfaction were not significantly related to perceived likelihood to use prosocial BATs. Hypothesis 6a was not supported.

Hypothesis $6 \mathrm{~b}$ predicted that students' self-reports of their cognitive learning, affective learning, state motivation, and student communication satisfaction would be related negatively to their perceived likelihood to use antisocial BATs. It was found (see Table 11) that cognitive 
learning, affective learning, state motivation, and student communication satisfaction were not significantly related to perceived likelihood to use antisocial BATs. Hypothesis $6 \mathrm{~b}$ was not supported.

\section{Summary}

This chapter reported the findings of this dissertation. Preliminary findings indicated that student perceptions of the effectiveness of each BAT were related positively to their likelihood of communicating each BAT. Overwhelmingly, the results revealed that student perceived effectiveness of, and likelihood to use, student prosocial and antisocial BATs did not influence the outcome variables, with the exception of the student motives to communicate with their instructor. Specifically, the relational, functional, participatory, and sycophancy motives were generally related to the perceived likelihood to use some prosocial BATs. The relational, functional, and participatory motives were not significantly related to the perceived effectiveness of, or likelihood to use, any of the antisocial BATs; however, the sycophancy motive was related positively to the perceived likelihood to use one antisocial BAT. The excuse-making motive was generally related to the perceived effectiveness of, and likelihood to use, antisocial BATs, but was not related negatively, as hypothesized, to the perceived effectiveness of, and likelihood to use, prosocial BATs. 


\section{CHAPTER IV}

\section{Discussion}

This dissertation aimed to extend the existing student BATs literature by examining the effects of students' perceived effectiveness of, and likelihood to use, prosocial and antisocial student BATs on both student initiated communicative behaviors with their instructors (i.e., students' motives to communicate with their instructors, WTT, OCC) and their self-reported gains in student learning (i.e., cognitive learning, affective learning, state motivation, student communication satisfaction). More specifically, it was expected that the relational, functional, participatory, and sycophancy motives would be related positively to students' perceived effectiveness of, and likelihood to use, prosocial BATs $(\mathrm{H} 1 \mathrm{a}, \mathrm{H} 2 \mathrm{a})$ and related negatively to students' perceived effectiveness of, and likelihood to use, antisocial BATs (H1b, H2b). Hypothesis $2 \mathrm{a}$ was partially supported, whereas hypotheses $1 \mathrm{a}, 2 \mathrm{a}$, and $1 \mathrm{~b}$ were not supported. Furthermore, it was expected that the excuse-making motive would be related positively to students' perceived effectiveness of, and likelihood to use, antisocial BATs (H3a, H3b) and related negatively to students' perceived effectiveness of, and likelihood to use, prosocial BATs ( $\mathrm{H} 4 \mathrm{a}, \mathrm{H} 4 \mathrm{~b})$. Hypothesis $3 \mathrm{a}$ and $4 \mathrm{a}$ were generally supported, whereas hypotheses $3 \mathrm{~b}$ and $4 \mathrm{~b}$ were not supported.

Additionally, it was proposed that a potential relationship would exist between students' self-reports of their WTT and OCC with their perceptions of the effectiveness of, and the likelihood to use, student BATs (RQ 1-2). No significant relationships were obtained for the two research questions. Finally, it was hypothesized that students' perceived effectiveness of, and likelihood to use, prosocial BATs would be related positively to gains in their learning, whereas students' perceived effectiveness of, and likelihood to use, antisocial BATs would be related 
negatively to their learning (H5-H6). Hypotheses 5-6 were not supported. Collectively, the results of this dissertation revealed three prominent issues in regard to the examination of student prosocial and antisocial BATs.

First, the situational demands of the classroom (e.g., instructor communicative behaviors, outcomes of the classroom assignment), more than students' motives to communicate or willingness to engage in student talk, may affect their students' perceived effectiveness of, and likelihood to use, student BATs. Although several correlations were obtained among the students' motives to communicate with their instructors and the prosocial and antisocial BATs, the relative strength of these relationships suggests these motives are not highly influential on students' perceived effectiveness of, or likelihood to use prosocial and antisocial BATs. Aside from the motives, another way students initiate communication with their instructors is through student talk (i.e., WTT, OCC). However, the lack of relationships obtained between students' perceived effectiveness of, and likelihood to use, prosocial and antisocial BATs and student talk suggests that a students' general orientation toward communicating in-class or out-side-of class does not influence whether students enact prosocial or antisocial BATs.

Despite the small correlations obtained, the relationships found between students' motives to communicate with their instructors and the perceived effectiveness of, and likelihood to use, students prosocial and antisocial BATs should not be overlooked. With regard to the prosocial BATs, it was found that the excuse-making motive, and, to a lesser extent, the relational, functional, participatory, and sycophancy motives were positively correlated to the perceived effectiveness, and likelihood to use, several prosocial BATs. Students motivated to communicate with their instructor for the excuse-making motive use prosocial BATs that attempt to flatter an instructor, contain logical reasoning, provide proof of effort, or demonstrate respect 
for the instructor to increase the potential for compliance. Students motivated to communicate with their instructor for the relational motive appear to be more inclined to use BATs that contain logical reasoning, demonstrate respect for the instructor, or attempt to flatter an instructor to increase the potential for compliance. Students motivated to communicate with their instructor for the functional motive used only one prosocial BAT (i.e., private persuasion), which demonstrated acquiring information regarding a particular assignment or course concept privately. Students motivated to communicate with their instructors for the participatory motive appear to use prosocial BATs that attempt to flatter the instructor or demonstrate student consensus by enacting the group persuasion approach, in which students join forces in the hopes that a collective response will influence instructors to acquiesce their request. Students motivated to communicate with their instructor for the sycophancy motive appear to be more inclined to use prosocial BATs that are non-threatening, attempt to flatter, demonstrate that more than one student would benefit from the request, contain evidence of effort, or demonstrate respect for an instructor to increase the potential for compliance.

The prosocial BATs used by the students in this dissertation (i.e., flattery, evidence of logic/preparation, private persuasion, group persuasion, utilitarian justice, and performance) do not place blame on the instructor, but rather attempt to provide justified reasons for why an assignment date should be changed or rationalize why an instructor should award additional points for a previously graded assignment. For example, because students who are liked by their instructors have a better chance of gaining compliance (Sidelinger et al., 2012), one possible explanation for the use of the flattery BAT may be due to the fact that students want to compliment their instructors to increase liking of the student prior to making a request to increase their chances of gaining compliance. Because the social ties between the requester and 
a target is a significant predictor of the likelihood of compliance, students who communicate for the sycophancy motive may perceive themselves as being favored by their instructor and believe they can "get away with" using the utilitarian justice BAT to justify why the entire class should receive an extension or delay the date for an examination.

Therefore, students who approach their instructors to make a request are cognizant that the prosocial nature of the BATs may lend to them gaining compliance from their instructors in an appropriate and nonthreatening way. Furthermore, since students favored by their instructors have the best chance to gain compliance (Sidelinger, Bolen, Frisby, \& McMullen, 2012), students would be wise to develop a positive relationship with their instructor prior to making a request. Moreover, when individuals are perceived as more competent and are perceived to have higher task attraction when using a prosocial compliance technique compared to an antisocial compliance technique and are subsequently more likely to gain compliance (Johnson, 1992). As a result, the perceived effectiveness of, and likelihood to use, prosocial BATs align with the relational, functional, participatory, and sycophancy motives, which may help students to demonstrate that they are capable, competent, and willing to put forth effort in the course to increase instructors' willingness to comply.

With regard to the antisocial BATs, it was found that the excuse-making motive was correlated positively to the perceived effectiveness, and likelihood to use, several antisocial BATs, whereas the relational, functional, and participatory were not related to either the perceived effectiveness of, and the likelihood to use, antisocial BATs. An unanticipated finding was that the sycophancy motive was related positively to the perceived likelihood to use two antisocial BAT (i.e., complaining, emotional displays. When viewed from an instructional dissent angle (Goodboy, 2011a, 2011b; Goodboy \& Myers, 2012), perhaps students perceive the 
complaining BAT as rhetorical dissent (i.e., complaining directly to the instructor), which would result in change to a perceived wrongdoing and thereby considered more prosocial in nature. Because these sycophantic students attempt to get on the instructors' good side, these same students may perceive the emotional displays BATs as a way to manipulate their instructor into complying with their request because the instructor feels sorry for them due to the tears or sad looks.

With regard to the other motives to communicate, there are two possible explanations for why a significant relationship was not found among the relational, functional, participatory, and sycophancy (with the exception of likelihood to use the complain and emotional displays BATs) motives and the perceived effectiveness of, and likelihood to use, antisocial BATs. First, students communicating for these motives may perceive the antisocial BATs as face threatening to their instructor and therefore would not perceive them as particularly effective. Second, students may perceive a lack of power in the instructor-student relationship, which makes them hesitant to use antisocial compliance-gaining strategies with their instructors (Golish, 1999, Golish \& Olson, 2000).

Students who are motivated to communicate with their instructors for the excuse-making motive use antisocial BATs that place the instructor at fault, bring attention to instructor ambiguity, make the instructor uncomfortable, attempt to elicit pity by showing emotions, or demonstrate a lack of respect for the instructor via threats to increase the potential for compliance. The antisocial BATs used by students in this dissertation (i.e., blame, complaining, public persuasion, emotional displays, and reference to higher authority) place blame on the instructor, and attempt to coerce or threaten the instructor, rather than justify why an assignment or grade should be modified. Therefore, students who approach their instructors to make a 
request may be aware that antisocial BATs are damaging to the instructor-student relationship, but use these antisocial BATs anyway as a way to gain compliance. Using the aforementioned antisocial BATs along with the excuse-making motive to communicate appear to be a way that students attempt to satisfy their rhetorical needs. Despite the perceived effectiveness of, and likelihood to use, antisocial BATs, students would not be wise to use such BATs when attempting to gain compliance from their instructor due to the potential harmful affects to the instructor-student relationship. However, why certain students are more likely to enact antisocial BATs to gain compliance remains unclear.

Collectively, these results reveal that students who are motivated to communicate with their instructors for the excuse-making reason are more opportunistic, willing to utilize both antisocial and prosocial BATs to support their excuses. Further, the excuse-making motives were more positively related to the student BATs than any of the other student motives to communicate. Because students who are motivated to communicate with their instructors for the excuse-making motive desire to rationalize their poor academic performance and try to convince their instructors to give them another chance to complete an assignment (Martin et al., 2002), this suggests that there is an underlying reason why these students need to communicate with their instructors to explain themselves. That said, it appears that students' perceptions of their everyday communicative behavior with their instructor does not influence BATs, but rather the BATs may be more largely dependent upon the situational characteristics of the classroom and the surrounding event, rather than their own general in class and out of class communicative behaviors. Given the relationship between the excuse-making motive and the prosocial and student BATs, it appears that these student initiated behaviors are most frequently used in response to a particular occurrence in the classroom. This suggests that the reason for making 
the excuse or requiring something may be a stronger predictor for student BATs use.

Second, students' perceived effectiveness of, and the likelihood to use prosocial and antisocial student BATs are not related to gains in their learning. No significant relationships were obtained between the perceived effectiveness of, and likelihood to use, student prosocial and antisocial BATs and affective learning, state motivation, and student communication satisfaction. Student cognitive learning, however, was positively correlated with the perceived effectiveness of one antisocial BAT (i.e., public persuasion; $\mathrm{H} 5 \mathrm{~b}$ ) and the likelihood to use two prosocial BATs (i.e., group persuasion, flattery; H6a). One speculative reason for the low correlations obtained between cognitive learning and public persuasion, group persuasion, and flattery may be due to the fact that students merely perceive joining forces and flattering their instructor as ways to increase instructor compliance. Despite the perceived effectiveness of public persuasion (i.e., purposefully making a request to the instructor in front of the class to make it more difficult for their to rebuff), students indicated using the prosocial group persuasion BAT to demonstrate to instructors that the request reflects the desires of the entire class and the flattery BAT to affirm their instructor in the hopes that increase positive affect would yield compliance.

Because the student BATs generally did not influence student learning (either positively or negatively), this finding may provide initial support for Golish's (1999) claim that student BATs may be more self-directed than learning-directed. Although Goodboy et al. (2011) suggested that student BATs are one way that students can achieve their academic and relational needs, students simply may not perceive student BATs as a communicative behavior they should use to fulfill those needs. For instance, Golish and Olson (2000) suggested that students' use of BATs may be damaging to their learning, but the results obtained in this dissertation did not 
support this, as no relationship was found between the perceptions of student BATs and student learning.

Because students who favor their instructors, and indicate being satisfied with their instructors, use fewer student BATs in general (Claus, Booth-Butterfield, et al., 2012; Goodboy, et al., 2011), one possible explanation for the lack of student BAT use in relation to student learning may be that students perceive their instructors engaging in effective teaching behaviors that allow them to fulfill their rhetorical and relational goals, and subsequently their goals. Therefore, at the time of survey completion, students may not have perceived the student BATs as effective nor were likely to use them (i.e., evidenced by the low means for both effectiveness of, and likelihood to use, all of the BATs) to fulfill their student learning needs. Although both students and instructors actively engage and influence each other to achieve their classroom needs, the lack of significant results indicates that students' BATs use may be explained more by their perceptions of their instructors' communicative behaviors and traits. While there are certain student traits and communicative behaviors that have been found to increase gains in student learning such as, student-student connectedness (Prisbell, Dwyer, Carlson, Bingham, \& Cruz, 2009), note taking (Titsworth, 2001), and state motivation (Zhang \& Huang, 2008); students' perceived effectiveness of, or likelihood to use, student BATs use is not one of them.

Third, it appears that students use BATs infrequently. Why students' perceived effectiveness of, and likelihood to use, student BATs were not related to many of the outcome variables may be due to the fact that the student BATs were not used frequently. Students reported that only five of the seven prosocial BATs had a mean greater than 2.0 for perceived effectiveness (i.e., private persuasion, evidence of logic/preparation, flattery, group persuasion, performance) and of those five, only three had a mean greater than 2.0 for perceived likelihood 
to use (i.e., private persuasion, evidence of preparation/logic, and performance). For the antisocial BATs, only one BAT (i.e., general excuses) had a mean greater than 2.0 for perceived effectiveness, whereas none of antisocial BATs had a mean of 2.0 or greater than two for perceived likelihood to use. Consistent with previous research on student BATs (Golish, 1999; Golish \& Olson, 2000) these findings are not too surprising as students consistently report prosocial BATs as more effective and more likely to use them with their instructor than any of the antisocial BATs; yet overall it appears that students are not using the BATs frequently with their instructors. Despite collecting during the $11^{\text {th }}$ and $12^{\text {th }}$ week of the 15 -week semester, a possible explanation for these infrequent reports could be due to the fact that the students did not perceive a use for them at that point during the semester. Perhaps students either did not have an assignment grade to dispute or did not perceive an assignment as worthwhile enough to engage in a BAT.

An interesting finding of this dissertation came from the comparison of the mean averages among the likelihood to use both prosocial and antisocial BATs. Within the prosocial BATs, honesty-sincerity yielded the lowest mean average, indicating that students would prefer to persuade their instructor privately, provide evidence of preparation, use flattery, engage in group persuasion, provide examples of their previous performance in the course, and persuade them based on appeals to fairness before even considering being honest with their instructor. This brings into question the authenticity of students' use of the student BATs. Although the purpose of the dissertation aimed to assess the perceived effectiveness of, and likelihood to use, student BATs, future research should assess whether students were using the BATs truthfully as opposed to fabricating stories or emotions as a way to increase their instructors' willingness to comply. 


\section{Limitations and Directions for Future Research}

Although these findings failed to elucidate the relationships among student BATs, student motives to communicate, student talk, and student learning, they must be tempered by three limitations. The first limitation involves students not able to perceive differences between the BATs types (i.e., prosocial, neutral, antisocial) as evidenced by the problematic factor loadings obtained when using the Student Behavior Alteration Techniques and Messages Typology (Golish, 1999). Recall, that only four prosocial BATs, three antisocial BATs for perceived effectiveness and three prosocial, two antisocial BATs for perceived likelihood to use loaded on their own factors. It may just be that students perceive the BATs as several ways to gain compliance, but do not view them as either prosocial or antisocial. As such, it may be beneficial to treat the BATs singly rather than place them in these three conceptual clusters in future research. Moreover, recall that the student BATs typology was inductively derived from students responding to three hypothetical situations that involved gaining compliance from a graduate teaching assistant (Golish, 1999). Thus, these strategies may not be techniques or messages students would use with full-time faculty. Utilizing a focus group approach, or openended questions, would capture students' actual accounts of student BATs use with both graduate teaching assistants and full-time faculty members. Additionally, from these qualitative responses, researchers could also gain an understanding of why students use particular BATs is an important consideration as perhaps the BATs students used with graduate teaching assistants differ from the BATS students use with full-time faculty members. Finally, while extending and updating the typology, efforts should be made to develop the typology into a valid and reliable scale.

The second limitation involves the atheotretical nature of this dissertation. A theoretical 
framework perhaps would have helped to explain why students prefer to use particular BATs in the way that they do. For example, continued exploration of the student BATs construct utilizing the relational power and instructional influence theory (e.g., Kennedy-Lightsey \& Myers, 2009) may help to explain why students would not use particular BATs with certain instructors. Overall, this theory explains how students' perceived instructors' use of verbal and nonverbal messages influences students' perceptions of the instructor-student relational power, which subsequently alters students' willingness to comply with instructors' requests (Mottet, Frymier, $\&$ Beebe, 2006). Specifically, the theory posits, however, that both instructors and students engage in mutual influence attempts, such that prosocial attempts increases long-term compliance, whereas antisocial attempts only seem to influence short-term compliance. Examining this theory from a student perspective, may help to elucidate which of the BATs singly lead to greater quality relationships with specific instructors.

Future research may also benefit from utilizing the dump-and-chase model in an attempt to examine students' use of multiple BATs. Specifically, in an attempt to avoid negative appraisals/outcomes from using BATs, a student could enact the dump-and-chase model (cf., Boster, Shaw, Hughes, Kotowski, Strom, \& Deatrick, 2009) in which the student would attempt to turn an instructors' initial rebuff (i.e., blunt, unelaborated refusal) into an obstacle (i.e., refusal with reason for not complying) in the hopes that he/she will be able to overcome the obstacle with another student BAT. If a student request is successful and the instructor complies, then there is no utility in a student making additional requests (i.e., using BATs). However, the instructor may refuse to comply by using several strategies (cf, Claus, LaBelle, Odenweller, \& Brann, 2011). To date, research suggests little about how instructor resistance to students' requests influences students' actual BATs use. It has been speculated that students primarily 
prefer to use prosocial BATs with their instructors, but if their instructor denies their request, students may decide to use antisocial BATs to gain compliance (Golish, 1999; Golish \& Olson, 2000). Future research should examine students' actual responses to non-compliant instructors to determine if instructor resistance influences students' BAT selection.

The third limitation is that the student BATs may be driven more by situational characteristics rater than students' initiated communicative behavior with instructors. For example, future research should determine if the weight of the assignment in terms of overall point value is a possible predictor of engaging in student BATs. To date, research examining student BATs has been collected during the semester (toward the end of the semester), but it may be beneficial for future research to collect at the end of the semester (i.e., after final grades have been posted) as some students may not realize the consequences of their actions in the classroom until final grades are posted and in response enact particular student BATs.

\section{Conclusion}

Specifically, the purpose of this dissertation was to examine the relationship between student communication (i.e., motives to communication with their instructors, WTT, and OCC) and students' perceived effectiveness of, and likelihood to use, student BATs and explored the effects these BATs may have on student learning (i.e., cognitive learning, affective learning, state motivation, and communication satisfaction). Generally, students' perceived effectiveness of, and likelihood to use student BATs were not significantly related to the outcomes variables, except for a few small correlations among the student motives to communicate with their instructors. In general, students' perceived effectiveness of, and likelihood to use, some BATs were related positively to the excuse-making motive to communicate with their instructors, and, to a lesser extent, the relational, functional, participatory, and sycophancy motives. In contrast, 
students' perceived effectiveness of, and likelihood to use, student BATs were generally not related to their perceptions of WTT, OCC, affective learning, cognitive learning, student state motivation, and student communication satisfaction. The lack of significant relationships may be due to the fact that students' perceived effectiveness of, and likelihood to use the BATs, are not closely associated with other student initiated communicative behaviors, but perhaps related directly to the students' own personality traits or the immediate situational factors of the classroom and instructor. Furthermore, this potential lack of perceived utility of the BATs might explain the lack of relationships with student talk and student learning, as students may use other communicative behaviors (i.e., WTT, OCC), instead of student BATs, to achieve their learning needs. As such, researchers should continue to examine what factors, either student-owned or instructor-owned that ultimately predict students to either use or refrain from enacting student BATs. 


\section{References}

Ames, R. (1986). Effective motivation: The contribution of the learning environment. In R. S. Feldman (Ed.), The social psychology of education: Current research and theory (pp.235-256). Cambridge, UK: Cambridge University Press.

Andersen, J. F. (1979). Teacher immediacy as a predictor of teaching effectiveness. In D. Nimmo (Ed.), Communication yearbook 3 (pp. 543-559). New Brunswick, NJ: Transaction Books.

Anderson, L. W., \& Krathwohl, D. R. (Eds.). (2001). A taxonomy for learning, teaching, and assessing: A revision of Bloom's taxonomy of educational objectives. New York, NY: Longman.

Aylor, B., \& Oppliger, P. (2003). Out-of-class communication and student perceptions of instructor humor orientation and socio-communicative style. Communication Education, 52, 122-134. doi: $10.1080 / 0363452032000085090$

Barraclough, R. A., Christophel, D. M., \& McCroskey, J. C. (1988). Willingness to communicate: A cross-cultural investigation. Communication Research Reports, 5, 187192. doi:10.1080/08824098809359822

Bippus, A. M., Kearney, P., Plax, T. G., \& Brooks, C. F. (2003). Teacher access and mentoring abilities: Predicting the outcome value of extra class communication. Journal of Applied Communication Research, 31, 260-275. doi:10.1080/00909880305379

Bloom, B. S. (1956). A taxonomy of educational objectives. New York, NY: Longman.

Bloom, B. S., Hastings, J. T., \& Madaus, G. F. (1971). Handbook on formative and summative evaluation of student learning. New York, NY: McGraw-Hill.

Brophy, J. (1987). Synthesis of research on strategies for motivating students to learn. 
Educational Leadership, 18, 40-48.

Brophy, J. (2004). Motivating students to learn $\left(2^{\text {nd }}\right.$ ed.). Mahwah, NJ: Earlbaum.

Burchfield, C. M., \& Sappington, J. (1999). Participation in classroom discussion. Teaching of Psychology, 26, 290-291.

Burroughs, N. F. (2007). A reinvestigation of the relationship of teacher nonverbal immediacy and student compliance-resistance with learning. Communication Education, 56, 453475. doi:10.1080/03634520701530896

Burroughs, N. F., Kearney, P., \& Plax, T. G. (1989). Compliance resistance in the college classroom. Communication Education, 38, 214-229. doi:10.1080/03634528909378758

Carrell, L. J., \& Menzel, K. E. (1997). The impact of preparation and motivation on learning performance. Communication Education, 46, 262-272. doi:10.1080/03634529709379100

Carrell, L. J., \& Menzel, K. M. (1998, November). Gender, cognitive style, anxiety, academic ability, and professor behavior as predictors of a student's willingness to talk in class. Paper presented at the annual meeting of the National Communication Association, Chicago, IL.

Cayanus, J. L., Martin, M. M., \& Goodboy, A. K. (2009). Teacher self-disclosure and student motives to communicate. Communication Research Reports, 26, 105-113. doi:10.1080/08824090902861523

Chan, B., \& McCroskey, J. C. (1987). The WTC scale as a predictor of classroom participation. Communication Research Reports, 4, 47-50.

Chory-Assad, R. M., \& Paulsel, M. L. (2004). Antisocial classroom communication: Instructor influence and interactional justice as predictors of student aggression. Communication Quarterly, 52, 98-114. doi:10.1080/0363452042000265189 
Christensen, L. J., Curley, K. E., Marquez, E. M., \& Mensel, K. E. (1995, November). Classroom situations which lead to student participation. Paper present at the Speech Communication Association, San Antonio, TX.

Christophel, D. M. (1990). The relationships among instructor immediacy behaviors, student motivation, and learning. Communication Education, 39, 323-340. doi: doi: $10.1080 / 03634529009378813$

Claus, C. J., Booth-Butterfield, M., \& Chory, R. M. (2012). The relationship between instructor misbehaviors and student antisocial behavioral alteration techniques: The roles of instructor attractiveness, humor, and relational closeness. Communication Education, 61, 161-183. doi:10.1080/03634523.2011.647922

Claus, C. J., Chory, R. M., \& Malachowski, C. C. (2011, April). The relationship between instructor aggressive communication traits and student antisocial behavioral alteration techniques. Paper presented at the annual meeting of the Eastern Communication Association, Alexandria, VA.

Claus, C. J., Chory, R. M., \& Malachowski, C. C. (2012). Student antisocial compliance-gaining as a function of instructor aggressive communication and classroom justice. Communication Education, 61, 17-43. doi:10.1080/03634523.2011.619270

Claus, C. J., LaBelle, S. B., Odenweller, K. O., \& Brann, M. (2012, April). Student perceptions of instructor resistance behaviors: A qualitative approach. Paper presented at the annual meeting of the Eastern Communication Association, Boston, MA.

Cohen, M. (1991). Making class participation a reality. PS: Political Science \& Politics, 24, 699-703.

Comrey, A. L., \& Lee, H. B. (1992). A first course in factor analysis $\left(2^{\text {nd }}\right.$ Ed.). Hillsdale, NJ: 
Erlbaum.

Cotton, S. R., \& Wilson, B. (2006). Student-faculty interactions: Dynamics and determinants. Higher Education, 51, 487-519.

Dancer, D., \& Kamvounias, P. (2005). Student involvement in assessment: A project designed to assess class participation fairly and reliably. Assessment \& Evaluation in Higher Education, 30, 445-454. doi:10.1080/02602930500099235

Deci, E., Vallerand, R., Pelletier, L., \& Ryan, R. (1991). Motivation and education: The self determination perspective. Educational Psychologist, 26, 325-346. doi:10.1080/00461520.1991.9653137

Donovan, L. A., \& Macintyre, P. D. (2004). Age and sex differences in willingness to communicate, communication apprehension, and self-perceived competence. Communication Research Reports, 21, 420-427. doi:10.1080/08824090409360006

Dunleavy, K. N. (2006). The effect of instructor humor on perceived instructor credibility, student state motivation, and student motives to communicate in the classroom. The Kentucky Journal of Communication, 25, 39-56.

Edwards, C., \& Myers, S. A. (2010). The relationship between students' self-reported aggressive communication and motives to communicate with their instructors. Psychological Reports, 106, 131-133. doi: 10.2466/pr0.106.1.131-133

Fassinger, P. A. (1995). Understanding classroom interaction. The Journal of Higher Education, $66,82-96$.

French, J. R. P., Jr., \& Raven, B. (1968). The bases for social power. In D. Cartwright (Ed.), Studies in social power (pp.259-270). Ann Arbor, Michigan: University of Michigan Press. 
Fritschner, L. M. (2000). Inside the undergraduate college classroom: Faculty and students differ on the meaning of student participation. The Journal of Higher Education, 71, 342-362.

Frymier, A. B. (2005). Students' classroom communication effectiveness. Communication Quarterly, 53, 197-212. doi:10.1080/01463370500089896

Frymier, A. B., \& Houser, M. L. (1999). The revised learning indicators scale. Communication Studies, 50, 1-12. doi:10.1080/10510979909388466

Fusani, D. S. (1994). "Extra-class" communication: Frequency, immediacy, self-disclosure, and satisfaction in student-faculty interaction outside of the classroom. Journal of Applied Communication Research, 22, 232-255. doi:10.1080/00909889409365400

Garside, C. (1996). Look who's talking: A comparison of lecture and group discussion teaching strategies in developing critical thinking skills. Communication Education, 45, 212-227. doi: $10.1080 / 03634529609379050$

Gendrin, D. M., \& Rucker, M. L. (2007). Student motive for communicating instructor immediacy: A matched-race institutional comparison. Atlantic Journal of Communication, 15, 41-60. doi:10.1080/15456870701212682

Golish, T. D. (1999). Students' use of compliance gaining strategies with graduate teaching assistants: Examining the other end of the power spectrum. Communication Quarterly, 47, 12-32. doi: $10.1080 / 01463379909370121$

Golish, T. D., \& Olson, L. N. (2000). Students' use of power in the classroom: An investigation of student power, teacher power, and teacher immediacy. Communication Quarterly, 48, 293-310. doi: 10.1080/01463370009385598

Goodboy, A. K. (2011a). Instructional dissent in the college classroom. Communication Education, 60, 296-313. doi:10.1080/03634523.2010.537756 
Goodboy, A. K. (2011b). The development and validation of the instructional dissent scale. Communication Education, 60, 422-440. doi:10.1080/036345523.2011.569894

Goodboy, A. K., \& Bolkan, S. (2009). College teacher misbehaviors: Direct and indirect effects on student communication behavior and traditional learning outcomes. Western Journal of Communication, 73, 204-219. doi:10.1080/10570310902856089

Goodboy, A. K., \& Bolkan, S. (2011). Student motives for communicating with instructors as a function of perceived instructor power use. Communication Research Reports, 28, 109114. doi:10.1080/08824096.2011.541368

Goodboy, A. K., Bolkan, S., Beebe, S. A., \& Shultz, K. (2010). Cultural differences between United States and Chinese students' use of behavioral alteration techniques and affinity seeking strategies with instructors. Journal Of Intercultural Communication Research, 39, 1-12. doi:10.1080/17475759.2010.520834

Goodboy, A. K., Bolkan, S., Myers, S. A., \& Zhao, X. (2011). Student use of relational and influence messages in response to perceived instructor power use in American and Chinese college classrooms. Communication Education, 60, 191-209. doi: $10.1080 / 03634523.2010 .502970$

Goodboy, A. K., Martin, M. M., \& Bolkan, S. (2009). The development and validation of the Student Communication Satisfaction scale. Communication Education, 58, 372-396. doi:10.1080/03634520902755441

Goodboy, A. K., \& Myers, S. A. (2008). The effect of teacher confirmation on student communication and learning outcomes. Communication Education, 57, 153-179. doi:10.1080/03634520701787777

Goodboy, A. K., \& Myers, S. A. (2012). Instructional dissent as an expression of students' 
verbal aggressiveness and argumentative traits. Communication Education, 61, 448-458. doi: $10.1080 / 03634523.2012 .699635$

Goodboy, A. K., Myers, S. A., \& Bolkan, S. (2010). Student motives for communicating with instructors as a function of perceived instructor misbehaviors. Communication Research Reports, 27, 11-19. doi:10.1080/08824090903526604

Graham, E. E., Barbato, C. A., \& Perse, E. M. (1993). The interpersonal communication motives model. Communication Quarterly, 41, 172-186. doi:10.1080/01463379309369877

Handelsman, M. M., Briggs, W. L., Sullivan, N., \& Towler, A. (2005). A measure of college student course engagement. The Journal of Educational Research, 98, 184-191.

Hecht, M. L. (1978). The conceptualization and measurement of interpersonal communication satisfaction. Human Communication Research, 4, 253-264. doi:10.1111/j.1468-2958.1978.tb00614.x

Hecht, M. L., \& Sereno, K. K. (1985). Interpersonal communication satisfaction: Relationship to satisfaction with self and other. Communication Research Reports, 2, 141-148.

Hecht, M. L., Sereno, K. K., \& Spitzberg, B. (1984). Communication satisfaction and satisfaction with self and other: The relevance of relationship level and topic level. Personality and Social Psychology Bulletin, 10, 376-384. doi:10.1177/0146167284103005

Houser, M. L., \& Frymier, A. (2009). The role of student characteristics and teacher behaviors in students' learner empowerment. Communication Education, 58, 35-53. doi: $10.1080 / 03634520802237383$

Howard, J. R., \& Henney, A. L. (1998). Student participation and instructor gender in the mixed age college classroom. Journal of Higher Education, 69, 384-405. doi:10.2307/2649271 
Hsu, C-F. (2012). The influence of vocal qualities and confirmation of nonnative Englishspeaking teachers on student receiver apprehension, affective learning, and cognitive learning. Communication Education, 61, 4-16. doi:10.1080/03634523.2011.615410

Jaasma, M. A., \& Koper, R. J. (1999). The relationship between student-faculty out-of-class communication to instructor immediacy and trust, and to student motivation. Communication Education, 48, 41-47. doi:10.1080/03634529909379151

Jaasma, M. A., \& Koper, R. J. (2001, May). Talk to me: An examination of the content of out-of class interaction between students and faculty. Paper presented at the meeting of the International Communication Association, Washington, D.C.

Johnson, G. M. (1992). Subordinate perceptions of superior's communication competence and task attraction related to superior's use of compliance-gaining tactics. Western Journal of Communication, 56, 54-67.

Jones, S. (2002). The internet goes to college: How students are living in the future with today's technology. Retrieved from http://www.pewinternet.org/pdfs/PIP_College_Report.pdf

Jordan, W. J., \& Powers, W. G. (2007). Development of a measure of student apprehension toward communicating with instructors. Human Communication, 10, 20-32.

Kearney, P., Plax, T. G., \& Burroughs, N. F. (1991). An attributional analysis of college students' resistance decisions. Communication Education, 40, 325-342. doi: $10.10 / 80 / 0364529109378858$

Kearney, P., Plax, T. G., Richmond, V. P., \& McCroskey, J. C. (1984). Power in the classroom IV: Alternatives to discipline. In R. N. Bostrom (Ed), Communication yearbook, vol. 8, (pp.724-746). Beverly Hills, CA: Sage.

Kearney, P., Plax, T. G., Richmond, V. P., \& McCroskey, J. C. (1985). Power in the classroom 
III: Teacher communication techniques and messages. Communication Education, 34, 19-28. doi:10.1080/03634528509378579

Kearney, P., Plax, T. G., Smith, V. R., \& Sorensen, G. (1988). Effects of teacher immediacy and strategy type on college student resistance to on-task demands. Communication Education, 37, 54-67. doi:10.1080/03634528809378703

Kearney, P., Plax, T. G., Sorenson, G., \& Smith, V. R. (1988). Experienced and prospective teachers' selections of compliance-gaining messages for "common" student misbehaviors. Communication Education, 37, 150-164. doi:10.1080/03634528809378712

Kennedy-Lightsey, C. D., \& Myers, S. A. (2009). College students' use of behavioral alteration techniques as a function of aggressive communication. Communication Education, 58 , 54-73. doi:10.1080/03634520802272299

Knapp, J. L. \& Martin, M. M. (2002). Out-of-class communication: The development and testing of a measure. Paper presented at the National Communication Association Convention, New York, New York.

Knapp, J. L. (2010). The influence of Students on instructor out-of-class communication, job satisfaction, and motivation. Human Communication, 13, 171-196.

Krathwohl, D. R., Bloom, B. S., \& Masia, B. B. (1964). Taxonomy of education objectives: The classification of educational goals. Handbook 2: Affective domain. New York, NY: McKay.

Kuh, G. D., \& Umbach, P. D. (2004). College and character: Insights from the National Survey of Student Engagement. New Directions for Institutional Research, 122, 37-54. doi: $10.1002 /$ ir. 108

Lee, C. R., Levine, T. R., \& Cambra, R. (1997). Resisting compliance in the multicultural 
classroom. Communication Education, 46, 29-43. doi:10.1080/03634529709379071

Levine, T. R. (2005). Confirmatory factor analysis and scale validation in communication research. Communication Research Reports, 22, 335-338.

doi:10.1080/00036810500317730

Maehr, M., \& Meyer, H. (1997). Understanding motivation and schooling: Where we've been,where we are, and where we need to go. Educational Psychology Review, 9, 371409. doi:10.1023/A:1024750807365

Mansson, D. H., \& Myers, S. A. (2009). A reexamination of Swedish and American college students' communicative attributes. Journal Of Intercultural Communication Research, 38, 9-22. doi: $10.1080 / 17475750903381622$

Mansson, D. H., \& Myers, S. A. (2011). Swedish college students' academic involvement: Bridging culture, traits, and communicative behaviors. Texas Speech Communication Journal, 36, 1-12.

Mansson, D. H., Myers, S. A., \& Martin, M. M. (2011). Students' aggressive communication traits and their motives for communicating with their instructors. College Student Journal, 45, 401-406. doi:10.1080/10417940903317710

Martin, M. M., Heisel, A. D., \& Valencic, K. M. (2000, April). Students' motives for communicating with their instructors: Considering instructors' use of BATs. Paper presented at the meeting of the Eastern Communication Association, Pittsburgh, PA.

Martin, M. M., Mottet, T. P., \& Myers, S. A. (1999, April). The relationship between students' motives for communicating with their instructors with affective learning, cognitive learning; and satisfaction. Paper presented at the annual meeting of the Eastern Communication Association, Charleston, WV. 
Martin, M. M., Mottet, T. P., \& Myers, S. A. (2000). Students' motives for communicating with their instructors and affective and cognitive learning. Psychological Reports, 87, 830834. doi: $10.2466 / \mathrm{pr} 0.2000 .87 .3 .830$

Martin, M. M., \& Myers, S. A. (2006). Students' communication traits and their out-of-class communication with their instructors. Communication Research Reports, 23, 283-289. doi:10.1080/08824090600962599

Martin, M. M., Myers, S. A., \& Mottet, T. P. (1999). Students' motives for communicating with their instructors. Communication Education, 48, 155-164.

doi:10.1080/03634529909379163

Martin, M. M., Myers, S. A., \& Mottet, T. P. (2006). Students' Machiavellianism and motives for communicating with instructors. Psychological Reports, 98, 861-864. doi:10.2466/pr0.98.3.861-864

Martin, M. M., Valencic, K., \& Heisel, A. D. (2002). The relationship between students' communication apprehension and their motives for communicating with their instructors. Communication Research Reports, 19, 1-7. doi:10.1080/08824090209384826

Mazer, J. P., Murphy, R. E., \& Simonds, C. J. (2007). I'll see you on "Facebook": The effects of computer-mediated teacher self-disclosure on student motivation, affective learning, and classroom climate. Communication Education, 56, 1-17.

doi:10.1080/03634520601009710

McCroskey, J. C. (1994). Assessment of affect toward communication and affect toward instruction in communication. In S. Morreale \& M. Brooks (Eds.), 1994 SCA summer conference proceedings and prepared remarks (pp. 55-71). Annandale, VA: Speech Communication Association. 
McCroskey, J. C., \& Richmond, V. P. (1983). Power in the classroom I: Teacher and student perceptions. Communication Education, 32, 175-184. doi:10.1080/03634528309378527

McCroskey, J. C., \& Richmond, V. P., Plax, T. G., \& Kearney, P. (1985). Power in the classroom V: Behavior alteration techniques, communication training and learning. Communication Education, 34, 214-226. doi:10.1080/03634528509378609

McCroskey, J. C., \& Young, T. J. (1979). The use and abuse of factor analysis in communication research. Human Communication Research, 5, 375-382. doi:10.1111/j.1468-2958.1979.tb00651.x

Menzel, K. E., \& Carrell, L. J. (1999). The impact of gender and immediacy on willingness to talk and perceived learning. Communication Education, 48, 31-40. doi:10.1080/03634529909379150

Mottet, T. P., Frymier, A. B., \& Beebe, S. A. (2006). Theorizing about instrucitional communication. In T. P. Mottet, V. P. Richmond, \& J. C. McCroskey (Eds.), Instructional communication: Rhetorical and relational perspectives (pp. 255-282). Boston: Allyn \& Bacon.

Mottet, T. P., Martin, M. M., \& Myers, S. A. (2004). Relationships among perceived instructor verbal approach and avoidance relational strategies and students' motives for communicating with their instructors. Communication Education, 53, 116-122. doi: $10.1080 / 0363452032000135814$

Myers, S. A. (2004). The relationship between perceived instructor credibility and college student in-class and out-of-class communication. Communication Reports, 17, 129-137. doi:10.1080/08934210409389382

Myers, S. A. (2006). Using leader-member exchange theory to explain students' motives to 
communicate. Communication Quarterly, 54, 293-304. doi:10.1080/01463370600878008

Myers, S. A. (2010). Using the Perry Scheme to explore college student classroom participation. Communication Research Reports, 27, 123-130. doi:10.1080/08824091003738016

Myers, S. A., \& Bryant, L. E. (2005). The relationship between students motives to communicate and perceived instructor functional communication skills. Speech Theatre Association of Missouri Journal, 35, 47-62.

Myers, S. A., \& Claus, C. J. (2012). The relationship between students' motives to communicate with their instructors and classroom environment. Communication Quarterly, 60, 386402. doi:10.1080/01463373.2012.688672

Myers, S. A., Edwards, C, Wahl, S. T., \& Martin, M. M. (2007). The relationship between perceived instructor aggressive communication and college student involvement. Communication Education, 56, 453-466. doi:10.1080/03634520701466398

Myers, S. A., \& Huebner, A. D. (2011). The relationship between students' motive to communicate with their instructors and perceived instructor credibility, attractiveness, and homophily. College Student Journal, 45, 84-91.

Myers, S. A., Martin, M. M., \& Mottet, T. P. (2002a). The relationship between student communication motives and information seeking. Communication Research Reports, 19, 352-361. doi:10.1080/08824090209384863

Myers, S. A., Martin, M. M., \& Mottet, T. P. (2002b). Students' motives for communicating with their instructors: Considering instructor socio-communicative style, student socio communicative orientation, and student gender. Communication Education, 51, 121-133. doi:10.1080/03634520216511

Myers, S. A., Mottet, T. P., \& Martin, M. M. (2000). The relationship between student 
communication motives and perceived instructor communicator style. Communication Research Reports, 17, 161-170. doi:10.1080/08824090009388762

Nadler, M. K., \& Nadler, L. B. (2000). Out-of-class communication between faculty and students: A faculty perspective. Communication Studies, 51, 176-188. doi:10.1080/10510970009388517

Nadler, M. K., \& Nadler, L. B. (2001). The roles of sex, empathy, and credibility in out-of-class communication between faculty and students. Women's Studies in Communication, 24, 241-261. doi:10.1080/07491409.2001.10162436

Paulsel, M. L., \& Chory-Assad, R. M. (2004). The relationships among instructors' antisocial behavior alteration techniques and student resistance. Communication Reports, 17, 103112. doi:10.1080/0363452042000265189

Plax, T. G., Kearney, P., McCroskey, J. C., \& Richmond, V. P. (1986). Power in the classroom VI: Verbal control strategies, nonverbal immediacy and affective learning. Communication Education, 35, 43-55. doi:10.1080/03634528609388318

Plax, T. G., Kearney, P., \& Downs, T. M. (1986). Communicating control in the classroom and satisfaction with teaching and students. Communication Education, 35, 32-42. doi: $10.1080 / 03634528609388362$

Plax, T. G., Kearney, P., \& Tucker, L. K. (1986). Prospective teachers' use of behavior alteration techniques on common student misbehaviors. Communication Education, 35, 32-42. doi: doi:10.1080/03634528609388317

Richmond, V. P. (1990). Communication in the classroom: Power and motivation. Communication Education, 39, 181-195. doi:10.1080/03634529009378801

Richmond, V. P., \& McCroskey, J. C. (1984). Power in the classroom II: Power and learning. 
Communication Education, 33, 125-136. doi:10.1080/03634528409384729

Richmond, V. P., McCroskey, J. C., Kearney, P., \& Plax, T. G. (1987). Power in the classroom VII: Linking behavior alteration techniques to cognitive learning. Communication Education, 39, 181-195. doi:10.1080/03634528709378636

Richmond, V. P., \& Roach. K. D. (1992). Power in the classroom: Seminal studies. In V. P. Richmond \& J. C. McCroskey (Eds.), Power in the classroom: Communication, control, and concern (pp. 47-66). Hillsdale, NJ: Erlbaum.

Roach, K. D. (1994). Temporal patterns and effects of perceived instructor compliance-gaining use. Communication Education, 43, 236-245. doi:10.1080/03634529409378980

Rubin, A. M., \& Martin, M. M. (1998). Interpersonal communication motives. In J. C. McCroskey, J. A. Daly, M. M. Martin, \& M. J. Beatty (Eds.), Communication and personality: Trait perspectives (pp.287-308). Cresskill, N. J.: Hampton Press

Sheer, V. C., \& Fung, T. K. (2007). Can email communication enhance professor-student relationship and student evaluation of professor? Some empirical evidence. Journal of Educational Computing Research, 37, 289-306. doi: 10.2190/EC.37.3.d

Sidelinger, R. J. (2010). College student involvement: An examination of student characteristics and perceived instructor communication behaviors in the classroom. Communication Studies, 61, 87-103. doi:10.1080/10510970903400311

Sidelinger, R. J., \& Booth-Butterfield, M. (2010). Co-constructing student involvement: An examination of teacher confirmation and student-to-student connectedness in the college classroom. Communication Education, 59, 165-184. doi:10.1080/03634520903390867

Sidelinger, R. J., Bolen, D. M., Frisby, B. N., \& McMullen, A. L. (2011). When instructors misbehave: An examination of student-to-student connectedness as a mediator in the 
college classroom. Communication Education, 60, 340-361.

doi:10.1080/03634523.2011.554991

Terenzini, P. T., Pascarella, E. T., \& Blimling, G. S. (1996). Students' out-of-class experiences and their influence in learning and cognitive development: A literature review. Journal of College Student Development, 37, 149-162. doi:10.1007/BF01730114

Theophilides, C., \& Terenzini, P. T. (1981). The relation between non-classroom contact with faculty and students' perception of instructional quality. Research in Higher Education, 15, 255-269. doi:10.1007/BF00976420

Tibbles, D., Richmond, V. P., McCroskey, J. C., \& Weber, K. (2008). Organizational orientations in an instructional setting. Communication Education, 57, 389-407. doi:10.1080/03634520801930095

Titsworth, S., Quinlan, M. M., \& Mazer, J. P. (2010). Emotion in teaching and learning: development and validation of the Classroom Emotions Scale. Communication Education, 59, 431- 452. doi: 10.1080/03634521003746156

Vogt, W. P. (1993). Dictionary of statistics and methodology: A nontechnical guide for the social sciences. Newbury Park, CA: Sage.

Waldeck, J. H., Plax, T. G., \& Kearney, P. (2010). Philosophical and methodological foundations of instructional communication. In D. L. Fassett \& J. T. Warren (Eds.), The SAGE handbook of communication and instruction (pp. 161-179). Thousand Oaks, CA: Sage.

Weiss, S. D., \& Houser, M. L. (2007). Student communication motives and interpersonal attraction toward instructor. Communication Research Reports, 24, 215-224. doi:10.1080/08824090701439091

Wei, F., \& Wang, Y. (2010). Students' silent messages: Can teacher verbal and nonverbal 
immediacy moderate student use of text messaging in class?. Communication Education, 59, 475-496. doi:10.1080/03634523.2010.496092

Wheeless, L. R., Barraclough, R., \& Stewart, R. (1983). Compliance-gaining and power in persuasion. In R. Bostrom (Ed.), Communication yearbook, vol. 7, (pp. 105-145). Beverly Hills, CA: Sage. 


\section{Appendix A}

\section{Recruitment Script}

Hello! My name is Christopher J. Claus and I am a doctoral candidate in the Department of Communication at West Virginia University. I am working on my dissertation in which I plan to examine undergraduate students' use of behavior alteration techniques and how this use affects their learning outcomes and willingness to talk in and outside of class with their instructor. If you are currently not over the age of 18 or enrolled as a full-time student, you are not allowed to participate. This research study is completely voluntary. This means that you do not need to participate, and if you do participate you may stop answering the questionnaire at any moment. This study has been acknowledged by West Virginia University's Institutional Review Board. The questionnaire will take approximately 15-20 minutes. If you have any questions, please raise your hand to ask. If you would like more information regarding this research project, feel free to contact Principal Investigator Dr. Scott A. Myers via email at scott.myers@mail.wvu.edu or CoInvestigator Christopher J. Claus via email at cclaus@mix.wvu.edu. Thank you for your participation. 


\section{Appendix B}

Cover Letter

\section{West VrginiaUniversity}

Department of Communication Studies

Dear Participant:

October 2012

This letter is a request for you to take part in a research project in which students' use of behavior alteration techniques will be examined in relationship to communication with instructors, and learning outcomes. This project is being conducted by Principal Investigator Dr. Scott A. Myers and Co-Investigator Christopher J. Claus both in the Department of Communication Studies at West Virginia University. Your participation in this project is greatly appreciated and will take approximately 15-20 minutes to fill out the attached questionnaire.

Your involvement in this project will be kept as confidential as legally possible. All data will be reported in the aggregate. You must be 18 years of age or older and enrolled as a full-time student to participate. I will not ask any information that should lead back to your identity as a participant. Please complete the questionnaire independently and be sure to read the instructions for each section carefully and answer all questions to the best of your ability. There is no right or wrong answer. Your participation is completely voluntary. You may skip any question that you do not wish to answer and you may discontinue at any time. Your class standing will not be affected if you decide either not to participate or withdraw. There are no known risks associated with participation in this study. If you have any questions about your rights as a research participant, you may contact the West Virginia University Institutional Review Board (IRB) at (304) 293-7073. West Virginia University's Institutional Review Board acknowledgement of this project is on file.

I hope that you will participate in this research project, as it could be beneficial in understanding the impact of student communication behavior within the classroom. Thank you very much for your time. Should you have any questions about this letter or research project, please feel free to contact Principal Investigator Dr. Scott A. Myers or Co-Investigator Christopher J. Claus at 304293-3905 or by email.

Sincerely,

Dr. Scott A. Myers

Principal Investigator

Scott.myers@mail.wvu.edu
Christopher J. Claus

Co-Investigator

cclaus@mix.wvu.edu
Phone: gotags:s9o5

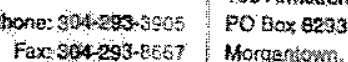

Morgentom. WN 265056293

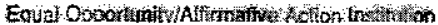




\section{Appendix C}

\section{Dissertation Questionnaire}

Complete these items in regard to the instructor of the course you attended immediately prior to receiving this questionnaire.

Identify this course by its subject matter (e.g., Biology, Math, Psychology):

Is this course within your major? (Circle one) $\quad$ Yes

Is this course a large lecture? (Circle one) Yes No

How many students are enrolled in this class? (Provide an estimate):

What is the sex of the instructor? (Circle one) Male Female

Recall a time when you asked your instructor for something class related. For example, you could have asked for an extension on an assignment or explained why you need to take a makeup assignment. In the space provided below explain how you approached your instructor and what you said. Also, please indicate whether you were successful in your request or if you were denied.

If you have never asked your instructor for anything class related, think of how you would ask (in-class or out-of-class) and what you would say. How effective do you think your message would be? In the space provided below explain how you would approach your instructor and what you would say. Also, please indicate how effective you perceive this message to be and why. 
Directions: Below is a series of statements that describe some messages that students use when trying to get their instructors to do what they want them to do (e.g., extend an assignment deadline, change a grade, etc.). Each of the following items represents several possible statements that may be used, but not necessarily at the same time. Read each of the messages and please indicate on a scale from 0 to 4 how effective you perceive each message and how likely you would be to use similar messages to persuade the instructor from the course you just identified above.

1. "To be totally honest, I was sick and didn't have enough time to study." "I didn't have enough time to complete the assignment." "I wish I had an excuse but I didn't get it finished."

How effective is this message?

How likely are you to use this?

\begin{tabular}{|l|l|l|l|l|l|l|}
\hline $\begin{array}{l}\text { Completely } \\
\text { Ineffective }\end{array}$ & 0 & 1 & 2 & 3 & 4 & $\begin{array}{l}\text { Very } \\
\text { Effective }\end{array}$ \\
\hline Not Very Likely & 0 & 1 & 2 & 3 & 4 & Very Likely \\
\hline
\end{tabular}

2. "We weren't prepared for this exam." "You didn't explain this assignment well enough." "You graded the assignment too hard." "The material was too difficult."

How effective is this message?

How likely are you to use this?

\begin{tabular}{|l|l|l|l|l|l|l|}
\hline $\begin{array}{l}\text { Completely } \\
\text { Ineffective }\end{array}$ & 0 & 1 & 2 & 3 & 4 & $\begin{array}{l}\text { Very } \\
\text { Effective }\end{array}$ \\
\hline Not Very Likely & 0 & 1 & 2 & 3 & 4 & Very Likely \\
\hline
\end{tabular}

3. "The questions were too ambiguous." "I have too much to do in other classes" (with statements such as these you continue to complain knowing that if you complain long enough, the professor will change his/her mind).

How effective is this message?

How likely are you to use this?

\begin{tabular}{|l|l|l|l|l|l|l|}
\hline $\begin{array}{l}\text { Completely } \\
\text { Ineffective }\end{array}$ & 0 & 1 & 2 & 3 & 4 & $\begin{array}{l}\text { Very } \\
\text { Effective }\end{array}$ \\
\hline Not Very Likely & 0 & 1 & 2 & 3 & 4 & Very Likely \\
\hline
\end{tabular}

Please Turn Over 
4. "Please can you think about changing my grade?" "I really need this grade to graduate." "I'll try to make it up some other way. Please?"

How effective is this message?

How likely are you to use this?

\begin{tabular}{|l|l|l|l|l|l|l|}
\hline $\begin{array}{l}\text { Completely } \\
\text { Ineffective }\end{array}$ & 0 & 1 & 2 & 3 & 4 & $\begin{array}{l}\text { Very } \\
\text { Effective }\end{array}$ \\
\hline Not Very Likely & 0 & 1 & 2 & 3 & 4 & Very Likely \\
\hline
\end{tabular}

5. "If we take the test now, we will not do as well as if we waited." "My paper will be better quality if I can just have one more day to work on it." "You want us to perform our best, don't you?"

How effective is this message?

How likely are you to use this?

\begin{tabular}{|l|l|l|l|l|l|l|}
\hline $\begin{array}{l}\text { Completely } \\
\text { Ineffective }\end{array}$ & 0 & 1 & 2 & 3 & 4 & $\begin{array}{l}\text { Very } \\
\text { Effective }\end{array}$ \\
\hline Not Very Likely & 0 & 1 & 2 & 3 & 4 & Very Likely \\
\hline
\end{tabular}

6. "This assignment has been very helpful, but it might be improved by..." "You have taught this material to us well, but there are a couple of things you could do differently."

How effective is this message?

How likely are you to use this?

\begin{tabular}{|l|l|l|l|l|l|l|}
\hline $\begin{array}{l}\text { Completely } \\
\text { Ineffective }\end{array}$ & 0 & 1 & 2 & 3 & 4 & $\begin{array}{l}\text { Very } \\
\text { Effective }\end{array}$ \\
\hline Not Very Likely & 0 & 1 & 2 & 3 & 4 & Very Likely \\
\hline
\end{tabular}

7. "Remember back when you were a student?" "You were in our shoes once, you should be able to relate to us."

How effective is this message?

How likely are you to use this?

\begin{tabular}{|l|l|l|l|l|l|l|}
\hline $\begin{array}{l}\text { Completely } \\
\text { Ineffective }\end{array}$ & 0 & 1 & 2 & 3 & 4 & $\begin{array}{l}\text { Very } \\
\text { Effective }\end{array}$ \\
\hline Not Very Likely & 0 & 1 & 2 & 3 & 4 & Very Likely \\
\hline
\end{tabular}

8. "We, the class, were talking before class and came to the conclusion that we need more time to study for this exam." "Most of us aren't ready to take on this project." "As a group, we don't fully understand what we are supposed to do for this assignment."

How effective is this message?

How likely are you to use this?

\begin{tabular}{|l|c|c|c|c|c|l|}
\hline $\begin{array}{l}\text { Completely } \\
\text { Ineffective }\end{array}$ & 0 & 1 & 2 & 3 & 4 & $\begin{array}{l}\text { Very } \\
\text { Effective }\end{array}$ \\
\hline Not Very Likely & 0 & 1 & 2 & 3 & 4 & Very Likely \\
\hline
\end{tabular}

9. Purposefully asking your professor about the class or an assignment in front of another student when persuading him/her, thinking that it would be more difficult for him/her to say "no."

How effective is this message?

How likely are you to use this?

\begin{tabular}{|l|l|l|l|l|l|l|}
\hline Completely Ineffective & 0 & 1 & 2 & 3 & 4 & $\begin{array}{l}\text { Very } \\
\text { Effective }\end{array}$ \\
\hline Not Very Likely & 0 & 1 & 2 & 3 & 4 & Very Likely \\
\hline
\end{tabular}

Please Continue on Next Page 
10. First running your request by your professor through email, telephoning him/her, or going to see him/her during office hours to discuss the matter.

How effective is this message?

How likely are you to use

this?

\begin{tabular}{|l|l|l|l|l|l|l|}
\hline $\begin{array}{l}\text { Completely } \\
\text { Ineffective }\end{array}$ & 0 & 1 & 2 & 3 & 4 & Very Effective \\
\hline Not Very Likely & 0 & 1 & 2 & 3 & 4 & Very Likely \\
\hline
\end{tabular}

11. "Looking at my essay again, I think I clearly laid out my argument by using evidence from the test and lecture." "I followed the criteria you gave us for how to receive a good grade on this paper."

How effective is this message?

How likely are you to use this?

\begin{tabular}{|l|l|l|l|l|l|l|}
\hline $\begin{array}{l}\text { Completely } \\
\text { Ineffective }\end{array}$ & 0 & 1 & 2 & 3 & 4 & Very Effective \\
\hline Not Very Likely & 0 & 1 & 2 & 3 & 4 & Very Likely \\
\hline
\end{tabular}

12. "I have really worked hard all semester." "This final grade doesn't represent how well I have been doing in the class." "I put a lot of time and effort into this assignment."

How effective is this message?

How likely are you to use this?

\begin{tabular}{|l|c|c|c|c|c|l|}
\hline $\begin{array}{l}\text { Completely } \\
\text { Ineffective }\end{array}$ & 0 & 1 & 2 & 3 & 4 & Very Effective \\
\hline Not Very Likely & 0 & 1 & 2 & 3 & 4 & Very Likely \\
\hline
\end{tabular}

13. "I have other classes besides this one." "I have a lot of tests right now." "I am bombarded with homework." "I'm stressed out."

How effective is this message?

How likely are you to use this?

\begin{tabular}{|l|l|l|l|l|l|l|}
\hline $\begin{array}{l}\text { Completely } \\
\text { Ineffective }\end{array}$ & 0 & 1 & 2 & 3 & 4 & Very Effective \\
\hline Not Very Likely & 0 & 1 & 2 & 3 & 4 & Very Likely \\
\hline
\end{tabular}

14. "If you delay the exam, it will benefit the whole class." "We will get better grades as a class if we delay the paper"" "Yoù will also benefit by not having to grade our papers this weekend."

How effective is this message?

How likely are you to use this?

\begin{tabular}{|l|l|l|l|l|l|l|}
\hline $\begin{array}{l}\text { Completely } \\
\text { Ineffective }\end{array}$ & 0 & 1 & 2 & 3 & 4 & $\begin{array}{l}\text { Very } \\
\text { Effective }\end{array}$ \\
\hline Not Very Likely & 0 & 1 & 2 & 3 & 4 & Very Likely \\
\hline
\end{tabular}


15. Attempting to look really sad, look like you are about to cry, or look the professor in the face so that he/she can see your emotion.

\begin{tabular}{|l|l|l|l|l|l|l|l|}
\hline How effective is this message? & $\begin{array}{l}\text { Completely } \\
\text { Ineffective }\end{array}$ & 0 & 1 & 2 & 3 & 4 & $\begin{array}{l}\text { Very } \\
\text { Effective }\end{array}$ \\
\cline { 2 - 8 } How likely are you to use this? & Not Very Likely & 0 & 1 & 2 & 3 & 4 & Very Likely \\
\cline { 2 - 7 }
\end{tabular}

16. Using any excuse available that sounds reasonable, such as "My grandparent died," or "My computer crashed," or "I got the flu."

\begin{tabular}{l|l|l|l|l|l|l|l|} 
How effective is this message? & $\begin{array}{l}\text { Completely } \\
\text { Ineffective }\end{array}$ & 0 & 1 & 2 & 3 & 4 & $\begin{array}{l}\text { Very } \\
\text { Effective }\end{array}$ \\
\cline { 2 - 8 } How likely are you to use this? & Not Very Likely & 0 & 1 & 2 & 3 & 4 & Very Likely \\
\hline
\end{tabular}

17. Giving the professor a bad course evaluation. You might also use statements like "This will reflect poorly on your evaluation or how students see the course."

\begin{tabular}{|l|l|l|l|l|l|l|l|} 
How effective is this message? & $\begin{array}{l}\text { Completely } \\
\text { Ineffective }\end{array}$ & 0 & 1 & 2 & 3 & 4 & $\begin{array}{l}\text { Very } \\
\text { Effective }\end{array}$ \\
\cline { 2 - 8 } How likely are you to use this? & Not Very Likely & 0 & 1 & 2 & 3 & 4 & Very Likely \\
\hline
\end{tabular}

18. "If you don't change my grade, I will talk to the dean or the chair of the department." "Other professors teaching this course don't have this many assignments."

How effective is this message?

How likely are you to use this?

\begin{tabular}{|l|l|l|l|l|l|l|}
\hline $\begin{array}{l}\text { Completely } \\
\text { Ineffective }\end{array}$ & 0 & 1 & 2 & 3 & 4 & $\begin{array}{l}\text { Very } \\
\text { Effective }\end{array}$ \\
\hline Not Very Likely & 0 & 1 & 2 & 3 & 4 & Very Likely \\
\hline
\end{tabular}

19. "I demand that you give me a better grade." "I deserve a grade better than the one you gave me." "You need to change this grade."

How effective is this message?

How likely are you to use this?

\begin{tabular}{|l|l|l|l|l|l|l|}
$\begin{array}{l}\text { Completely } \\
\text { Ineffective }\end{array}$ & 0 & 1 & 2 & 3 & 4 & $\begin{array}{l}\text { Very } \\
\text { Effective }\end{array}$ \\
\hline Not Very Likely & 0 & 1 & 2 & 3 & 4 & Very Likely \\
\hline
\end{tabular}


Directions: Below are some reasons students give for why they talk to their instructors in general. For each statement, please put the appropriate number in the space provided that expresses how likely you would be to communicate for the following reasons. Complete these items in regard to the instructor of the course you attended immediately prior to receiving this questionnaire.

$\begin{array}{ccccc}\text { Not at All } & \text { Not Much } & \text { Somewhat } & \text { A Lot } & \text { Exactly } \\ \text { Like Me } & \text { Like Me } & \text { Like Me } & \text { Like Me } & \text { Like Me } \\ 1 & 2 & 3 & 4 & 5\end{array}$

I would talk to my instructor:

1. To learn about him/her personally

2. So we can develop a friendship

3. To build a personal relationship

4. To learn more about the instructor's personality

5. Because I find the instructor's interesting

6. Because we share common interests

7. To clarify the material

8. To get assistance on assignments/exams

9. To learn how I can improve in the class

10. To ask questions about the material

11. To get accademic advice

12. To get more information on the requirements of the course

13. To explain why work is late

14. To explain my absences

15. To explain why I do not have my work done

16. To challenge a grade I received

17. To explain why my work does not meet the instructor's expectations

18 . To explain the quality of my work

19. To appear involved in class

20. To demonstrate I understand the material

21. To demonstrate my intelligence

22. Because my input is vital for class discussion

23. Because my classmates value my contribution to class discussions

24 . Because my instructor values class participation

25. To pretend I'm interested in the course

26. To give the instructor the impression that I like him/her

27. To give the impression that I think the instructor is an effective teacher

28. To give the impression that I'm learning a lot from the instructor

29. To give the impression that I'm interested in the course content

30. To get special permission/privileges not granted to all students

\section{Please Turn Over}


Directions: Listed below are several situations that might affect whether or not you choose to talk in the class that you attended immediately prior to this class. For each statement, please put the appropriate number in the space provided that expresses how often you would choose to talk in that class.

Never

Rarely

Sometimes

Frequently

Very Often

0 1

2

3

4

I would talk to my instructor:

1. When I am in a small group in class

2. When the topic is interesting

3. When my views differ from my classmates' views

4. When the class is engaged in a heated debate

5. When my views differ from the professor's views

6. When I am angry about a topic

7. When I can really help clarify the discussion

8 . When I am prepared for class

9. When the class is engaged in an open discussion

10. When I am graded on participation

11. When 1 am comfortable with the subject matter

12. When I know the correct answer

13. When the professor asks for a response from the class

14. When an assignment is being discussed

15. When no one else is talking

16. When I am sitting in the front of the class

17. When I am sitting in the back of the class

18. When everyone is talking

19. When I dislike my classmates 
Directions: Listed below are several situations that might affect whether or not you choose to talk to your instructor outside of class. For each statement, please put the appropriate number in the space provided that expresses how often you would choose to talk outside of class with the instructor of the course you attended immediately prior to receiving this questionnaire.

$\begin{array}{ccccc}\begin{array}{c}\text { Strongly } \\ \text { Disagree }\end{array} & \text { Disagree } & \text { Neutral } & \text { Agree } & \begin{array}{c}\text { Strongly } \\ \text { Agree } \\ 1\end{array} \\ 2 & 3 & 4 & 5\end{array}$

1. I often talk to my instructor during his/her office hours

2. If I see my instructor on campus, I often talk to him/her

3. I rarely talk to my instructor outside of the classroom

4. If I see my instructor in the hallway, I often stop to talk to her/him

5. I only talk to my instructor outside of the classroom once in a while

6. I frequently talk to my instructor outside of the classroom

7. When I see ny lnstructor off campus I usually spend some time talking to him/her

8. When I see my instructor in public, I avoid talking to him/her

9. I never talk to my instructor outside of the classroom

Directions: Below are some behaviors students use in the classroom. For each statement, please put the appropriate number in the space provided that expresses how frequently you would be to engage in each behavior in the class that you had immediately prior to this class.

Never Rarely Sometimes Frequently Very Often

$\begin{array}{lllll}0 & 1 & 2 & 3 & 4\end{array}$

I frequently:

1. Talk about what $\mathrm{I} m$ doing in the class with friends and family.

2. Explain course content to other students.

3. Think about the course content outside of class.

4. See the connections between the course content and my career goals.

5. Review the course content.

6. Compare the information from the class with other things I have learned.

7. Feel that I have learned alot in the class. 
Directions: Using the following scales, please evaluate the class and instructor that you had immediately prior to this class. Please circle the number toward either word which best represents your feelings. Note: Sometimes the most positive score is "1" in other cases it is "7."

My attitude about the course content in this class is:

$\begin{array}{lllllllll}\text { 1. Good } & 1 & 2 & 3 & 4 & 5 & 6 & 7 & \text { Bad } \\ \text { 2. Worthless } & 1 & 2 & 3 & 4 & 5 & 6 & 7 & \text { Valuable } \\ \text { 3. Fair } & 1 & 2 & 3 & 4 & 5 & 6 & 7 & \text { Unfair } \\ \text { 4. Negative } & 1 & 2 & 3 & 4 & 5 & 6 & 7 & \text { Positive }\end{array}$

My attitude about the behaviors recommended in this class is:

$\begin{array}{lllllllll}\text { 5. Good } & 1 & 2 & 3 & 4 & 5 & 6 & 7 & \text { Bad } \\ \text { 6. Worthless } & 1 & 2 & 3 & 4 & 5 & 6 & 7 & \text { Valuable } \\ \text { 7. Fair } & 1 & 2 & 3 & 4 & 5 & 6 & 7 & \text { Unfair } \\ \text { 8. Negative } & 1 & 2 & 3 & 4 & 5 & 6 & 7 & \text { Positive }\end{array}$

My attitude about the instructor in this class is:

$\begin{array}{lllllllll}\text { 9. Good } & 1 & 2 & 3 & 4 & 5 & 6 & 7 & \text { Bad } \\ \text { 10. Worthless } & 1 & 2 & 3 & 4 & 5 & 6 & 7 & \text { Valuable } \\ \text { 11. Fair } & 1 & 2 & 3 & 4 & 5 & 6 & 7 & \text { Unfair } \\ \text { 12. Negative } & 1 & 2 & 3 & 4 & 5 & 6 & 7 & \text { Positive }\end{array}$

My likelihood of actually attempting to engage in the behaviors recommended in this class is:

\begin{tabular}{|c|c|c|c|}
\hline Likely & 1 & & Unlikely \\
\hline 4. Impossible & 1 & & Possible \\
\hline 5. Probable & 1 & ? & Improbable \\
\hline 16. Would Not & 1 & & Would \\
\hline
\end{tabular}

My likelihood of actually enrolling in another class with similar content, if I had the choice and if my schedule permitted: (If you are graduating, assume you would still be here.)
17. Likely
2.3
3
$4 \quad 5$
6
7 Unilikely
18. Impossible 1
19. Probable
2
20. Would Not
2
3.4
45
$\begin{array}{ll}6 & 7\end{array}$
$6: 7$
Possible
Improbable
Would

The likelihood of my taking another course with this instructor, if I had a choice, is: (If you are graduating, assume you would still be here.)
21. Likely
1 .
2 - 3
34
45
5
$6 \quad 7$
7
$\begin{array}{lllllllll}\text { 22. Impossible } & 1 & 2 & 3 & 4 & 5 & 6 & 7 \\ \text { 23. Probable } & 1 & 2 & 3 & \because & 4 & 5 & 6 & 7\end{array}$
24. Would Not
$2 \quad 3 \quad 4$

5
$6 \quad 7$
Unnilikely
Possible
Improbable
Would 
Directions: Using the following scales, please evaluate the class that you had immediately prior to this class. Please circle the number toward either word which best represents the way that you feel when you are in this specific class. Note: Sometimes the most positive score is " 1 " in other cases it is "7."

When I am in class I feel:

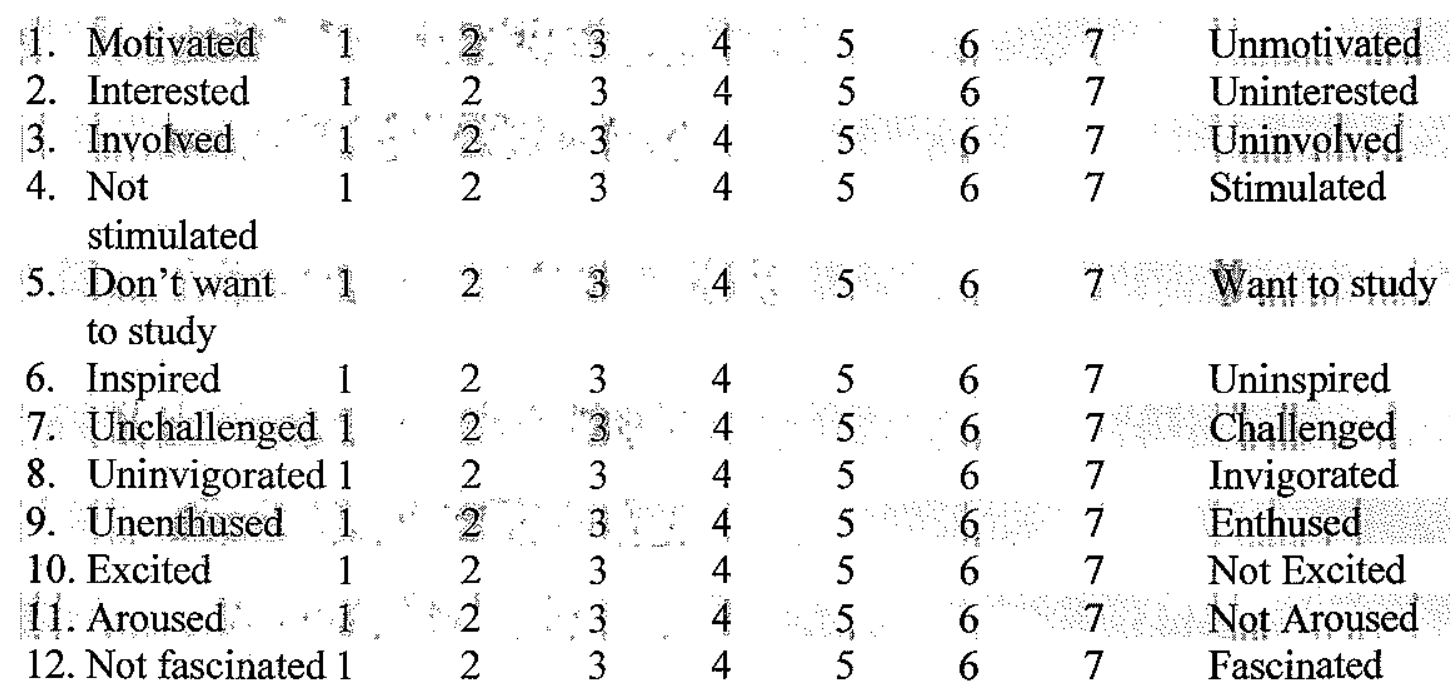

Directions: Listed below are several examples describing your satisfaction with the communication you have with the instructor of the class that you take immediately prior to this class. For each statement, please put the appropriate number in the space provided that expresses how satisfied you are with that instructor.

$\begin{array}{ccccccc}\begin{array}{c}\text { Strongly } \\ \text { Disagree }\end{array} & \text { Disagree } & \begin{array}{c}\text { Somewhat } \\ \text { Disagree }\end{array} & \text { Neutral } & \begin{array}{c}\text { Somewhat } \\ \text { Agree }\end{array} & \text { Agree } & \begin{array}{c}\text { Strongly } \\ \text { Agree }\end{array} \\ 1 & 2 & 3 & 4 & 5 & 6 & 7\end{array}$

1. My communication with my teacher feels satisfying

2. I dislike talking with my teacher

3. I am not satisfied after talking to my teacher

4. Talking with my teacher leaves me feeling like I accomplished something

5. My teacher fulfills my expectations when I talk to him/her

6. My conversations with my teacher are worthwhile

7. When I talk to my teacher, the conversations are rewarding

8. My teacher makes an effort to satisfy the concerns I have

\section{Please Turn Over}


Directions: Below are different ways to communicate with your instructor. For each statement, please put the appropriate number in the space provided that expresses how often you have already communicated with the instructor this semester. Remember to report on the instructor you had immediately prior to receiving this questionnaire.

\begin{tabular}{|c|c|c|c|c|}
\hline $\begin{array}{c}\text { Never or Not } \\
\text { Yet }\end{array}$ & Once or Twice & $\begin{array}{c}\text { More than three times, } \\
\text { but less than once a } \\
\text { week }\end{array}$ & Weekly & Several Times a Week \\
\hline 0 & 1 & 2 & 3 & 4 \\
\hline
\end{tabular}

1. I communicate with my instructor during class.

2. I communicate with my instructor outside of class.

3. I communicate with ny instuuctor face-to-face.

4. I communicate with my instructor through e-mail.

Please respond to a few additional items about yourself.

1. What grade do you expect to receive in the class you attended immediately prior to receiving this questionnaire? (Circle one.)
A
$\mathrm{B}$
$\mathrm{C}$
$\mathrm{D}$
F

2. Sex (Circle one.): Male Female

3. Age: Years

4. What year in school are you? (Circle one.)

First Year Sophomore Junior Senior Graduate

5. Which of the following best describes your racial/ethnic background (Please check one)?

Caucasian

African American
Hispanic

Asian
Native American

Other 
Appendix D

The Student Behavioral Alteration Techniques and Messages Typology (Golish, 1999)

1. "To be totally honest, I was sick and didn't have enough time to study" "I didn't have enough time to complete the assignment." "I wish I had an excuse but I didn't get it finished."

\begin{tabular}{|c|l|l|l|l|l|l|l|}
\hline How effective is this message? & $\begin{array}{l}\text { Completely } \\
\text { Ineffective }\end{array}$ & 0 & 1 & 2 & 3 & 4 & $\begin{array}{l}\text { Very } \\
\text { Effective }\end{array}$ \\
\hline How likely are you to use this? & Not Very Likely & 0 & 1 & 2 & 3 & 4 & Very Likely \\
\hline
\end{tabular}

2. "We weren't prepared for this exam." "You didn't explain this assignment well enough." "You graded the assignment too hard." "The material was too difficult."

\begin{tabular}{|c|l|l|l|l|l|l|l|}
\hline How effective is this message? & $\begin{array}{l}\text { Completely } \\
\text { Ineffective }\end{array}$ & 0 & 1 & 2 & 3 & 4 & $\begin{array}{l}\text { Very } \\
\text { Effective }\end{array}$ \\
\hline How likely are you to use this? & Not Very Likely & 0 & 1 & 2 & 3 & 4 & Very Likely \\
\hline
\end{tabular}

3. "The questions were too ambiguous." "I have too much to do in other classes" (with statements such as these you continue to complain knowing that if you complain long enough, the professor will change his/her mind).

\begin{tabular}{|c|l|l|l|l|l|l|l|}
\hline How effective is this message? & $\begin{array}{l}\text { Completely } \\
\text { Ineffective }\end{array}$ & 0 & 1 & 2 & 3 & 4 & $\begin{array}{l}\text { Very } \\
\text { Effective }\end{array}$ \\
\hline How likely are you to use this? & Not Very Likely & 0 & 1 & 2 & 3 & 4 & Very Likely \\
\hline
\end{tabular}

4. "Please can you think about changing my grade?" "I really need this grade to graduate." "I'Il try to make it up some other way. Please?".

\begin{tabular}{|c|l|l|l|l|l|l|l|}
\hline How effective is this message? & $\begin{array}{l}\text { Completely } \\
\text { Ineffective }\end{array}$ & 0 & 1 & 2 & 3 & 4 & $\begin{array}{l}\text { Very } \\
\text { Effective }\end{array}$ \\
\hline How likely are you to use this? & Not Very Likely & 0 & 1 & 2 & 3 & 4 & Very Likely \\
\hline
\end{tabular}

5. "If we take the test now, we will not do as well as if we waited" "My paper will be better quality if I can just have one more day to work on it." "You want us to perform our best, don't you?"

How effective is this message?

How likely are you to use this?

\begin{tabular}{|l|l|l|l|l|l|l|}
$\begin{array}{l}\text { Completely } \\
\text { Ineffective }\end{array}$ & 0 & 1 & 2 & 3 & 4 & $\begin{array}{l}\text { Very } \\
\text { Effective }\end{array}$ \\
\hline Not Very Likely & 0 & 1 & 2 & 3 & 4 & Very Likely \\
\hline
\end{tabular}

6. "This assignment has been very helpful, but it might be improved by..." You have taught this material to us well, but there are a couple of things you could do differently."

How effective is this message?

\begin{tabular}{|l} 
Completely \\
Ineffective
\end{tabular}

\begin{tabular}{|l|l|}
0 & 1 \\
\hline
\end{tabular}

2

\begin{tabular}{|l|l|l|l}
\hline & 3 & 4 & $\begin{array}{l}\text { Very } \\
\text { Effective }\end{array}$ \\
\hline
\end{tabular}


How likely are you to use this? Not Very Likely

\begin{tabular}{|l|l|l|l|l|l|}
0 & 1 & 2 & 3 & 4 & Very Likely \\
\hline
\end{tabular}

7. "Remember back when you were a student?" "You were in our shoes once, you should be able to relate to us."

\begin{tabular}{|c|l|l|l|l|l|l|l|}
\hline How effective is this message? & $\begin{array}{l}\text { Completely } \\
\text { Ineffective }\end{array}$ & 0 & 1 & 2 & 3 & 4 & $\begin{array}{l}\text { Very } \\
\text { Effective }\end{array}$ \\
\hline How likely are you to use this? & Not Very Likely & 0 & 1 & 2 & 3 & 4 & Very Likely \\
\hline
\end{tabular}

8. "We, the class, were talking before class and came to the conclusion that we need more time to study for this exam." "Most of us aren't ready to take on this project." "As a group, we don't fully understand what we are supposed to do for this assignment."

How effective is this message?

How likely are you to use this?

\begin{tabular}{|l|l|l|l|l|l|l|}
$\begin{array}{l}\text { Completely } \\
\text { Ineffective }\end{array}$ & 0 & 1 & 2 & 3 & 4 & $\begin{array}{l}\text { Very } \\
\text { Effective }\end{array}$ \\
\hline Not Very Likely & 0 & 1 & 2 & 3 & 4 & Very Likely \\
\hline
\end{tabular}

9. Purposefully asking your professor about the class or an assignment in front of another student when persuading him/her, thinking that it would be more difficult for him/her to say "no."

How effective is this message?

How likely are you to use this?

\begin{tabular}{|l|l|l|l|l|l|l|}
\hline $\begin{array}{l}\text { Completely } \\
\text { Ineffective }\end{array}$ & 0 & 1 & 2 & 3 & 4 & Very Effective \\
\hline Not Very Likely & 0 & 1 & 2 & 3 & 4 & Very Likely \\
\hline
\end{tabular}

10. First running your request by your professor through email, telephoning him/her, or going to see him/her during office hours to discuss the matter.

How effective is this message?

How likely are you to use this?

\begin{tabular}{|l|l|l|l|l|l|l|}
\hline $\begin{array}{l}\text { Completely } \\
\text { Ineffective }\end{array}$ & 0 & 1 & 2 & 3 & 4 & Very Effective \\
\hline Not Very Likely & 0 & 1 & 2 & 3 & 4 & Very Likely \\
\hline
\end{tabular}

11. "Looking at my essay again, I think I clearly laid out my argument by using evidence from the test and lecture." "I followed the criteria you gave us for how to receive a good grade on this paper."

\begin{tabular}{|l|l|l|l|l|l|l|l|l|}
\hline How effective is this message? & $\begin{array}{l}\text { Completely } \\
\text { Ineffective }\end{array}$ & 0 & 1 & 2 & 3 & 4 & Very Effective \\
\hline How likely are you to use this? & Not Very Likely & 0 & 1 & 2 & 3 & 4 & Very Likely \\
\hline
\end{tabular}

12. "T have really worked hard all semester." "This final grade doesn't represent how well I have been doing in the class. "I put a lot of time and effort into this assignment."

How effective is this message?

How likely are you to use this?

\begin{tabular}{|l|l|l|l|l|l|l|}
\hline $\begin{array}{l}\text { Completely } \\
\text { Ineffective }\end{array}$ & 0 & 1 & 2 & 3 & 4 & Very Effective \\
\hline Not Very Likely & 0 & 1 & 2 & 3 & 4 & Very Likely \\
\hline
\end{tabular}


13. "I have other classes besides this one." "I have a lot of tests right now." "I am bombarded with homework." "I'm stressed out.".

How effective is this message?

How likely are you to use this?

\begin{tabular}{|l|l|l|l|l|l|l|}
\hline $\begin{array}{l}\text { Completely } \\
\text { Ineffective }\end{array}$ & 0 & 1 & 2 & 3 & 4 & Very Effective \\
\hline Not Very Likely & 0 & 1 & 2 & 3 & 4 & Very Likely \\
\hline
\end{tabular}

14. "If you delay the exam, it will benefit the whole class." "We will get better grades as a class if we delay the paper." "You will also benefit by not having to grade our papers this weekend"

\begin{tabular}{|c|l|l|l|l|l|l|l|}
\hline How effective is this message? & $\begin{array}{l}\text { Completely } \\
\text { Ineffective }\end{array}$ & 0 & 1 & 2 & 3 & 4 & $\begin{array}{l}\text { Very } \\
\text { Effective }\end{array}$ \\
\hline How likely are you to use this? & Not Very Likely & 0 & 1 & 2 & 3 & 4 & Very Likely \\
\hline
\end{tabular}

15. Attempting to look really sad, look like you are about to cry, or look the professor in the face so that he/she can see yeur emotion.

\begin{tabular}{|c|l|l|l|l|l|l|l|}
\hline How effective is this message? & $\begin{array}{l}\text { Completely } \\
\text { Ineffective }\end{array}$ & 0 & 1 & 2 & 3 & 4 & $\begin{array}{l}\text { Very } \\
\text { Effective }\end{array}$ \\
\hline How likely are you to use this? & Not Very Likely & 0 & 1 & 2 & 3 & 4 & Very Likely \\
\hline
\end{tabular}

16. Using any excuse available that sounds reasonable, such as 'My grandparent died,' or "My computer disk crashed," or "I got the flu."

\begin{tabular}{|c|l|l|l|l|l|l|l|}
\hline How effective is this message? & $\begin{array}{l}\text { Completely } \\
\text { Ineffective }\end{array}$ & 0 & 1 & 2 & 3 & 4 & $\begin{array}{l}\text { Very } \\
\text { Effective }\end{array}$ \\
\hline How likely are you to use this? & Not Very Likely & 0 & 1 & 2 & 3 & 4 & Very Likely \\
\hline
\end{tabular}

17. Giving the professor a bad course evaluation. You might also use statements like "This will reflect poorly on your evaluation or how students see the course."

\begin{tabular}{|c|l|l|l|l|l|l|l|}
\hline How effective is this message? & $\begin{array}{l}\text { Completely } \\
\text { Ineffective }\end{array}$ & 0 & 1 & 2 & 3 & 4 & $\begin{array}{l}\text { Very } \\
\text { Effective }\end{array}$ \\
\hline How likely are you to use this? & Not Very Likely & 0 & 1 & 2 & 3 & 4 & Very Likely \\
\hline
\end{tabular}

18. "If you don't change my grade, I will talk to the dean or the chair of the department." "Other professors teaching this course don't have this many assignments."

\begin{tabular}{|c|l|l|l|l|l|l|l|l|}
\hline How effective is this message? & $\begin{array}{l}\text { Completely } \\
\text { Ineffective }\end{array}$ & 0 & 1 & 2 & 3 & 4 & $\begin{array}{l}\text { Very } \\
\text { Effective }\end{array}$ \\
\hline How likely are you to use this? & Not Very Likely & 0 & 1 & 2 & 3 & 4 & Very Likely \\
\hline
\end{tabular}


19. "I demand that you give me a better grade." "I deserve a grade better than the one you gave me." "You need to change this grade."

How effective is this message?

\begin{tabular}{|l|l|l|l|l|l|l|}
$\begin{array}{l}\text { Completely } \\
\text { Ineffective }\end{array}$ & 0 & 1 & 2 & 3 & 4 & $\begin{array}{l}\text { Very } \\
\text { Effective }\end{array}$ \\
\hline Not Very Likely & 0 & 1 & 2 & 3 & 4 & Very Likely \\
\hline
\end{tabular}


Appendix E

The Student Communication Motives Scale (Martin et al., 1999)

$\begin{array}{ccccc}\text { Not at All } & \text { Not Much } & \text { Somewhat } & \text { A Lot } & \text { Exactly } \\ \text { Like Me } & \text { Like Me } & \text { Like Me } & \text { Like Me } & \text { Like Me } \\ 1 & 2 & 3 & 4 & 5\end{array}$

I would talk to my instructor:

1. To learn about him/her personally.

2. So we can develop a friendship.

3. To build a personal relationship.

4. To learn more about the instructor's personality.

5 . Because I find the instructors interesting.

6. Because we share common interests.

7. To clarify the material.

8. To get assistance on assignments/exams.

9. To learn how I can improve in the class.

10. To ask questions about the material.

11. To get academic advice.

12. To get more information on the requirements of the course.

13. To explain why work is late.

14. To explain my absences.

15. To explain why I do not have my work done.

16. To challenge a grade $I$ received.

17. To explain why my work does not meet the instructors' expectations.

18. To explain the quality of my work.

19. To appear involved in class.

20. To demonstrate I understand the material.

21. To demonstrate my intelligence.

22. Because my input is vital for class discussion.

23. Because my classmates value my contribution to class discussions.

24. Because my instructor values class participation.

25 . To pretend I'm interested in the course.

26. To give the instructor the impression that I like him/her.

27. To give the impression that I think the instructor is an effective teacher.

28. To give the impression that I'm learning a lot from the instructor.

29. To give the impression that I'm interested in the course content.

30. To get special permission/privileges not granted to all students. 
Appendix F

Student Willingness to Talk in Class Scale (Christensen et al., 1995)

$\begin{array}{ccccc}\text { Never } & \text { Rarely } & \text { Sometimes } & \text { Frequently } & \begin{array}{c}\text { Very } \\ \text { Often }\end{array} \\ 0 & 1 & 2 & 3 & 4\end{array}$

I would talk to my instructor:

1. When I am in a small group in class.

2. When the topic is interesting.

3. When my views differ from my classmates' views.

4. When the class is engaged in a heated debate.

5 . When my views differ from the professor's views.

6 . When I am angry about a topic.

7. When I can really help clarify the discussion.

8. When I am prepared for class.

9. When the class is engaged in an open discussion.

10. When I am graded on participation.

11. When I am comfortable with the subject matter.

12. When I know the correct answer.

13. When the professor asks for a response from the class.

14. When an assignment is being discussed.

15 . When no one else is talking.

16. When I am sitting in the front of the class.

17. When I am sitting in the back of the class.

18. When everyone is talking.

19. When I dislike my classmates. 


\section{Appendix G}

Out-of-Class Communication Scale (Knapp \& Martin, 2002)

\begin{tabular}{l} 
Strongly \\
$\begin{array}{l}\text { Disagree } \\
1\end{array}$ \\
1. I often talk to my instructor during his/her office hours. \\
2. If I see my instructor on campus, I often talk to him/her. \\
3. I rarely talk to my instructor outside of the classroom. \\
4. If I see my instructor in the hallway, I often stop to talk to her/him. \\
5. I only talk to my instructor outside of the classroom once in a while. \\
6. I frequently talk to my instructor outside of the classroom. \\
7. When I see my instructor off campus, I usually spend some time talking to \\
him/her. \\
8. When I see my instructor in public, I avoid talking to him/her. \\
9. I never talk to my instructor outside of the classroom. \\
\hline
\end{tabular}


Appendix $\mathrm{H}$

The Revised Cognitive Learning Indicators Scale (Frymier \& Houser, 1999)

$\begin{array}{ccccc}\text { Never } & \text { Rarely } & \text { Sometimes } & \text { Frequently } & \begin{array}{c}\text { Very } \\ \text { Often }\end{array} \\ 0 & 1 & 2 & 3 & 4\end{array}$

I frequently:

1. Talk about what I'm doing in the class with friends and family.

2. Explain course content to other students.

3. Think about the course content outside of class.

4. See the connections between the course content and my career goals.

5. Review the course content.

6. Compare the information from the class with other things I have learned.

7. Feel that $I$ have learned a lot in the class. 


\section{Appendix I}

The Instructional Affect Assessment Instrument (McCroskey, 1994)

My attitude about the course content in this class is:
1. Good

23

3
2. Worthless $1 \quad 2$
3. Fair

23
4. Negative
2

$\begin{array}{ll}4 & 5 \\ 4 & 5 \\ 4 & 5 \\ 4 & 5\end{array}$

6
$7 \quad$ Bad
$\begin{array}{lll}6 & 7 & \text { Valuable }\end{array}$
$\begin{array}{lll}6 & 7 & \text { Unfair }\end{array}$
$\begin{array}{lll}6 & 7 & \text { Positive }\end{array}$

My attitude about the behaviors recommended in this class is:
5. Good
23
6. Worthless
34
4
7. Fair
2
3
$4 \quad 5$
6
$7 \quad \mathrm{Bad}$
8. Negative

2
4
5

6
$7 \quad$ Valuable
7
Unfair
Positive

My attitude about the instructor in this class is:
9. Good
23
4
10. Worthless

2
34
11. Fair

23
12. Negative
23
4

5
5
5
5

$\begin{array}{ll}6 & 7 \\ 6 & 7 \\ 6 & 7 \\ 6 & 7\end{array}$
$7 \quad$ Bad
$7 \quad$ Valuable
7 Unfair
7 Positive

My likelihood of actually attempting to engage in the behaviors recommended in this class is:
13. Likely
14. Impossible
15. Probable

2
2
2
2
$4 \quad 5$
45
607
7
Unlikely
45

$\begin{array}{ll}6 & 7 \\ 6 & 7\end{array}$
16. Would Not

My likelihood of actually enrolling in another class with similar content, if I had the choice and if my schedule permitted: (If you are graduating, assume you would still be here.)
17. Likely
23
$4 \quad 5$
56
67
7 Unlikely
18. Impossible 1
19. Probable 112
20. Would Not

2

3
3
3

$\begin{array}{ll}4 & 5 \\ 4 & 5 \\ 4 & 5\end{array}$
$6 \quad 7$
7
7
Possible
7 Improbable
$\begin{array}{lll}6 & 7 & \text { Would }\end{array}$

The likelihood of my taking another course with this teacher, if I had a choice, is: (If you are graduating, assume you would still be here.)
21. Likely
22. Impossible
23. Probable
$\begin{array}{ll}2 & 3 \\ 2 & 3\end{array}$

$\begin{array}{ll}4 & 5 \\ 4 & 5 \\ 4 & 5 \\ 4 & 5\end{array}$
67
$6 \quad 7$
7 Unlikely
24. Would Not

23
$6 \quad 7$
Possible
Improbable
Would 


\section{Appendix J}

Student Motivation Scale (Christophel, 1990)

When I am in class I feel:

1. Motivated 1

2. Interested 1

3. Involved

4. Not

$1 \quad 2 \quad 3$
stimulated

5. Don't want to study

6. Inspired

12

7. Unchallenged 1

8. Uninvigorated 1

9. Unenthused 1

10. Excited 1

11. Aroused

12

12. Not fascinated 1

$\begin{array}{ll}2 & 3 \\ 2 & 3 \\ 2 & 3 \\ 2 & 3\end{array}$

455

456

456

456

$\begin{array}{lll}6 & 7 & \text { Unmotivated } \\ 6 & 7 & \text { Uninterested } \\ 6 & 7 & \text { Uninvolved } \\ 6 & 7 & \text { Stimulated }\end{array}$

4

$5 \quad 6$

$\begin{array}{ll}6 & 7\end{array}$

Want to study

$\begin{array}{lllll}4 & 5 & 6 & 7 & \text { Uninspired } \\ 4 & 5 & 6 & 7 & \text { Challenged } \\ 4 & 5 & 6 & 7 & \text { Invigorated } \\ 4 & 5 & 6 & 7 & \text { Enthused } \\ 4 & 5 & 6 & 7 & \text { Not Excited } \\ 4 & 5 & 6 & 7 & \text { Not Aroused } \\ 4 & 5 & 6 & 7 & \text { Fascinated }\end{array}$


Appendix K

Student Communication Satisfaction Scale (Goodboy et al., 2009)

$\begin{aligned} & \text { Strongly } \\ & \text { Disagree }\end{aligned}$
1

